University of Louisville

ThinkIR: The University of Louisville's Institutional Repository

8-2018

\title{
An examination of the linkages between climate, engagement, and wellbeing in higher education.
}

Ebo Kobena Atomo Osam

University of Louisville

Follow this and additional works at: https://ir.library.louisville.edu/etd

Part of the Organizational Behavior and Theory Commons

\section{Recommended Citation}

Osam, Ebo Kobena Atomo, "An examination of the linkages between climate, engagement, and wellbeing in higher education." (2018). Electronic Theses and Dissertations. Paper 3061.

https://doi.org/10.18297/etd/3061

This Doctoral Dissertation is brought to you for free and open access by ThinkIR: The University of Louisville's Institutional Repository. It has been accepted for inclusion in Electronic Theses and Dissertations by an authorized administrator of ThinkIR: The University of Louisville's Institutional Repository. This title appears here courtesy of the author, who has retained all other copyrights. For more information, please contact thinkir@louisville.edu. 


\title{
AN EXAMINATION OF THE LINKAGES BETWEEN CLIMATE, ENGAGEMENT, AND WELLBEING IN HIGHER EDUCATION
}

\author{
By \\ Ebo Kobena Atombo Osam \\ B.S., University of Ghana, 2010 \\ M.S., Western Kentucky University, 2014

\begin{abstract}
A Dissertation
Submitted to the Faculty of the in Partial Fulfillment of the Requirements

for the Degree of

Doctor of Philosophy

In Educational Leadership and Organizational Development

Department of Educational Leadership and Organizational Development

University of Louisville

Louisville, Kentucky
\end{abstract} \\ College of Education and Human Development of the University of Louisville
}

August 2018 



\section{AN EXAMINATION OF THE LINKAGES BETWEEN CLIMATE, ENGAGEMENT, AND WELLBEING IN HIGHER EDUCATION}

\section{By}

Ebo Kobena Atombo Osam

B.S., University of Ghana, 2010

M.S., Western Kentucky University, 2014

A Dissertation Approved on

May 29, 2018

by the following Dissertation Committee:

Dr. Brad Shuck, Dissertation Chair

Dr. Jason Immekus Committee Member

$\overline{\text { Dr. Meera Alagaraja, Committee Member }}$

Dr. Matt Bergman, Committee Member

Dr. Devon Twyford, Committee Member 


\section{DEDICATION}

This work is dedicated to my lovely wife Deborah, who has been a constant source of

support, love, encouragement, and my number one cheerleader throughout my doctoral journey. I am truly blessed to have you in my life. 


\section{ACKNOWLEDGMENTS}

I would like to thank my entire committee for their support during the dissertation process. To my chair, Dr. Brad Shuck, your unwavering belief in my ability to succeed from day one served as a source of inspiration. You are not just my advisor and mentor, but have become a good friend. To Dr. Immekus, thank you for the multiple conversations we had in your office that spurred my thinking and guided my writing. To Dr. Bergman, your sprightly speeches during our weekly meetings really fired me up, and motivated me to press on to the finish line. To Dr. Twyford, I really got the hang of translating academic knowledge to practitioner speak thanks to you. And finally to Dr. Alagaraja, thank you for being a sounding board and an encouraging voice during this process. I also want to say a special thanks to Drs. Cumberland, Johnson, and Rose for their wonderful support, and taking an interest in my work. Also, to Melody and Steve in the Office of Research, thank you for answering my millions of questions each semester.

Finally, I would like to thank my friends and family. Dr. and Mrs. Osam, your endless parental love and sacrifices you made for me have brought me this far, and I am forever grateful. To Esi and the Kokomlemle princess, never has there been a more supportive sister and aunt. Thank you. My sincerest thanks to Dr. Addo and Dr. DeVeer, whose love and support all the way from New Zealand kept me going. Thank you Dr. Kathleen Wicker, my adoptive grandmother, your calls meant a lot to me throughout graduate school. And to all my friends who encouraged me every step of the way, you 
made all the difference, and I cannot express how much I appreciate all of you. Thank you. 


\begin{abstract}
AN EXAMINATION OF THE LINKAGES BETWEEN CLIMATE, ENGAGEMENT, AND WELLBEING IN HIGHER EDUCATION

Ebo Kobena Atombo Osam
\end{abstract}

May 29, 2018

Research coalescing around psychological climate, engagement, and wellbeing has been receiving considerable attention in management and HRD literature recently. However, research associated with these variables has generally been limited to for-profit businesses and organizations with little of note done using higher educational institutions. Thus, this cross sectional research study examined the extent to which psychological climate, engagement, and wellbeing are associated with each other in higher educational institutions. The study begins with an overview of how these variables have been identified as being connected with each other in research and practice, as well as discusses context specific factors in higher education (i.e. changing nature of operations and an increasing emphasis on employee wellbeing) that warrant the need for this study.

A sample of 259 people employed by institutions of higher education in the United States was surveyed. Using mediation and moderation analyses, the study showed that psychological climate, engagement, and wellbeing are positively associated with each other, and that engagement mediated the relationship between psychological climate and wellbeing. Additionally, results indicated that employee role in higher education (i.e. 
faculty or staff) did not moderate the relationship between psychological climate and wellbeing. Finally, no significant differences in wellbeing were found between faculty and staff. Implications for HRD theory and research, as well as specific recommendations for leaders and administrators in higher education are discussed.

Keywords: Psychological Climate, Employee Engagement, Wellbeing 
TABLE OF CONTENTS

PAGE

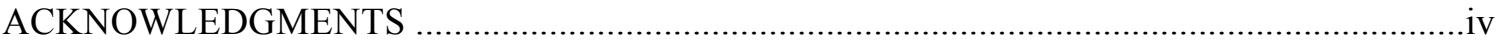

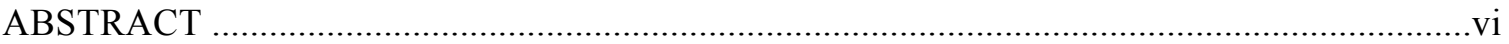

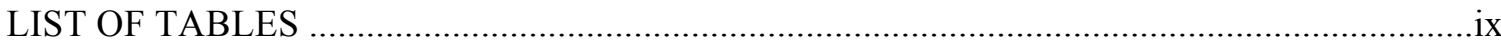

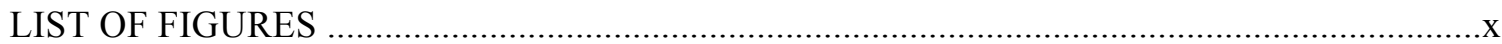

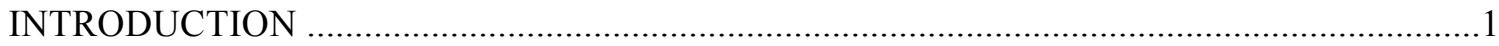

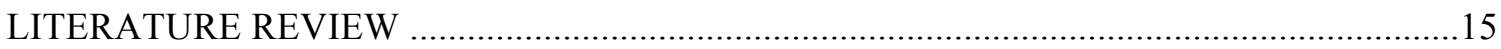

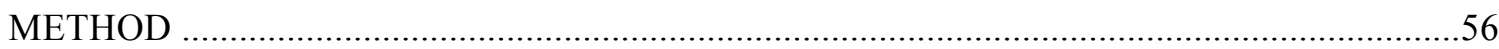

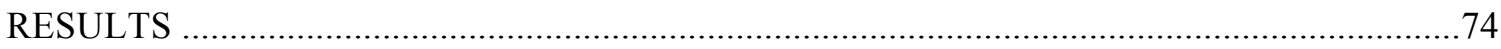

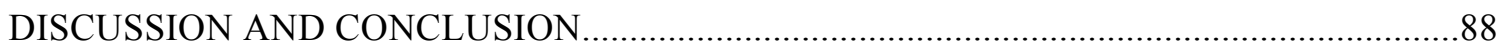

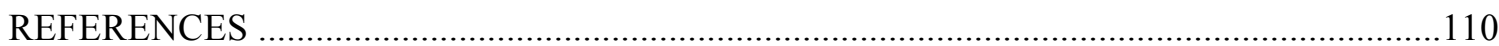

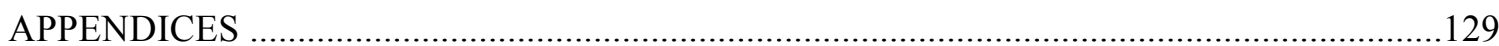

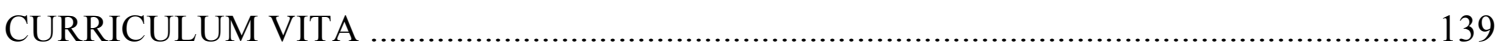




\section{LIST OF TABLES}

TABLE

PAGE

Correlations Between Psychological Climate, Engagement And Wellbeing .53

Participants' Personal and Professional Attributes

Selected Instruments and Reliability Statistics of Survey Items .63

Respondents' Personal and Professional Attributes .75

Descriptive Statistics for Psychological Climate Engagement and Wellbeing .77

Cases with Data Contributing to Outliers .78

Skewness and Kurtosis of Variables .79

Summary of Hierarchical Regression Analysis for Psychological Wellbeing .83

Summary of Hierarchical Regression Analysis for Physical Wellbeing .84

Direct and Indirect Effects .85

Direct and Indirect Effects .86 


\section{LIST OF FIGURES}

$\begin{array}{lll}\text { FIGURE PAGE } & \text { PAR }\end{array}$

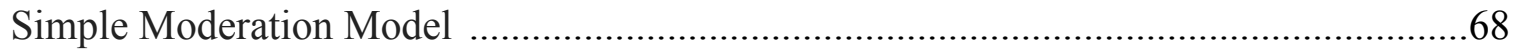

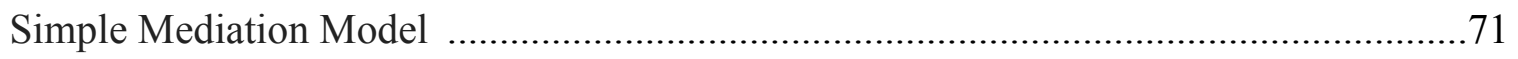

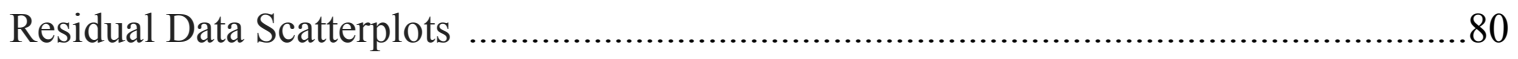

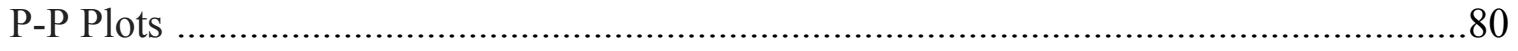




\section{CHAPTER I}

\section{INTRODUCTION}

In the United States, there are close to 4 million people who are employed by institutions of higher education (National Center for Education Statistics, 2016). For

these individuals, as with employees in any other industry, work not only provides money to maintain livelihood but also gives a sense of purpose, meaning, community, identity, and structure (Cartwright \& Homes, 2006). Thus, employees seek out positive experiences in their workplaces in order to realize the non-monetary benefits associated with work (Salkever, 2000). These desired positive experiences go beyond general satisfaction or commitment, and are grounded in how employees experience and make meaning of their workplaces (Harter, Schmidt, \& Hayes, 2002; Shuck \& Reio, 2014). More, workplace environments that result in positive experiences lead to higher engaged employees (Shuck, Osam, Zigarmi, \& Nimon, 2017; Shuck \& Reio, 2014).

Engaged employees feel more connected to their workplace, have increased enthusiasm to work, and consistently perform their jobs at high levels (Buckingham \& Coffman, 1999; Shuck, Shuck, \& Reio, 2013). Employers also benefit positively from engaged employees, thereby making an engaged workforce highly desirable for any organization (Bakker, 2011; Stander, De Beer, \& Stander, 2015). For example, research has indicated engaged employees are less likely to leave their employers (Saks, 2006; Shuck, Reio, \& Rocco, 2011), and are more likely to help their organizations achieve 
increased revenue growth (Harter, Schmidt, Asplund, Killham, \& Agrawal, 2010). Thus, it seems clear that engagement is a good thing for both employee and employer - a sentiment also shared broadly by Human Resource Development (HRD) scholars (e.g. Alagaraja \& Shuck, 2015; Saks, 2006; Seijts \& Crim, 2006; Shuck \& Reio, 2014). Although engagement yields many positive outcomes, emerging reports from the national media has suggested that the benefits obtained from an engaged workforce are under threat. The New York Times recently signaled the rise of gloomy workplaces, termed toxic workplaces (Slaughter, 2015). Exposés on the workplace climates of leading organizations in online retail and the ride share industry in the U.S. within the last few years adds evidence to The New York Times' assertion. Toxic workplaces are fraught with negative experiences such as chronically long workweeks, regular employee layoffs, backstabbing, and excessive jobs demands (Macklem, 2005). These negative experiences are indicative of poor psychological climate; a term used to describe employees' perception of their work environment (Baltes, Zhdanova, \& Parker, 2009) For example, in Kantor and Streitfeld's (2015) exposé on a major online retailer, there were revelations that employees suffering from various physical ailments were often evaluated unfairly or pushed out of work completely. In another exposé on a giant in the rideshare industry, The New York Times gave details of discrimination, intimidation, and sexual harassment that appeared to be commonplace so much such that they became associated with the culture of the organization (Isaac, 2017).

Research has suggested that toxic workplaces go beyond impacting productivity to negatively affecting employees' wellbeing (Kantor \& Streitfeld, 2015). For example, Shuck et al. (2017) noted that elements of negative workplaces such as overly long work 
hours are linked to over 100,000 deaths per year. Similarly, Colligans and Higgins (2005) suggested that toxic workplaces are linked with multiple health problems such as unstable blood pressure, diabetes, substance abuse, and clinical depression. Employers also pay a heavy price for negative work environments. According to Goh, Pfeffer, and Zenios (2015), approximately $5-8 \%$ of annual healthcare costs among U.S companies can be attributed to the type of environment that employees are made to work in. Toxic workplaces negatively impact the psychological climate and are hazardous to employees' wellbeing (Shuck et al., 2017). According to Shuck et al., this also contributes to large health costs that plague employers. In sum, employees' experiences in their workplace appear to be linked to their engagement and wellbeing.

The link between employees' workplace experiences, engagement and wellbeing is not limited to traditional organizations and businesses. In higher education, there is evidence of these connections, as psychological climate, engagement, and wellbeing are slowly gaining ground as issues of interest. For example, according to Krause (2005), engagement is becoming a cornerstone of the higher education lexicon. Many universities are therefore starting to include engagement as a key strategic focus in order to boost performance (Pittaway, 2012). But, within higher education institutions, the meaning of the term engagement differs from what pertains in management literature (Betts, 2009). In academia, engagement has been commonly viewed as the scholarship of teaching, discovery, and application (see Colbeck \& Wharton-Michael, 2006; O’Meara, Sandmann, Saltmarsh, \& Giles, 2011; Wade \& Demb, 2009) or as an active commitment to student learning (see: Carini, Kuh, \& Klein 2006; Kahu, 2013). These alternate engagement conceptualizations dominate university engagement research, and consequently very little 
is known about the grounding of employee engagement stemming from positive work experiences that fall within the higher education industry (Bretts, 2009). Bretts asserted that the increasing evidence linking engagement to low turnover, increased productivity, as well as happier and healthier employees should provide cause for researchers to study engagement in universities as has been done in traditional businesses and organizations, but, at present, very little work has moved from the sideline to the center stage (Bretts, 2009).

Connected, universities are increasingly concerned about the health of their employees, hence the proliferation of wellness programs across many campuses (Cooper \& Barton, 2016). These programs are often targeted efforts meant to improve the physical wellbeing of university employees, particularly those that have non-manual jobs, as their work is sedentary (Puig-Ribera, McKenna, Gilson, \& Brown, 2008). Extant research has suggested that psychological wellbeing is also of growing concern to universities as academic work environments have become more stressful for both faculty and staff (Winefield, Boyd, \& Winefield, 2014). Poor psychological functioning among university employees has been associated with elevated stress levels, and results in negative outcomes such as poor communication, impaired work relationships, and burnout (Tytherleigh, Webb, Cooper, \& Ricketts, 2005; Watts \& Robertson, 2011).

\section{Problem Statement}

Given that psychological climate influences on an employee's level of engagement as well as their overall wellbeing, it stands to reason that scholars would be interested in investigating the connections between these variables. Within the HRD literature, there is growing interest among scholars coalescing around these three areas 
(e.g., psychological climate, engagement, and wellbeing). Most of the research that has collectively examined around these variables has focused on for profit organizations and businesses with little of note targeting institutions of higher education. Notwithstanding, institutions of higher education are undergoing rapid shifts to their operations, moving them ever-so closer to the way traditional business organizations operate (Shin \& Harman, 2009). For example, to achieve enhanced performance and efficiency, many universities are adopting a more central approach to management rather than the decentralized approach they are historically known for (Giroux, 2015). Thus, as institutions of higher education continue to mirror a for-profit operational approach, HRD researchers must begin to consider widening the scope of their scholarly focus to cover the growing needs in higher education, particularly in the areas of psychological climate and employee engagement, as well as implications for the health and wellbeing of their employees. In light of the strategic role employee engagement has demonstrated in forprofit organizations, the increasing role of health and wellness on university campuses, as well as the role of climate in driving such outcomes, exploring these domains collectively in higher education settings has the potential to provide strategic leverage points for HRD as well as spur future research opportunities and extend current engagement theory; a significant potential outcome of this research.

\section{Purpose of the Study}

The purpose of this study was to examine the relationship between psychological climate, engagement, and wellbeing in higher education. Study implications tie towards gaining a deeper understanding of the ways in which psychological climate, engagement, and wellbeing may be viewed from an HRD perspective within the context of higher 
education. Additionally, study findings may provide information that might be related to climate-engagement-wellbeing efforts and/or initiatives of institutions of higher education.

\section{Research Questions and Hypotheses}

There were three overarching research questions that guided this study:

(a) What is the relationship between psychological climate, engagement, and wellbeing in higher education?

(b) Does employee role influence the relationship between psychological climate and wellbeing in higher education? and,

(c) Does engagement mediate the relationship between psychological climate and wellbeing in higher education?

A cross-sectional survey research design was used to examine the relationships between psychological climate, engagement, and wellbeing within higher education. Cross-sectional survey research enables inferences to be made about a population of interest at one point in time using data collected. It is best suited for gaining information about behaviors, perceptions and attitudes of a population, however it cannot be used to track this information across time (Sedgwick, 2014). The target population for this study was individuals employed as faculty or staff in colleges and universities. This research differs from extant studies in HRD using these variables in that it uses a different contextual setting that is higher education. Further, this study examined how the relationships between psychological climate, engagement, and wellbeing might be impacted by the role an employee occupies (i.e., faculty or staff). Finally, because of this study's emphasis on analyzing relationships between psychological climate, engagement, 
and wellbeing, mediation and moderation analyses were used. To summarize, this study is unique in that there are no known studies in the extant HRD literature that examined psychological climate, engagement, and wellbeing within a higher educational setting using mediation and moderation analyses.

\section{Conceptual Framework}

The guiding conceptual framework for this study is derived from Shuck and Reio's (2014) hypothesized model of employee engagement. In their work, Shuck and Reio drew the conclusion that positive relationships existed between psychological climate, engagement, and wellbeing. Furthermore, they mentioned that, engagement impacted the relationship between psychological climate and wellbeing. Thus, this study seeks to draw from Shuck and Reio's model in order to examine possible linkages between psychological climate, engagement, and wellbeing, within the context of higher education. In summary, the conceptual framework for this study consists of three variables: psychological climate, wellbeing, and engagement. These variables are introduced below starting with psychological climate, followed by engagement, and finally, wellbeing.

\section{Psychological Climate}

Research on psychological climate can be traced back to Lewin, Lippitt, and White's (1939) examination of leadership styles that influence social climates among workers. Since then, there have been substantial amounts of research within organizational literature focused on employee climate perceptions and their relationship with organizational and individual outcome variables (Parker et al., 2003). At the organizational level, employees' perception of their workplace has been used to predict 
group level outcomes, including customer satisfaction and financial performance (Schneider, White, \& Paul, 1998). At the individual level, Parker et al.'s (2003) metaanalysis suggested that workplace perceptions are commonly associated with outcomes such as job satisfaction, job performance, and organizational citizenship behavior. While numerous studies exist that examined the concept of climate in the workplace, Parker et al. noted that there is considerable confusion surrounding the boundaries of the climate construct. The confusion stems from researchers' practice of using multiple terms (e.g., organizational climate, organizational culture, psychological climate) when examining perceptions of the workplace at the individual level of analysis (Parker et al., 2003). Group level climate terminologies, (e.g. organizational climate and organizational culture) should not be used interchangeably with individual level climate terminologies like psychological climate (Parker et al., 2003).

In order to avoid adding to the confusion noted in the extant literature, this study heeded Klein, Dansereau, and Hall's (1994) advice and examined climate at the individual unit of analysis i.e. psychological climate. Connectedly, psychological climate is defined as a "construct comprising an individual's psychologically meaningful representations of proximal organizational structures, processes, and events" (Parker et al., 2003 p. 391). Psychological climate was an appropriate term to use for this study because, according to Jones and James (1979), perceptions of psychological climate enables an individual to interpret events and subsequently influences decisions to engage in a behavior. Several climate models exist in the extant literature; however this study drew from Brown and Leigh's (1996) model as it is theoretically grounded in Kahn's (1990) theory of personal engagement. According to Brown and Leigh, psychological 
workplace climate is based on employees' interpretation of the workplace associated with social and physical structures and cues for the purpose of safeguarding their wellbeing. Brown and Leigh's model was also selected because it focused on the psychological perceptions related to the workplace environment as opposed to solely physical structures, and is consistent with Parker et al.'s definition, as well as with prior research (e.g. Shuck \& Reio, 2014).

\section{Engagement}

The term engagement stems from Kahn's (1990) seminal work on personal engagement. Kahn defined engagement as "the simultaneous employment and expression of a person's 'preferred self' in task behaviors that promote connections to work and to others, personal presence (physical, cognitive, and emotional) and active, full performances” (p. 700). Since Kahn's work, several engagement typologies and definitions have emerged that are often misused in research (Shuck, 2011; Shuck et al., 2017; Shuck \& Reio, 2014). Examples of the emergent typologies include employee engagement (Shuck, Adelson, \& Reio, 2016), work engagement (Schaufeli, Salanova, González-Romá, \& Bakker, 2002), job engagement (Rich, Lepine, \& Crawford, 2010) and organizational engagement (Saks, 2006). In this study, engagement refers to employee engagement. Employee engagement is defined as "a positive, active, workrelated psychological state operationalized by the maintenance, intensity, and direction of cognitive, emotional, and behavioral energy" (Shuck et al., 2017, p. 269). Employee engagement was chosen to measure engagement because according to Shuck and Reio (2014), it incorporates Kahn's (1990) key assumptions that shape a person's decision to 
be engaged, unlike many of the other engagement typologies (cf. Cole, Walter, Bedeian, \& O’Boyle, 2011; Rich et al., 2010).

Employee engagement occurs in three distinguishable levels: cognitive, emotional, and behavioral (Shuck et al., 2016; Shuck \& Reio, 2014; Shuck et al., 2017). Cognitive engagement is drawn from Kahn's (1990) idea that an employee will seek to appraise their work to determine meaningfulness, safety, and the availability of resources to perform their work (Shuck et al., 2017). This appraisal forms part of a broader, more situation specific assessment that ultimately informs an employee whether or not to engage (Shuck et al., 2017; Shuck \& Reio, 2014). To put this into context, employees whose cognitive appraisal of the workplace is negative results in shrinkage of resources that adversely impacts behavioral outcomes of engagement such as turnover (Nimon, Zigarmi, Houson, Witt, \& Diehl, 2011; Shuck \& Reio, 2014).

While cognitive engagement seeks to determine availability of resources, emotional engagement on the other hand focuses on widening and expending emotions related to work (Shuck \& Reio, 2014). Connectedly, Shuck and Wollard (2010) stated that emotional engagement (stemming from affective appraisal) results in the maintenance, intensity, and direction of energy focused on a target. Common terms associated with employees who are emotionally engaged include pride, trust, and knowledge (Shuck \& Reio, 2014). Emotional engagement is thus dependent on the outcome of an employee's cognitive appraisal of the workplace (Shuck et al., 2017). According to Shuck et al., (2016), the cognitive and affective appraisal that characterize cognitive and emotional engagement respectively, are intertwined and reliant upon each other for intentional work behavior to occur. 
Behavioral engagement is the overt manifestation of the engagement process (Shuck et al., 2016; Shuck et al., 2017; Shuck \& Reio, 2014). This is the observable behavior that employers typically expect of their employees in the pursuit of organizational goals (Macey \& Schneider, 2008; Shuck \& Reio, 2014). Employees who are behaviorally engaged expend more individual effort, and are likely to be the ones who go 'above and beyond' or 'work twice as hard' to meet goals and targets (Shuck \& Reio, 2014). According to Shuck et al. (2017), engagement thus consists of a series of sequential states that results in deliberate efforts of action (cognition $\rightarrow$ emotion $\rightarrow$ behavior).

\section{Wellbeing}

Wellbeing is a broad construct that has different conceptualizations (Brunetto, Shacklock, Teo, \& Farr-Wharton, 2014). Broadly speaking, wellbeing is often used in reference to an employee's psychological experiences (Cartwright \& Cooper, 2014; Van De Voorde, Paauwe, \& Van Veldhoven, 2012) and employees' physical functioning (Bakker, 2009; Brunetto et al., 2014; Danna \& Griffin, 1999). Danna and Griffin (1999) noted that the two terms associated with wellbeing i.e. psychological and physical are often used inconsistently in research. In some cases, the two terms are interpreted as the same construct (i.e. wellbeing) and are used interchangeably, while in other cases they are seen as two separate constructs (Danna \& Griffin, 1999). In this study, wellbeing is conceptualized as consisting of two separate constructs: psychological and physical. In the first form of wellbeing, that is psychological, the focus of an employee's wellbeing is on the outcome of their subjective experiences within the workplace (Grant et al., 2007; Van De Voorde et al., 2012). According to the extant research, these experiences 
influence employees' psychological functioning (Bakker, 2009; Cartwright \& Cooper, 2014), and may have an impact on an employee's decision to engage (Shuck et al., 2017). Examples of terms associated with psychological functioning noted in the literature include happiness (Van De Voorde et al., 2012), positive affect (Wright et al., 2007), anxiety (Warr, 2002), burnout (Maslach, Schaufeli, \& Leiter, 2001), and exhaustion (Iverson, Olekalns, \& Erwin, 1998). The second form of wellbeing focuses on the physical health of an employee (Brunetto, et al., 2012; Grant et al., 2007). This is related to physiological symptomology and includes the presence or absence of illness or disease.

\section{Definition of Terms}

Terms used throughout this study are defined as follows:

Psychological Climate: Operationally defined as an individual's "psychologically meaningful representations of proximal organizational structures, processes, and events" (Parker et al., 2003 p. 391).

Engagement: Defined as "a positive, active, work-related psychological state operationalized by the maintenance, intensity, and direction of cognitive, emotional, and behavioral energy" (Shuck et al., 2017, p. 269).

Wellbeing: This is defined as "the overall quality of an employee's experience and functioning at work" (Grant et al., 2007, p. 52).

Physical Wellbeing: This refers to the physical functioning of a person and is defined as the subjective experiences of bodily health (Brunetto, et al., 2012) Psychological Wellbeing: The outcome of an employee's subjective experiences within the workplace (Grant et al., 2007; Van De Voorde et al., 2012). 
Faculty: Employees in higher education institutions whose primary responsibilities include a combination of teaching, research, and/or service.

Staff: University employees whose roles do not consist of teaching, service, and research and hold either salaried or hourly positions. This includes positions in academic support (e.g. computing, library, admissions, human resources, finance), and facility support (e.g. catering, cleaning, manual and security).

Employee role: A dichotomous variable consisting of employees who are either faculty or staff.

\section{Significance of the Study}

This study holds value for the HRD field as scholars and practitioners alike are increasingly focused on improving individual and organizational outcomes through effective people management (Alagaraja \& Shuck, 2015; Truss, et al., 2013). Thus, outcomes from this study expand current knowledge and thinking on factors at play that affect engagement and wellbeing. In practice, findings from this study may guide HRD professionals' efforts to design and implement effective interventions for the work place. These interventions could include improving communication channels to foster a more positive psychological climate at work. HRD practitioners could also facilitate increased levels of engagement by developing training programs that create awareness among management and leaders about the conditions that foster engagement. Similarly, the findings proffered by this study could serve as resource that university administrators and officials could use to drive strategic efforts aimed at improving engagement and wellbeing. 
From a theoretical perspective, there is sufficient evidence in the extant organizational literature linking climate, engagement, and wellbeing, thereby giving rise to several conceptual models (e.g. employee engagement moderation model; Shuck \& Reio, 2014). However, since there is little to no research on these variables conducted in higher education settings, there is no definitive evidence that these models will hold. Therefore, this study provided conceptualized the relationships between psychological climate, engagement, and wellbeing using a different contextual setting that is higher education. By so doing, this study highlighted the important role that HRD can play in examining organizational issues in institutions of higher education. Finally, the findings proffered from this study added more evidence to the idea that engagement best explains the relationship between organizational variables when used as a mediator (Kataria et al., 2013a). This information may serve as a useful pivot for future researchers interested in exploring other relationships that engagement could influence. Connected, as this study does, researchers could also examine these relationships using contexts other than the traditional business organization.

\section{Summary}

This chapter introduced several aspects of the study including the background purpose, conceptual framework, research questions and hypotheses, and operational definitions. The remainder of this study is arranged as follows: a) Chapter 2 provides a synthesized and critical review of the literature to support the study, b) Chapter 3 describes the research method that used to conduct the study, c) Chapter 4 presents results from the study, and d) Chapter 5 provides a discussion of the results and implications for theory, research, and practice. 


\section{CHAPTER II}

\section{REVIEW OF THE LITERATURE}

The main focus of this review is to present and discuss relevant literature on psychological climate, employee engagement, and wellbeing. The foundation of this study is based on literature suggesting that positive psychological climate is associated with increased levels of engagement and wellbeing (Shuck et al., 2017; Shuck \& Reio, 2014). More, recent research has indicated that not only are these variables positively associated with each other, but also that engagement impacts the relationship between psychological climate and wellbeing (Shuck \& Reio, 2014). However, there is evidence hinting that employees' perceptions of psychological climate affect their engagement, which in turn affects their wellbeing (Colligans \& Higgins, 2005; Kantor \& Streitfeld, 2015). This relationship (i.e. psychological climate $\rightarrow$ engagement $\rightarrow$ wellbeing) suggested that engagement might mediate the relationship between psychological climate and wellbeing. That engagement might serve as a mediator rather than a moderator in the relationship between psychological climate and wellbeing is an idea that remains largely untested in the HRD literature, and thus is an issue this study seeks to address.

While there is growing interest among HRD scholars in examining psychological climate, engagement, and wellbeing, most of the research that examined these variables collectively is conducted using for profit businesses and organizations, with little of note 
using institutions of higher education. This dearth of information should be of concern to HRD scholars because institutions of higher education are undergoing rapid shifts to their operations, moving them ever-so closer to the way traditional business organizations operate (Giroux \& Myrsiades, 2005). These shifts represent prime opportunities for HRD scholars to bring their scholarly expertise to the fore in higher education. Nested within higher education is the existence of two very different types of employees: faculty and staff. While both faculty and staff are employees, their roles are markedly different (Fuller, Hester, Barnett, \& Reylea, 2006). Faculty roles are characterized by a considerable amount of flexibility, autonomy, and personal control (Tytherleigh, Webb, Cooper \& Ricketts, 2007). Staff on the other hand, are university employees whose duties to do not involve the production and distribution of knowledge to students (Fuller et al., 2006). These roles might contribute to differing experiences of psychological climate, engagement, and wellbeing. Thus, this study sought not only to investigate psychological climate, engagement, and wellbeing in higher education, but also examined how employees' role in higher education might influence these relationships.

\section{Structure and Organization of Review}

This chapter is divided in to three sections. The first section of this chapter examines the contextual setting for this study: higher education. This first section explores the changes in operational approach that are nudging institutions of higher education closer to traditional business operational models and details the need for HRD scholars to include higher education in their research, the growing emphasis on wellbeing, as well as the unique nature of employee roles in higher education (e.g., staff and faculty). Second, the conceptual approaches to psychological climate, engagement, 
and wellbeing are explored in greater detail. The third and final section provides a synthesis of previous research that has demonstrated the relationship between psychological climate, engagement, and wellbeing. Finally, this chapter concludes with a summary of the research questions and hypotheses.

\section{Examining Higher Education as a Context for this Study}

This section focuses on higher education as the context for this study. To begin, the change in operations that has characterized universities and colleges is presented. Next, wellbeing in higher education is discussed, followed finally by the unique employee groups and how it they are represented in research.

\section{The Changing Operational Approach}

In recent times, there is a growing body of literature that suggested that the way higher educational institutions operate has changed (Deshields, Kara, \& Kaynak, 2005). Much of this literature indicated that changes in the environment, structures, strategies, and processes in higher education are a consequence of the economic landscape in the world today (Parker, 2011). According to Parker, universities and colleges have traditionally enjoyed considerable protection from the ups and downs of the economy largely in the form of government funding. This protection is slowly being stripped away, and institutions of higher education are now expected to generate their own resources to sustain academic activity (Parker, 2011). As a result, there have been profound changes to the overall operations of institutions in higher education, moving them closer to the way traditional for-profit organizations are run (Giroux \& Myrsiades, 2001; Parker, 2011). These changes have led the rise of the 'corporate university', where universities and colleges are expected to be managed as business enterprises in order for academic 
activity to be sustained, and the productivity of university employees to be improved (Gallardo \& Navarro, 2003; Parker, 2011). Giroux and Myrsiades (2001) defined the corporate university as being characterized by "corporate ideologies of efficiency, performance, and the bottom line" (p. 5). Ohmann (2002) provided a deeper description of the corporate university. According to Ohmann, the corporate university:

"Acts like a profit-making business rather than a public or philanthropic trust. Thus, we hear of universities applying productivity and performance measures to teaching (Illinois); of plans to put departments in competition with one another for resources (Florida); of cutting faculty costs not only by replacing full-timers with part-timers and temps and by subcontracting for everything from food services to the total management of physical plants, but also by substituting various schemes of computerized instruction (p. 9)

In this new university setting, there are changes to the expectations of members of the academic community, and the role that colleges and departments play. For example, senior administrative roles such as the university president are assuming the role of CEO, and more specialized 'Senior Executive' appointments in charge of areas like international affairs and research are being made (Bleiklie \& Kogan, 2007; Parker, 2002). Bleiklie and Kogan further noted that universities now consider their colleges and schools that house academic programs as strategic business units. In these units, Deans are considered as senior management and wield an increasing amount of decision-making power. Additionally, Deans are beginning to be evaluated based on their ability to attract and secure external funding while establishing models of leadership and accountability akin to models in business organizations (Giroux, 2009). At the faculty level, Giroux (2009) maintained that academic labor is being transformed to mirror the for-profit business workforce. This is reflected in the endearment of colleges and universities to popular corporate principles such as efficiency, downsizing, and reorganization (Giroux, 2009). Resultantly, there is, and continues to be, an increase in adjunct faculty, non- 
tenured faculty, and a decline in full time tenure faculty positions in a bid to become more cost efficient (Ehrenberg, 2012; Ehrenberg, \& Zhang, 2005), while meeting the demands of a growing and diverse student population (Osam, Bergman, \& Cumberland, 2017). Thus, faculty are now under increasing pressure to teach and advise larger numbers of students, while simultaneously obtain external research funding and publish (Kinman, 2014). The increased demands on faculty has made the higher education work environment more stressful, and has been linked to negative effects on physical and psychological wellbeing (Gillespie, Walsh, Winefield, Dua \& Stough, 2001).

The reorganization of academic labor in the new higher education landscape includes changes to faculty decision-making and power. Traditionally, universities were largely governed by faculty, and were characterized by collegial decision-making on many issues and subjects such as the appointment of a president (Altbach, 1999; Giroux, 2009). However, as universities and college organizational structures become more convoluted in a bid to survive in a new financial environment, the mode of governance has changed (Altbach, 1999). Important academic decisions are now channeled through a medley of committees and administrators, including boards of trustees, and is resulting in a decision making culture that tends to exclude faculty (Kinman, 2014). These authority groups have become increasingly more powerful, and drive academic decision-making often to the dismay of many faculty who sometimes are not in agreement with decisions made (Altbach, 1999; Thelin, 2001). According to Thelin, relations between faculty and the new authority groups, such as Boards of Trustees, in some universities are breaking down because faculty see them as agents in pursuit of their own partisan interest and agendas. This shift in power has resulted in unpleasant work environments for faculty. 
For example at Boston University, the board's decision to hire President John Silber was met with discord from faculty (Giroux, 2009). John Silber's tenure as president, although considered successful, was often turbulent and fraught with several run-ins with university faculty over merits and raises, tenure requirements, and unionization (Aronowitz \& Giroux, 2000; Giroux, 2009). This frequently left some faculty frustrated, unhappy, and disillusioned with working at Boston University (Giroux, 2009).

The example of John Silbur represents an example of how a characteristic of the corporate university (i.e. shift in governance power) might negatively impact the working environment for its employees, and lead to an unhappy workforce. Other features of the corporate university that may impact the work environment for employees include the changing roles and reorganization. For example, as Deans continue to wield more decision-making power, will they institute measures that will be unpopular and negatively impact faculty? Similarly, will the reduction of tenured faculty, increase in adjuncts, and change of focus on revenue generation negatively impact the work environment for university employees? The changes accompanying the rise of the corporate university, however, have piqued the interest of management and HRD scholars, and have led them to research the university environment from their perspective (Geissler, \& Grave, 2017). Some of the management perspectives that have been applied to higher education include theories like entrepreneurial climate (Geissler, \& Grave, 2017), diversity management (Oertel, 2017), organizational performance (Graf, 2017), and social entrepreneurship (Tekula, Shah, \& Jhamb, 2015). The crossover of management and HRD scholars into the higher educational research domain provides a 
measure of justification for this study as it applies human resource development (HRD) theory to university settings.

In sum, the traditional mode of operations in higher education is changing. These changes are reflected in the roles of university employees, and includes a growing focus on revenue generation, increasing numbers of adjunct faculty, and the reduction of tenure faculty lines (Bleiklie \& Kogan, 2007; Ehrenberg, 2012). Additionally, university governance - something once considered to be shared among faculty - is now concentrated in the hands of 'top management' such as a Board of Trustees (Thelin, 2001). Such changes have the potential to create negative work environments, and consequently make for unhappy employees (Giroux, 2009). However, these changes have also influenced management and HRD researchers to take up the study of the university environment, in hopes that such research could lead to solutions or measures that will help universities and colleges adjust to the changing nature of management in higher education (Geissler, \& Grave, 2017).

\section{Wellbeing in Higher Education}

The changes affecting higher educational institutions are not limited to employee roles and jobs, but extend to the approach of managing health and wellness. In the past few decades, there has been a proliferation of wellness activities and programs on college campuses in an effort to improve the health and wellbeing of employees as a result of the growing health related problems associated with weight, nutrition, exercise, and mental health (Cooper \& Barton, 2016; Ewing, Ryan, \& Zarco, 2007; Fullerton, 2011; Strand, Egeberg, \& Mozumdar, 2010). These wellness programs combine a variety of tools such as extensive awareness building through health education, health risk assessments, and 
health coaching (Bryne et al., 2011). Some examples of these wellness activities and programs include the Healthy Plus Program (Vanderbilt University) and MHealthy (University of Michigan). In addition to helping improve the wellbeing of employees, these wellness programs are used as a mechanism for institutions of higher education to combat the steep rise in healthcare costs (Byrne et al., 2011). In order to manage the costs of healthcare, Bryne et al. noted that employers have moved from passively purchasing services to treat illness and disease to actively developing wellness programs aimed at disease prevention. At Vanderbilt University, for example, the Healthy Plus Program was developed as a health risk reduction program that makes use of incentives to encourage employees who are at risk of illnesses and diseases stemming from unhealthy lifestyles to pursue healthier lifestyle options (Bryne et al., 2011) Incentives used include an increase of up to $\$ 20$ a month to employees' paychecks if they completed the three tiers of the program: a) completing a health risk assessment form, b) completing a self-directed lifestyle management tool to improve health risk/maintain health and c) watching educational videos that discuss practical ways to improve specific health risks (Bryne et al., 2011) The MHealthy program at the University of Michigan also employs similar programming needs to improve the health and wellbeing of its members. This includes the use of incentives, and health risk assessment forms in addition to periodic biometric screenings and physical activity tracking programs to reduce the health risks of its employees (Beck et al., 2016).

Programs such as the MHealthy and the Healthy Plus program suggest that universities are actively encouraging positive lifestyle changes to enhance quality of life of its members (Floyd, 2003). Thus, as emphasis on health and wellness continues to 
grow among institutions of higher education, university administrators have a responsibility to create an environment that encourages and promotes healthy lifestyles (Ewing et al., 2007). This includes integrating personal and public health into university wide polices, programs, and practices (Kupchella, 2009). It should be noted that workplace health wellness programs are widely used in for-profit organizations, and consequently, employee wellbeing has become a subject of HRD research. For example, there is research linking higher levels of wellbeing to increased productivity (DeVries III, 2010), increased organizational commitment (Berry, Mirabito, \& Baun, 2010), as well as increased employee satisfaction and engagement (Morrison \& MacKinnon, 2008; Shuck \& Reio, 2014). At present however, research on wellbeing in higher education is lacking, and underscores the need for studies investigating how wellbeing might be linked to organizational variables such as engagement (Cooper \& Barton, 2016), - a gap this study seeks to fill. These types of studies are important because they may provide information that universities can use to optimize their health and wellness programs, and also help create and/or sustain a work environment that promotes healthy lifestyles. This includes understanding the physical and psychological work environment that university employees work in, and its connections to employee wellbeing. Researching and understanding the connection between the physical and psychological work environment will enable universities to put measures in place to reduce or avoid stressful conditions/factors that may negatively impact employees' wellbeing. This will have the added benefit of helping mitigate the cost of healthcare by essentially creating a work environment that is aimed at preventing physical and psychological sickness rather than paying for the cost of treating illness and diseases stemming from the work environment. 


\section{The Unique Employee Situation in Higher Education}

As management and HRD researchers start to shift their research focus on higher education, careful consideration must be given to the unique employee roles, as they differ from traditional business organizations. Employees in higher education are grouped into two broad categories: faculty and staff. While both faculty and staff are considered as university employees, they perform different roles and are assessed differently (Fuller, et al., 2006). Faculty work is oriented towards the production and/or application of knowledge as well as its delivery to students (Fuller et al., 2006). Additionally, faculty roles are characterized by a considerable amount of flexibility, autonomy, and personal control (Tytherleigh, Webb, Cooper \& Ricketts, 2007). Staff on the other hand, are university employees whose duties to do not involve the production and distribution of knowledge to students (Fuller et al., 2006). Individuals in staff roles are also unlikely to have the flexibility, autonomy, and control over their work (Tytherleigh et al, 2007). Examples of staff employees include academic support (e.g. computing, library, admissions, human resources, finance), and facility support (e.g. catering, cleaning, manual and security). These distinctions are important because they may influence the way faculty and staff experience organizational constructs such as engagement or wellbeing. For example, while researchers agree that the academic work environment is becoming more stressful, factors that trigger stress differ among faculty and staff, and may result in different individual outcomes on wellbeing (Winefield, et al., 2014).

For faculty, stress has been linked to increased expectations to publish more research, attracting grant funding, and dealing with larger numbers of students that includes a growing number of non-traditional students (Jerejian, Reid, \& Rees, 2013; 
Osam et al., 2017). Among staff, stress is linked with pressure to respond to more and more administrative and/or operational requests and demands from faculty and students (Winefield, Boyd, Saebel, \& Pignata, 2008). Even though both faculty and staff experience stress, the degree of control and autonomy has a role to play in outcomes on wellbeing. Higher degrees of perceived control and autonomy over one's work is linked with better levels of physical and psychological health (Guppy \& Rick, 1996). Thus, it is expected that while stressful work environments negatively affects wellbeing for university employees, it might be more detrimental for staff than faculty because perceived control and autonomy acts as a buffer from high levels of stress (Tytherleigh et al., 2005). In spite of these differences between faculty and staff, research on university employees tends to be one sided with more emphasis on faculty, and a dearth of information comparing both groups (Winefield et al., 2013). As mentioned earlier, perceptions of constructs such as psychological climate, engagement, and wellbeing are likely to differ among faculty and staff, and as such they need to be equally captured as much as possible in HRD research moving forward. Doing so will allow university administrators to utilize information to guide policy and develop interventions that are tailored to meet the needs of both faculty and staff.

\section{A Conceptual Examination of Psychological Climate, Engagement, and Wellbeing}

The purpose of this section is to present information relating to the theories that underpin the variables of interest in this study. In particular, since there are different conceptualizations of climate, engagement, and wellbeing in the literature, the foci of this section is to distinguish between different conceptualizations and to identify, as well as justify the chosen conceptualization for this study. To achieve this, each variable will be 
broken down starting from its earliest use in the management and organizational literature, and traced to current conceptual variations. In what follows, a synthesis of empirical evidence linking each variable to individual and organizational outcomes is presented, followed by research questions and hypotheses that guide this study.

\section{Psychological Climate}

The study of how people think and feel about their workplaces goes back nearly a hundred years starting with Lewin, Lippitt, and White's (1939) examination of social climates at work. This area of study has grown tremendously since Lewin et al.'s seminal work, and can now be grouped into two distinct streams of research. In the first stream of research, the emphasis is placed on examining specific functions that are considered to be strategic to the operation of the organization (Eisele \& D'Amato, 2011). Examples of these functions include safety and service delivery (Burke, Borucki, \& Kaufman, 2002; Schneider, White, \& Paul, 1998). The second stream of climate research is broader in nature, meant to encompass employees' holistic perception of the organization rather than only specific organizational functions (Burke et al., 2002; D'Amato \& Ziljstra, 2008;

Jones \& James, 1979). In this study, the emphasis is on employees' perspective of the organization in its entirety, and not just specific functions.

Within the second stream, there are two subsets of research. The existence of these subsets is credited to James and Jones (1974), who first made the distinction between climate as an individual level construct and a group level construct. In one subset, research is centered on an individual's perceptions and interpretations of an organization's structures, processes and events. This is termed psychological climate (Parker et al., 2003). According to Parker et al., the term psychological climate stems 
from Lewin et al.'s (1939) idea of life space, which was used to explain a person's motivational and affective response to change. While there are many definitions that exist for psychological climate, each definition captures the idea that the perception of the work climate differs from employee to employee (Brown \& Leigh, 1996; James, James, \& Ashe, 1990; James \& James, 1989), it influences employee behavior at work (Carr, Schmidt, Ford, \& DeShon, 2003; Eisele \& D'Amato, 2011) and it is descriptive and not evaluative in nature (Hartman \& Rutherford, 2015; Johns, 2006; O’Neil \& Arendt, 2008). James and James (1989) went even further to suggest that in addition to these, psychological climate is associated with how employees perceive their workplaces as affecting their wellbeing.

In the second subset, researchers examined the beliefs of an organization and the shared employee perception of how the organization functions as a whole (Coyle-Shapiro et al., 2004). This is differs from the first subset because psychological climate is defined by a singular employee's perception of the workplace, while this focuses on the collective perception among groups of employees about their organization. Unlike psychological climate, the extant literature shows that there are several terms associated with this form of research. These terms include collective climate, organizational climate, and organizational culture, and are all used to refer to employees' collective perception of the organization (Parker et al., 2003). Parker et al. also noted that these terms are often used in a confusing manner in research, and has contributed to the lack of clarity on workplace climate research. For example, there is one school of thought that believes that it is only when individuals agree on a similar perception of the work environment that the terms (i.e. collective climate, organizational climate, organizational culture) are applicable 
(James, 1982; Klein et al., 2000). Conversely, other scholars believe that these terms are applicable when employees' perceptions of the workplace are aggregated, irrespective of whether or not employees share a common perception of their workplace (Burton, Lauridsen, \& Obel, 2004; Zohar \& Luria, 2004). In spite of the confusion, many researchers view collective climate, organizational climate, and organizational culture as group-level constructs that should be measured using an aggregation of an individual level construct i.e. psychological climate. However, Glick (1985) appealed to researchers to carefully consider their operational definition of psychological climate in their work to prevent confounding their levels of analysis. He warned against aggregating psychological climate to make inferences about climate at the organizational level, as it results in inconsistencies between the unit of measurement (aggregated) and the unit of theory (individual). For this study, psychological climate provides the best fit because the aim is to examine individualized and not aggregated perceptions of the workplace. To provide further understanding of psychological climate, models that have been developed in prior research are discussed next.

Psychological climate models. While there is general agreement on the definition of psychological climate, there is considerably less agreement on the specific dimensions that constitute the construct (Hartman \& Rutherford, 2015; James \& James, 1989; Parker et al., 2003; Patterson et al., 2005). Parker et al. (2003) noted that several dimensions of psychological climate have been measured in the extant literature resulting in challenges identifying the boundaries of the construct. These dimensions include job characteristics, physical environment, senior management, and co-workers. In order to provide more clarity to this issue, and help move the field forward, Parker et al. recommended the use 
of psychological climate models that encapsulate the following: shared definition of psychological climate, reference to theoretical and analytical work of previous researchers (e.g. Muchinsky, 1976; Payne \& Pugh, 1976), and adequate coverage of the construct. Within organizational and management literature, there are two models that dominate psychological climate research: Jones and James' (1979) psychological climate model and Brown and Leigh's (1996) model. Together these models have been cited well over 2,000 times in research related to the workplace climate. This study draws from Brown and Leigh's model as it is theoretically grounded in Kahn's (1990) theory of personal engagement, and therefore aligns well with the variables of interest in this study. In the next section the Brown and Leigh model is discussed in more detail.

Brown and Leigh model. Brown and Leigh's (1996) model is built on the idea that psychological climate is associated with the degree to which employees deem their organizations to be meaningful and a psychologically safe place to work. In developing their model, Brown and Leigh relied on Kahn's (1990) research on personal engagement. Specifically, Brown and Leigh assumed that psychological climate influenced employees' decision to be fully immersed in their work or psychologically distanced from their work. Researchers that have incorporated this model into their research have found that employees who find meaning in their work make more personal investments to ensure the achievement of organizational goals (May, Gilson, \& Harter, 2004; Neal, Griffin, \& Hart, 2000; Patterson et al., 2005). According to Griffin and Neal (2000), when individuals ascribed positive meaning to their work environment, it motivated them to increase their performance. Conversely, when employees had negative perceptions of their work environment it resulted in lower performance levels (Griffin \& Neal, 2000) as 
well as counterproductive work behaviors including making disparaging remarks about the organization (Cartwright \& Holmes, 2006). Brown and Leigh's model consisted of six dimensions: supportive management, role clarity, freedom of self-expression, the employee's perceived contribution toward organizational goals, adequacy of recognition received from the organization, and job challenge. These dimensions can also be grouped into 2 categories (i.e. psychological safety and psychological meaningfulness) that represent the Brown and Leigh's operationalized definition of psychological climate. According to Kahn (1990), psychological safety is the employee's "sense of being able to show and employ one's self without fear of negative consequences to self-image, status, or career" (p. 708). The dimensions listed above that represent psychological safety are supportive management, role clarity, and freedom of expression. Kahn also interpreted psychological meaningfulness to be "a feeling that one is receiving a return on investments of one's self in a currency of physical, cognitive, or emotional energy" (pp. 703-704). In Brown and Leigh's (1996) model, employees' perceived contribution toward organizational goals, adequacy of recognition received from the organization, and job challenge constitute psychological meaningfulness.

In summary, psychological climate is an area of research that emerged from previous research in the last century on social climates in the workplace. Psychological climate falls under the branch of organizational research that focuses on an employee's perception of the entire organization. This differs from research that examines employee perception of select aspects of organizational functioning such as safety climate, and service delivery. A key feature of psychological climate is its emphasis on individual perceptions of an organization and thus juxtaposes organizational climate, where the 
emphasis is on groups of employees' collective perception of an organization. This key feature makes psychological climate the most suitable climate variable to use in this study, due its focus on individual perceptions of the workplace.

\section{Engagement}

Engagement has recently emerged as a hot button issue for many employers (Macey \& Schneider, 2008). This emergence is due to the belief that engagement is a source of competitive advantage that ultimately improves an organization's productivity by solving challenges such as high turnover and absenteeism (Macey, Schneider, Barbera, \& Young, 2011). This notion is reinforced by research that suggested that organizations with higher levels of engagement report positive individual and organizational outcomes (Kular, Gatenby, Rees, Soane, \& Truss, 2008). The popularity of engagement is such that its growth has bucked the typical trend associated with emergence and development of a construct (Shuck et al., 2017). Engagement has seen significant development in its definition and measurement leading to the rise of several engagement scales used in practice and research (Shuck et al., 2017). However, the numerous scales in existence have preceded proper theoretical development of the engagement construct (Macey \& Schneider, 2008). Thus, this has led to confusion both in research and practice as there are several definitions of engagement, and engagement scales that are misused (Shuck et al., 2017). According to Zigarmi et al., (2009) this has contributed to the different perspectives that practitioners and researchers have about engagement.

In practice, the purpose of engagement is to improve organizational outcomes such as retention and productivity. Thus, employers are often keen on collecting 
numerical data to explain employee behavior and devise interventions to improve employee behavior and the resulting data associated with it (Bakker \& Schaufeli (2008). In their work, Bakker and Schaufeli (2008) indicated that employers are actively searching employees who are proactive, good team players, and contribute maximum effort towards the success of the organization. While this intention is well meant by employers, it tends to result in the description of constructs that are considered related to engagement, but not engagement itself such as job satisfaction and commitment (Czarnowsky, 2008). In research, work on engagement has been focused on defining the construct itself (Wefald \& Downey, 2009). However as noted by Shuck et al. (2017), there are lack of clear distinctions to separate the different engagement forms that have been conceptualized. This has resulted in the misapplication of theory and measurement to engagement research. To help stem the tide of engagement misuse, this portion of the literature review differentiates employee engagement from other common engagement forms such as work engagement, job engagement, and organizational engagement. To do this, Kahn's seminal work in engagement is discussed, followed by a description of alternate engagement forms (i.e. burnout and trait approaches), and how they differ from employee engagement.

Kahn's theory on personal engagement. Scholars often credit Kahn (1990) as the seminal author on engagement (Shuck, Rocco, Albornoz, 2011). In his study, Kahn first presented the idea of engagement in the workplace. He defined engaged employees as individuals who immerse themselves fully at work, characterized by cognitive, emotional, and behavioral expressions in the performance of their duties. Kahn further stated that the opposite of engagement is disengagement. Disengaged employees are not 
fully immersed in their jobs because they withhold cognitive, emotional, and behavioral expressions in the discharge of their duties. According to Kahn, to fully understand engagement in the workplace, there is a need to understand the meaning that people attach to their workplaces (psychological conditions), and the individuals and groups within the workplace that could influence the meaning (context). In a later study, Kahn (1992) redefined the psychological aspect of engagement as the presence of meaningfulness, safety and availability. Meaningfulness, according to Kahn, is a "sense of return on investments of self in role performance" (Kahn, 1990, p. 705). Safety was described as the ability to present oneself "without fear or negative consequences to self image, status, or career" (Kahn, 1990, p. 705). Finally, availability was considered to be the possession of a complete range of cognitive, emotional, and behavioral resources required to perform work duties. These three, i.e. meaningfulness, safety, and availability thus form the crux of the engagement construct. Since Kahn's (1990; 1992) work, researchers have tested and confirmed his conceptualization of engagement (e.g. May, Gilson, \& Harter, 2004) and has also lead to the emergence of the employee engagement construct (cf. Shuck \& Reio, 2014, Shuck et al., 2016, Shuck et al., 2017). Employee engagement draws heavily from Kahn's theory of personal engagement. For example, a central tenant of the employee engagement theory is that an employee's thoughts (cognition) and feelings (emotion) about their workplace influence their actions (behavior) in the workplace (Shuck et al., 2017). Additionally, employee engagement is characterized by an active pull resulting in performance that is proportional to the investment of an individual's personal resources (Kahn, 1990; Shuck et al., 2017). Finally, Shuck et al. (2017) noted that employee engagement is a state as opposed to a 
trait, and is comprised of increased levels of energy before the full state of being engaged is achieved.

Aside from employee engagement, there are other engagement frameworks that have emerged from Kahn's (1990; 1992) conceptualization. These include organizational engagement (Saks, 2006) and job engagement (Rich et al., 2010). While these frameworks are derivatives of Kahn's theory of personal engagement, they bear features that distinguish them from employee engagement. In 2006, Saks defined organizational engagement as "the extent to which an individual is psychologically present in a particular organizational role" (p. 604). Since then, an examination of the studies that have utilized Saks' conception of engagement revealed that it shares two of the four key features of employee engagement, i.e. consisting of an active pull and being state-based (Shuck et al. 2017). Additionally, Shuck et al. noted that organizational engagement focuses only on an employee's psychological presence within an organization, thus making it a narrower view of employee engagement. Rich et al. (2010) defined job engagement as "multi-dimensional motivational concept reflecting the simultaneous investment of an individual's physical, cognitive, and emotional energy in active, full work performance" (p. 619). The unique feature of Rich et al.'s job engagement theory is the focus of energy in an active form towards performance of a job. This conceptualization of engagement as being specific to job performance distinguishes job engagement from employee engagement. The emergence of different engagement frameworks indicates how influential Kahn's work was to the development of engagement, as it is known today. However, even though Kahn conceptualized engagement in the early 1990's, engagement did not start to become popular among 
social science researchers until later in the decade. The 're-emergence' of scholarly interest in engagement was triggered by research on employee burnout, and led to alternate conceptualizations of engagement.

Alternate forms of engagement. The alternate forms of engagement discussed in this section starts with the burnout approach followed by the trait approach. Maslach and her colleagues published a number of works on employee burnout (e.g. Leiter, Maslach, \& Frame, 1998; Maslach \& Jackson, 1984; 1996). As they developed their theory, they presented the idea that engagement is the opposite of burnout. In other words, burnout is the diminution of the positive aspects of an employee's job (Maslach et al., 2010). Therefore, anything at work that was important, meaningful, and challenging becomes "unpleasant, unfulfilling, and meaningless" (Maslach, et al., 2001, p. 416). It is important to note that when Maslach and colleagues first provided this conceptualization, they did not have a scale to measure engagement. Instead they considered employees that scored low on their burnout scale (Maslach Burnout Inventory; Maslach \& Leiter, 1997) to be engaged. Thus, for Maslach and her colleagues, engagement and burnout were considered to be opposite ends of a spectrum. Building on the work by Maslach and her colleagues, Schaufeli et al. (2002) put forth what is now considered the most widely used engagement term: work engagement (Shuck et al., 2017). Schaufeli et al. (2002) tested Maslach and colleagues' engagement framework, but in the process used a slightly different definition and created a scale purposively meant to measure engagement. According to Schaufeli et al., engagement is a "positive, fulfilling, work related state of mind that is characterized by vigor, dedication, and absorption" (p. 74). The major characteristic that distinguishes this form of engagement from employee engagement is 
the lack of the cognitive element (Shuck et al., 2017). Work engagement focuses only on the emotional and physical elements associated with burnout. The trait approach takes a different view from the approaches to engagement that has been discussed so far. These approaches to engagement i.e. the 'Kahn approach' and the burnout approach, each viewed engagement as a state. In other words, engagement is not permanently achieved, but rather comes into being when the right combination of conditions or factors are present. Some scholars take an opposing view, and suggest that engagement is trait that employees either have or do not have (e.g. Langelaan, Bakker, Van Doornen, \& Schaufeli, 2006; Wildermuth, 2008). This view, also known as trait engagement (Macey $\&$ Schneider, 2008), implies that engagement is a stable trait that persists regardless of an individual's context and experiences at work. Further, proponents of this view have put forth the idea that specific personality traits such as the 'Big 5 personality model' (i.e. Openness, Conscientiousness, Extraversion, Agreeableness, and Neuroticism) may result in some individuals being more inclined to experiences of engagement than others (Shuck et al., 2017; Wildermuth, 2010). The trait view of engagement is at odds with employee engagement because it limits the full experience engagement to individuals who have certain personalities, and does not account for the influence that the work environment might have. Trait engagement is somewhat controversial and a highly contested matter (Shuck et al., 2017), but the lack of sufficient empirical evidence to justify this approach means that it is not as widely used as the other approaches described.

In summary, this section discussed three different approaches that can be used to study engagement: (a) engagement grounded in Kahn's personal engagement theory (Kahn, 1990; 1992; Rich et al., 2010; Saks, 2006; Shuck et al., 2017) (b) the burnout- 
antithesis approach (Maslach et al., 2001; Schaufeli et al., 2002), and (c) the trait approach (Langelaan, et al., 2006; Wildermuth, 2008). More than a decade ago, the burnout approach was found to be the most cited by researchers studying engagement (Christian \& Slaughter, 2007). In spite of the emergence of new engagement frameworks since Christian and Slaughter's work, the burnout definition and measurement of engagement provided by Schaufeli and his colleagues continues to be the most widely used in engagement research (Shuck et al., 2017). While each of these approaches provides differing perspectives on engagement, they are all in agreement that engagement can result in positive outcomes that employers desire (Maslach et al., 2001; Saks, 2006; Shuck and Reio, 2014). In this study, engagement is defined and measured using the employee engagement approach. Employee engagement was selected for this study because it contains the cognitive element of engagement that the burnout approach lacks, and provided insight into why employees feel the way they do about their workplaces. Also, this study takes the view that any employee can be engaged if the right factors are in place in the work environment. This is counter to the trait approach that assumes that not everyone has the capacity to be engaged, thus making the trait approach unsuitable for this study.

\section{Wellbeing}

Wellbeing has many conceptualizations, and according to Brunetto et al. (2012), some scholars look at it as one construct (i.e. wellbeing) or as consisting of separate constructs (e.g. physical wellbeing and psychological wellbeing). The variation in the operationalization of wellbeing poses a challenge for researchers, as there is no unifying definition of wellbeing. It is not the intention of this study to establish a universal 
definition for wellbeing. Given that many studies on wellbeing examine psychological and/or physical health as separate constructs of wellbeing, this study will do same. Hence, in this study, wellbeing is defined as comprising of two things: the psychological functioning and physical health outcomes of individuals. The position the researcher takes on wellbeing is not novel, but is consistent with prior research (e.g. Keilmann, Limberger, \& Mann, 2007; Marks, Jun, \& Song, 2007; McKee-Ryan). Next, psychological and physical wellbeing are discussed in further detail.

Psychological wellbeing. For many decades, the study of psychological wellbeing was guided by two conceptions of positive functioning: hedonism and eudiamonia (Ryan \& Deci, 2001; Ryff \& Keyes, 1995; Springer \& Hauser, 2006). Hedonism is grounded in Bradburn's (1969) seminal work, and equates wellbeing with happiness. Thus, psychological wellbeing is operationalized as the balance between positive and negative affect (Springer \& Hauser, 2006). The second conception, eudiamonia, revolves around life satisfaction as a key indicator of psychological wellbeing that compliments happiness (Ryff \& Keyes, 1995). Further, eudiamonia concerns itself with the extent to which individuals feel fulfilled, and are able to realize their full potential (Grant et al., 2007; Waterman, 1993). Within this conception, researchers have examined wellbeing by posing general questions about overall life satisfaction, or more domain specific questions related to the workplace and income earned (Andrews, 1991). The eudiamonic view of wellbeing offers a broader description of psychological wellbeing, going beyond happiness as is proffered by hedonism. Therefore, in this study, psychological wellbeing will be approached from the eudiamonic perspective. 
According to Ryff's (1989) seminal work, psychological wellbeing is rooted in theories of positive psychological functioning such as self-actualization (Maslow, 1968), the concept of maturity (Allport, 1961) and Roger's (1961) concept of the fully functioning person. Prior to Ryff's seminal piece, these theories existed in isolation and, consequently, scholars disagreed on what should constitute wellbeing. Ryff argued that the dominant positive psychology theories should be integrated into a parsimonious summary that could serve as a unified description of psychological wellbeing. Ryff then captured this information and categorized them as dimensions of psychological wellbeing. These dimensions are: self acceptance (defined as the key feature of mental health function of an individual), positive relations with others (the capability to empathize and show affection towards others), autonomy (the sense of freedom derived from evaluating oneself using personal standards), environmental mastery (the ability to choose or create an environment that suits an individual's psychic conditions), purpose in life (having goals and a sense of direction that makes life meaningful, and personal growth (being able to continuously harness one's potential). Together, these dimensions help facilitate the evaluation of a person's level of positive functioning and wellbeing (van Dierendonck, 2005). Research has shown that these dimensions of wellbeing are associated with the workplace (Ryff, 2014). For example, Lindfors, Berntsson, and Lundberg (2006) noted that the type of work influences the relationship between work and psychological wellbeing. In their study, unpaid work was found to be associated with lower levels of self-acceptance and environmental mastery. For men, paid work was linked to increased levels of personal growth. Psychological wellbeing has also been shown to influence career pursuits. Using a sample of female workers in education and 
banking, Johansson, Huang, and Lindfors (2007) found that female teachers found to have higher levels of wellbeing as compared to their counterparts in the banking industry.

Physical wellbeing. Employee health has received considerable attention in the extant literature, in part, due to the rising costs associated with health care costs (Danna \& Griffin, 1999; Naydeck, Pearson, Ozminkowski, Day \& Goetzel, 2008). As mentioned earlier, the wellbeing research is rife with inconsistent operational definitions and categories. The physical nature of wellbeing is no stranger to this. Among the many terms that researchers use when referring to physical concerns includes physical health, mental health, and physical well being (Dana \& Griffith, 1999). Often, these terms are used in reference to a person's physiological functioning, particularly in the medicine and science fields. In social science research, employees' physical wellbeing is typically measured using self-reports of bodily symptoms that indicate the presence or absence of sickness (Spector \& Jex, 1998). For example, the Physical Symptoms Inventory (Spector, 1987) asks respondents about physical symptoms they have experienced, and whether they have been serious enough to justify medical attention. The way physical wellbeing is measured in the social sciences differs from the medical and science fields, where the emphasis is on specific medical diagnoses and not self-report data (Spector \& Jex, 1998). It is also common for social science researchers to adapt physical wellbeing scales used in medicine research. For example Shuck et al. (2017) utilized the Medical Outcomes Study-Short Form (MOS-20; Stewart, Hays, \& Ware, 1988) to examine employees' perception of their health.

In studying physical wellbeing in the workplace, researchers have examined the relationship between specific symptoms and workplace behaviors. For example, Darr and 
Johns (2008) found fatigue to be moderately correlated with absenteeism in their study ( $r$ $=.32$ ). Common physical symptoms that have been examined by previous researchers include backache, headache, eyestrain, sleep disturbance, dizziness, fatigue, appetite (Nixona, Mazzolab, Bauera, Kruegerc, \& Spector, 2011). Nixona et al. (2011) noted that job stressors, that is, aspects of the work environment that employees find unpleasant, trigger these physical symptoms. Examples of job stressors noted in Nixona et al.'s (2011) meta analysis that impact employees' health include interpersonal conflict, excessive workload and work hours. Nixona et al. (2011) found each of these stressors to be significantly associated with physical symptoms. More, they found interpersonal conflict to have the highest mean correlation with sleep disturbances, workload to fatigue and dizziness and appetite loss. The findings noted above suggested a link between the workplace environment and health of employees, and thus serve as an impetus for this study.

In summary, researchers have conceptualized wellbeing in different ways, including as a stand-alone construct or, consisting of two separate constructs such as psychological wellbeing and physical wellbeing. In psychological wellbeing research, wellbeing is either equated to a person's happiness (hedonism) or satisfaction with outcomes in life (eudiamonia). Physical wellbeing is focused on health outcomes of employees, and is measured either by specific medical diagnoses or self-report data based on an employee's perception of their health. Because this study goes beyond mere happiness, and examined the meaning employees' ascribe to the workplace, the eudiamonic view of psychological wellbeing was used. Also, given that employee health is receiving considerable attention in institutions of higher education, physical wellbeing 
was examined in addition to psychological wellbeing. By doing so, this study approached wellbeing as consisting of separate constructs. In the next section, a synthesis of empirical evidence linking psychological climate, engagement, and wellbeing to each other, and to individual and organizational outcomes is presented.

\section{Synthesis of Relevant Empirical Studies}

The purpose of this section is to review previous studies that have collectively examined psychological climate, engagement, and wellbeing. To do this a two-staged approach was used to gather studies. First, data sources representative of human resource development and management fields were searched. The databases searched included: PsycInfo, ABI/Inform, the Academy of Management database, and all four Academy of Human Resource Development (AHRD) journals. Google scholar was searched as well to capture studies outside of human resource development that collectively measured psychological climate, engagement, and wellbeing. Data sources were abstract queried using the following key terms: psychological climate, engagement, wellbeing. Articles selected for review had to be empirical, listed all three key terms in the title of the study, measured all three key terms, and be peer-reviewed. This search did not yield any results. The result of the search highlights the paucity of information on the relationship between psychological climate, engagement, and wellbeing. Because of the lack of studies that collectively examine psychological climate, engagement, and wellbeing, the article selection approach/parameters were modified to include studies that examined at least two of the three study variables. This represented the second stage in the search for studies. The modified approach yielded 8 studies that were grouped as follows: psychological climate and engagement $(n=2)$, engagement and wellbeing $(n=5)$, and 
psychological climate and wellbeing $(n=1)$. Shuck and Reio's (2014) study is reviewed first, as it is the only study that includes all three variables. Following this, the remaining groups of studies identified using the modified parameters are reviewed. Because many of the studies in these three groups also examined variables unrelated to this study, only the findings and outcomes associated with psychological climate, engagement, and wellbeing are reviewed.

\section{Psychological Climate, Engagement, and Wellbeing}

Shuck and Reio (2014) conducted their study during a period where employers were beginning to understand the concept of engagement, and the benefits (e.g. increased productivity, lower turnover) their organizations stood to gain from it. Additionally, emergent research at the time had begun to link lower levels of engagement with poor individual health outcomes such as burnout and exhaustion (Schaufeli et al., 2002). The purpose of Shuck and Reio's study therefore, was to determine if there was a link between "the central elements within a workplace climate (i.e. psychological climate) that foster the development of engagement and stimulate wellbeing" (p. 44). Further, they sought to find out whether employees who vary in levels of engagement differed in their reports of their wellbeing.

A sample of 216 healthcare employees from US, Canada, and Japan with membership in a professional association was used for this study. The research design was a cross-sectional correlation study design, and involved participants answering a survey battery consisting of six measures. Psychological climate was measured using Psychological Climate Measure (PCM; Brown \& Leigh, 1996) and engagement was measured using the Job Engagement Scale (JES; Rich et al., 2010). Shuck and Reio 
measured wellbeing using four scales: emotional exhaustion scale (EES; Iverson et al., 1998), depersonalization scale (DS; Iverson et al., 1998), Personal Accomplishment Scale (PAS; Iverson et al., 1998), and the Schwartz Outcome Scale-10 (SOS-10; Blais et al., 1999) to measure psychological wellbeing.

Results from the study showed that psychological climate had a moderately strong association with engagement $(r=.56, p<.001)$. Further, there were significant negative correlations between engagement and emotional exhaustion $(r=-.41, p<.001)$, as well as depersonalization $(r=-.41, p<.001)$. Psychological climate was also negatively correlated with emotional exhaustion $(r=-.45, p<.001)$ and depersonalization $(r=-.40$, $p<.001)$. On the other hand, psychological climate was found to be positively associated with personal accomplishment $(r=.48, p<.001)$ and psychological wellbeing $(r=.37, p$ $<.001)$. The same held true for the relationship between engagement and personal accomplishment $(r=.48, p<.001)$ and psychological wellbeing $(r=.37, p<.001)$. Also, Shuck and Reio (2014) found that the relationship between psychological climate and psychological wellbeing, as well as personal accomplishment, was stronger when engagement was high. Thus, they concluded that engagement acted as a moderator, by strengthening the relationship between psychological climate and wellbeing. Finally, Shuck and Reio found that employees who had high engagement levels had significantly lower scores on depersonalization and emotional exhaustion than employees who had lower engagement levels.

These findings suggested two things. First, psychological climate and engagement, are positively associated with more positive forms of wellbeing (i.e. personal accomplishment, and psychological wellbeing), and negatively associated with 
negative forms of wellbeing (emotional exhaustion and depersonalization). Second, employees who have positive perceptions of their work climate, and are engaged, are more likely to have higher levels of wellbeing than employees who are not engaged, or have negative perceptions of their workplaces. While Shuck and Reio's (2014) study findings indicated associations between psychological climate, engagement, and wellbeing, their findings are limited to employees in the healthcare industry, and thus may not be applicable to employees in higher education institutions. This makes the case for the examination of these variables within a higher education setting. Also, their study measured wellbeing using two 'positive' forms (psychological wellbeing and personal accomplishment) and two 'negative' forms (depersonalization and emotional exhaustion) of wellbeing. However, there was no examination of how psychological climate and engagement might affect the physical functioning of an employee. Finally, while Shuck and Reio's study indicated that employees differed in terms of wellbeing based on their engagement level, there was no information on whether different job roles might impact the relationships uncovered. Thus, this study examined whether differences in job roles might impact the relationship between psychological climate, engagement, and wellbeing in order to help close this existing gap in the literature.

\section{Psychological Climate and Engagement}

In Shuck and Reio's (2014) study, engagement was positively correlated with psychological climate. Thus this section explores this further by examining other studies that used psychological climate and engagement. The two studies reviewed (Kataria et al., 2013a; Kataria et al., 2013b) used other variables in addition to psychological climate and engagement, so the focus of the review will only be on the findings and outcomes 
associated the current study's variables of interest. Kataria et al.'s, (2013a) study was based on the premise that psychological climate impacts organizational performance but only indirectly through individual outcomes such as engagement. Thus, the authors sought to determine if engagement mediated the relationship between psychological climate and organizational performance. To answer the research question, Kataria et al. (2013) conducted a study using a sample of 300 employees in the service industry. Data were gathered using three measures: Psychological Climate Measure (Brown \& Leigh, 1996), Utrecht Work Engagement Scale (Schaufeli et al., 2006), and an organizational effectiveness scale (Mott, 1972). The mediation was tested using path analysis. The results showed a significantly moderate positive correlation between psychological climate and engagement $(r=.53, p<.001)$. Using Baron and Kenny's (1986) test of mediation, Kataria et al., found that engagement fully mediated the relationship between psychological climate and organizational effectiveness.

In a similar study, Kataria et al. (2013b) examined the role of engagement as a mediator between psychological climate and organizational citizenship behavior (OCB). Data were collected from a sample of 278 employees in the Information Technology (IT) industry using the Psychological Climate Measure (Brown \& Leigh, 1996), UWES (Schaufeli et al., 2006) and an OCB measure (Podsakoff \& MacKenzie's, 1989). The mediation was tested using path analysis. The results showed a significantly moderate positive correlation between psychological climate and engagement $(r=.43 p<.001)$. The mediation analysis using Baron and Kenny's (1986) approach showed that engagement partially mediated the relationship between psychological climate and OCB. In summary, the two studies reviewed suggested two key findings about the relationship 
between psychological climate and engagement: that a) there is a positive association between psychological climate and engagement and $b$ ) engagement mediated the relationship between psychological climate and organizational outcomes. Consistent with existing research (Shuck \& Reio, 2014), these studies highlighted that engagement is not only positively associated with psychological climate, but causes the relationship between psychological climate and individual, as well as organizational outcomes. The studies reviewed in this section are limited in generalizability because they used a nonUS sample, and also did not include employees in higher education, and therefore it is not clear whether the mediating effects of engagement will hold in a sample with those characteristics.

\section{Engagement and Wellbeing}

Since Kahn (1990) introduced the concept of engagement, scholarly interest in the subject has grown exponentially. The nature, measurement, and best practices of engagement have been heavily documented in organizational and management literature (Fairlie, 2017). This includes the effects of engagement on key employee outcomes such as job satisfaction, organizational commitment, turnover intention, and financial returns (Saks, 2006; Schaufeli and Bakker, 2004; Xanthopoulou et al., 2009b.). However, there remains a shortage of information on the connection between engagement and wellbeing (Fairlie, 2017). According to Fairlie, the lack of information on engagement and wellbeing is surprising because engagement has been positively linked to other constructs (e.g. job satisfaction) that are also associated with wellbeing. Thus, the connection between engagement and wellbeing should seem intuitive. For each of the studies reviewed in this section, highly engaged employees reported better wellbeing. Because 
many of the studies in the three groups also examined variables unrelated to this study, only the findings and outcomes associated with engagement, and wellbeing are reviewed In Brunetto, Teo, Shacklock, and Farr-Wharton's (2012) study, a sample of 193 police officers were administered a survey that consisted of the UWES (Schaufeli \& Bakker, 2003) and a wellbeing scale (Brunetto et al. 2011). Brunetto et al. examined the associations between engagement, wellbeing, emotional intelligence, affective commitment and turnover intentions using path analyses. In this study, the term wellbeing was used interchangeably with psychological wellbeing, and was proposed as an antecedent to engagement. The results showed a significantly strong positive correlation between engagement and wellbeing $(r=.69, p<.001)$. Further, results from a path analysis indicated a significant path from wellbeing to engagement $(\beta=.43, p<$ .001) suggesting that as police officers' wellbeing increased, so did their engagement.

Brunetto et al., (2014) conducted a similar study, but positioned engagement as an antecedent to wellbeing in a model that also included perceived organizational support, organizational commitment and turnover intentions. The sample consisted of 510 nurses and 193 police. Engagement was measured using the UWES (Schaufeli \& Bakker, 2003), and wellbeing was measured using a scale developed by Brunetto et al. (2011). In this study, wellbeing referred to psychological wellbeing. The results showed a significantly strong positive correlation between engagement and wellbeing $(r=.74, p<.001)$. Further results from the path analysis on the model indicated a significant path from engagement to wellbeing $(\beta=.67, p<.001)$ suggesting that as engagement increased, so did wellbeing. 
Atkins, Hassed and Fogliati (2015) explored factors that could improve employee wellbeing and performance. These factors included engagement and autonomous motivation. They used a sample of 233 university faculty and staff and administered the UWES (Schaufeli et al., 2006) to measure engagement. Wellbeing was measured using two scales: the Positive and Negative Affect Scale (PANAS; Watson et al., 1988) for emotional/hedonic wellbeing, and the Satisfaction with Life Scale (SWLS; Diener et al., 1985) for meaningfulness/eudaiamonic wellbeing. Participants completed the survey measures at three different time points: before a mindfulness program, immediately after, and then six months following the program. At all three time points, engagement was positively correlated with both measures of wellbeing. Specifically, before the intervention, the correlation between engagement and hedonic wellbeing was $r=.51, p<$ .001 , engagement and eudaiamonic wellbeing was $r=.47 p<.001$. After the intervention, engagement was correlated with hedonic wellbeing $(r=.25, p<.001)$ and eudaiamonic wellbeing $(r=.38, p<.001)$. Finally, after six months, engagement was correlated with hedonic wellbeing $(r=.20, p<.05)$ and eudaiamonic wellbeing $(r=.41$, $p<.001)$. These findings are particularly relevant to this study as the sample used were university employees. The most notable finding is that across time, engagement and wellbeing remained positively associated with each other, but the strength of the relationships were reduced. There was no distinction between faculty and staff in the findings, and this presented as a limitation of this study.

The final study reviewed, Trinchero, Borgonovi and Farr-Wharton (2014), examined the relationship between engagement, wellbeing, and the supervisorsubordinate relationship. In this study wellbeing was used as a term to refer to 
psychological wellbeing. A sample of 773 nurses were administered the UWES

(Schaufeli \& Bakker, 2003), and a wellbeing scale developed by Brunetto et al. (2011).

The results indicated a strong and positive relationship between engagement and wellbeing $(r=.75, p<.01)$. Thus, employees with higher levels of engagement were more likely to have higher levels of wellbeing. Unlike other empirical studies that examined relationships between similar variables, Trinchero et al. (2014) did not specify whether engagement followed wellbeing or vice versa (cf. Brunetto et al., 2012; Brunetto et al., 2014). Also, this study was conducted using a sample of nurses from a non U.S. population and thus limits generalizability to higher education employees in the U.S.

From the studies reviewed above, it is clear that there is a positive association between engagement and wellbeing. There are however, several limitations that contribute to the gap in current literature on engagement and wellbeing. First, none of these studies included measures for physical wellbeing. Second, the consistent use of Schaufeli et al.'s work engagement definition and measure confirms its popularity as the most widely used engagement measure. However, the underrepresentation of other conceptualizations of engagement underscores the need to include their use in future studies of this nature. Finally, none of these studies examined what effect employee roles might have on the relationship between engagement and wellbeing.

\section{Psychological Climate and Wellbeing}

Previous research has suggested that there is an association between employees' perception of the psychological climate and outcomes in the workplace (Kataria et al., 2013a; Shuck \& Reio, 2014). These include organizational level outcomes such as 
performance and OCBs (Kataria et al., 2013a) and individual level outcomes such as wellbeing and withdrawal (DeShon, 2003). The impact of psychological climate on individual and organizational outcomes is however thought to be indirect, and can be determined through measuring the mediating effect of variables such as engagement, job involvement, and effort (Brown \& Leigh, 1996; Eisele \& D'Amato, 2011; Kataria et al., 2013a). Since the development of the psychological climate scale by Brown and Leigh, there have been numerous studies that have shown significantly positive indirect associations between psychological climate and workplace outcomes, thus highlighting the importance of mediating variables (Eisele \& D'Amato, 2011). The outcome variables that are used in these studies tend to be organizational level outcomes, and as such there is little known about the indirect effect of psychological climate on individual outcomes, and, for that matter, wellbeing in particular (Eisele \& D'Amato, 2011). Eisele and D'Amato, the authors of the study reviewed in this section, sought to close the gap in the literature by examining the influence of psychological climate on wellbeing using OCB as a mediating variable.

Data were collected from a sample of 599 employees in the health care industry using the Majer_D'Amato Organizational Questionnaire 10 (M_DOQ10) to measure psychological climate (D'Amato \& Majer, 2005), and an OCB measure developed by Koys (2001). Wellbeing was measured using the Maslach Burnout Inventory (Leiter \& Leiter, 2005) and individuals who scored high on burnout were considered to be low on wellbeing and vice versa. In conducting their analyses, Eisele and D'Amatio only reported results on the subscales of all the measures used. Initial findings indicated significant and moderately negative correlations between psychological climate and 
burnout. The correlations are as follows: job procedures and emotional exhaustion $(r=-$ $.50 p<.001)$, job procedures and depersonalization $(r=-.39 p<.001)$, managerial practices and emotional exhaustion $(r=-.56 p<.001)$, managerial practices and depersonalization $(r=-.43 p<.001)$, organizational policies and emotional exhaustion $(r$ $=-.45 p<.001)$ and finally organizational policies and depersonalization $(r=-.38 p<$ $.001)$. These results suggested that better perceptions of psychological climate were associated with lower levels of burnout (or un-wellbeing) and vice versa. Eisele and D'Amatio used structural equation modeling to test a mediation model where OCB mediated the relationship between psychological climate and wellbeing. Results from this analyses indicated good model fit, and indicated a strong association between psychological climate and $\mathrm{OCB}$, as well as a negative association between OCB and wellbeing.

Eisele and D'Amato's (2011) study results add additional evidence to the body of information that suggested that psychological climate is positively associated with wellbeing. However, only a measure of un-wellbeing was used, i.e. burnout, and Eisele and D'Amato only sampled employees in the healthcare industry. Thus, it is unclear from this study how psychological climate might be related to other forms of wellbeing, (such as physical wellbeing) using a study population of employees outside the healthcare sector. Another limitation of the Eisele and D'Amato study is that correlations were only reported for some of the scales of the measures. For example, there was no information reported on the relationship between the psychological climate subscales and the personal achievement subscale of the burnout scale. Additionally, aggregate scores and correlations of both measures were not reported, and so it is difficult to conclude that the 
entire constructs of psychological wellbeing and wellbeing as measured in Eisele and D'Amato's study are positively associated with each other.

Table 1

Selected Correlation Estimates Between Psychological Climate, Engagement And Wellbeing

\begin{tabular}{|c|c|c|c|}
\hline Relationship & Sample size & Source & Correlations $(r)$ \\
\hline PC- Eng & 300 & Kataria et al., 2013a & $.53 * *$ \\
\hline PC- Eng & 278 & Kataria et al., 2013b & $.43 * *$ \\
\hline Eng-Wellbeing & 193 & Brunetto et al., 2012 & $.69 * *$ \\
\hline Eng-Wellbeing & 703 & Brunetto et al., 2014 & $.74 * *$ \\
\hline Eng-Wellbeing & 233 & Atkins et al., 2015 & $.47 * *, .38^{* *}, .41^{* *}$ \\
\hline Eng-Wellbeing & 773 & $\begin{array}{l}\text { Trinchero et al., } \\
2014\end{array}$ & $.75 * *$ \\
\hline PC-Wellbeing ${ }^{\mathrm{a}}$ & 599 & $\begin{array}{l}\text { Eisele \& D’Amato, } \\
2011\end{array}$ & $\begin{array}{l}-.50 * *,-.39 * *,-.56 * * \\
-.43 * *,-.45 * *,-.38 * *\end{array}$ \\
\hline PC-Eng & 216 & Shuck \& Reio, 2014 & $.56^{* *}$ \\
\hline PC-Wellbeing & 216 & Shuck \& Reio, 2014 & $.37 * *$ \\
\hline Eng-Wellbeing & 216 & Shuck \& Reio, 2014 & $.37 * *$ \\
\hline
\end{tabular}

\section{Section Conclusions}

The empirical studies reviewed in this section highlighted three key pieces of information that are relevant to the current study. First, it is clear that psychological climate, engagement, and wellbeing are positively related. Therefore, employees who have more positive perceptions of their places of work are more likely to be engaged, and are more likely to report better levels of wellbeing (See Table 1). Second, engagement acts as an intermediary between psychological climate and wellbeing because it is difficult to establish direct effects of psychological climate on individual and 
organizational outcomes (Brown \& Leigh, 1996). In doing so, engagement mediates the relationship between psychological climate and wellbeing. Third, there are still several gaps in the current literature surrounding psychological climate, engagement, and wellbeing. For example, while there is empirical evidence linking psychological climate and engagement to un-wellbeing and psychological wellbeing, there remains little to no information on physical wellbeing. Also, while it is known that employees who are engaged are more likely to report better wellbeing, there is very little known about whether an employee's role might influence this. Last but not least, there is a shortage of information on how psychological climate, engagement, and wellbeing might be related among employees of higher education institutions. These three key pieces of information prompted the need for this study, and influenced the research questions and hypotheses that guide this study. As such, the research questions and hypotheses proposed in this study are as follows:

(a) What is the relationship between psychological climate, engagement, and wellbeing in higher education?

$\mathrm{H}_{1}$ : There is a positive relationship between psychological climate, engagement, and wellbeing.

$\mathrm{H}_{2}$ : There will be a significant difference between faculty and staff in the level of wellbeing.

(b) Does employee role influence the relationship between psychological climate and wellbeing in higher education?

$\mathrm{H}_{3}$ : Employee role will moderate the relationship between psychological climate and psychological wellbeing. 
$\mathrm{H}_{4}$ : Employee role will moderate the relationship between psychological climate and physical wellbeing.

(c) Does engagement mediate the relationship between psychological climate and wellbeing in higher education?

$\mathrm{H}_{5}$ : Engagement will mediate the relationship between psychological climate and psychological wellbeing.

$\mathrm{H}_{6}$ : Engagement will mediate the relationship between psychological climate and physical wellbeing. 


\section{CHAPTER THREE METHODOLOGY}

A cross-sectional survey research design was used to examine the relationship between psychological climate, engagement, and wellbeing. Cross-sectional survey research enables inferences to be made about a population of interest at one point in time using data collected. It is best suited for gaining information about behaviors, perceptions and attitudes of a population, however it cannot be used to track this information across time (Sedgwick, 2014). This study specifically examined whether engagement served as a mediator of the relationship between psychological climate and engagement. This study also investigated whether employee role moderated the relationship between psychological climate and wellbeing. This chapter discusses the research design and methodology and is organized in the following order: a) research questions and hypothesis b) population and sample c) instrumentation d) controlling for survey error and e) data collection and analyses.

\section{Research Questions and Hypotheses}

Three research questions were addressed:

RQ1: What is the relationship between psychological climate, engagement, and wellbeing in higher education?

$\mathrm{H}_{1}$ : There is a positive relationship between psychological climate, engagement, and wellbeing. 
$\mathrm{H}_{2}$ : There will be a significant difference between faculty and staff in the level of wellbeing.

RQ2: Does employee role influence the relationship between psychological climate and wellbeing in higher education?

$\mathrm{H}_{3}$ : Employee role will moderate the relationship between psychological climate and psychological wellbeing.

$\mathrm{H}_{4}$ : Employee role will moderate the relationship between psychological climate and physical wellbeing.

RQ3: Does engagement mediate the relationship between psychological climate and wellbeing in higher education?

$\mathrm{H}_{5}$ : Engagement will mediate the relationship between psychological climate and psychological wellbeing.

$\mathrm{H}_{6}$ : Engagement will mediate the relationship between psychological climate and physical wellbeing.

\section{Population and Sample}

The data for this study was based on 259 employees in higher educational institutions in the United States who met the research criteria and completed the online survey. To participate in this study, individuals had to be employed by an institution of higher education as faculty or staff. Faculty role was operationally defined as an employee in higher education whose work consists of a combination of research, teaching, and service. Staff role on the other hand was operationally defined as an employee in higher education whose work does not consist of any combination of research or teaching. According to recent data from the National Center for Education 
Statistics (NCES), there are an estimated 3.9 million individuals employed by institutions of higher education in the United States (NCES, 2016). This includes 1.6 million faculty members and about 2 million staff (NCES, 2016). Further, the NCES data showed that there are 1.9 million employees in public four year institutions, 1.1 million employees in private four year institutions, six hundred thousand employees in public two year institutions, as well as thirty two thousand employees in private two year institutions. Demographically, the NCES data estimated the demographic distribution to be $42 \%$ White males, 35\% White females, $6 \%$ Asian/Pacific Islander males, 4\% Asian/Pacific Islander females, 3\% Black males, 3\% Black females, 2\% Hispanic males and 3\% Hispanic females. Making up less than $1 \%$ were individuals who were American Indian/Alaska Native and two or more races.

To estimate the sample size, a power analysis was performed using the G*Power 3.1 statistical software (Faul, Erdfelder, Buchner, \& Lang, 2009). The desired amount of power (.80), alpha level (.05), and effect size (.15) were set based Cohen's (1988) guidelines to calculate the required sample size. The result indicated a sample size of 77 was required to detect the minimum effect size. However, studies that test for moderation and mediation are prone to low statistical power and often require much larger sample sizes (Aguinis, 1995). For example, Aguinis noted that in a sample size of 120, small effects are likely to go undetected. Thus for this study the researcher sought sample size of $\mathrm{N}>240$ (i.e. greater than double the sample size Aguinis mentioned) in order to strengthen statistical power and reduce the likelihood of Type II error. Additionally, this study employed a resampling method called bootstrapping to generate robust confidence intervals to detect significant effects. Bootstrapping is a non-parametric approach to 
effect size and hypothesis testing that repeatedly samples from the original sample size to compute robust confidence intervals to determine an effect (Preacher \& Hayes, 2004). The final sample size for this study $(n=259)$ was resampled 5,000 times to generate confidence intervals to determine mediation.

In order to make inferences about the population in this study, non-probability sampling by means of a convenience sample was used. Non-probability sampling is an effective means of collecting data to extend current knowledge of a population (Uprichard, 2013). Convenience sampling is popular among researchers due to the low costs associated with it, and the ease of access to willing participants (Bornstein, Jager, \& Putnick, 2013). However, a disadvantage of convenience sampling is its lack of generalizability to the larger population because it may not always be representative (Bornstein et al., 2013). The population for this study consisted of individuals who were employed by institutions of higher education in the United States as faculty or staff. Participation in the survey was voluntary and participants could drop out of the study without any penalty. The survey was created and managed using an online database management software called Blue.

\section{Variables and Instrumentation}

The variables measured in this study were psychological climate, engagement, and wellbeing. Additionally, demographic information was obtained and included gender, type of institution, length of employment, role, race, and position or rank. Wellbeing served as the dependent variable and was measured using two scales; psychological wellbeing and physical wellbeing. Psychological climate served as an independent variable and consisted of six dimensions: supportive management, role clarity, 
contribution, recognition, self-expression, and challenge. Engagement served as the mediator variable. Finally, role served as the moderating variable. Table 2 displays the list of variables measured and corresponding codes used to analyze responses. The instrument used to collect the data is discussed next.

Table 2

Participants Personal and Professional Attributes

\begin{tabular}{|c|c|c|}
\hline Variable & $\begin{array}{l}\text { Scale of } \\
\text { Measurement }\end{array}$ & Coding \\
\hline Gender & Categorical & $1=$ Male $; 0=$ Female \\
\hline Race/ Ethnicity & $\begin{array}{l}\text { Categorical } \\
5 \text { levels }\end{array}$ & $\begin{array}{l}1=\text { Asian; } 2=\text { Black or } \\
\text { African American; } 3= \\
\text { Hispanic or Latino; } 4= \\
\text { White; } 5=\text { Two or More } \\
\text { Races }\end{array}$ \\
\hline Institution & Categorical & $\begin{array}{l}1=\text { four year public } \\
\text { institutions; } 2=\text { four year } \\
\text { private institutions; } 3=\text { two } \\
\text { year public institutions }\end{array}$ \\
\hline Role & Categorical & $1=$ Faculty $0=$ Staff \\
\hline Length of Employment & Categorical & $\begin{array}{l}1=0-5 \text { years; } 2=6-10 \\
\text { years; } 3=11-15 \text { years; } 4= \\
16-20 \text { years; } 5=\text { More than } \\
20 \text { years }\end{array}$ \\
\hline
\end{tabular}

\section{Measures}

A survey battery consisting of four scales was used to measure the variables of interest in this study. These scales were the Psychological Climate Scale (Brown \& Leigh, 1996), the Employee Engagement Scale (Shuck et al., 2017), Ryff Psychological Well Being Scale (Ryff, 1995), and the Medical Outcomes Study-Short Form (Stewart, Hays, \& Ware, 1988). All the responses were scored using Likert scale anchors. Information of each of the scales used is presented below. 
Psychological climate. The Psychological Climate measure (PCM; Brown \& Leigh, 1996) was used to assess workplace climate. The PCM has 21 items that are grouped into six different subscales: supportive management, role clarity, contribution, recognition, self-expression, and challenge. Responses to items on the PCM are based on a 5-point Likert Scale $(1=$ Strongly Disagree, $2=$ Disagree, $3=$ Neither agree nor disagree, $4=$ Agree, $5=$ Strongly agree). Higher responses were indicative of more positive perceptions of psychological climate. Scores are reported on each subscale, and for the overall measure. In a recent study by Shuck and Reio (2014), evidence of reliability using Cronbach's alpha were reported as follows: supportive management= .93 ; contribution $=.82 ;$ recognition $=.75 ;$ role clarity $=.80 ;$ self-expression $=.92 ;$ challenge $=.68$; overall measure $=.92$. The reliability estimate obtained from the sample in this study was .90 , with a $95 \%$ confidence interval of .88 to .92 . A sample item from the PCM is "I rarely feel my work is taken for granted."

Employee engagement. The Employee Engagement Scale (EES) developed by Shuck et al. (2016) was used to measure engagement. The EES is a 12-item measure consisting of three subscales: cognitive engagement, emotional engagement, and behavioral engagement. Responses to items on the EES are based on a 5-point Likert Scale $(1=$ Strongly Disagree, $2=$ Disagree, $3=$ Neither agree nor disagree, $4=$ Agree, $5=$ Strongly agree). Higher responses on each scale were indicative of higher levels of engagement. The internal consistency estimates (Cronbach's alpha) reported in Shuck et al.'s (2016) norming sample were $.94, .88$, and .91 for the emotional, behavioral, and cognitive subscales respectively. The reliability estimate obtained from the sample in this study was .88 , with a $95 \%$ confidence interval of .86 to .90 . Shuck et al. (2016) reported 
convergent validity estimates of $.77, .89$, and .62 when paired with measures of job satisfaction, discretionary effort, and wellbeing respectively. A sample item from the EES is "I feel a strong sense of belonging to my job."

Psychological wellbeing. The Ryff Psychological Well Being Scale (RPWB; Ryff, 1995) was used to measure psychological wellbeing. The RPWB consists of 18 items. Responses to items on the RPWB are based on a 6-point Likert Scale (1= Strongly Disagree, 2 = Moderately disagree, $3=$ Slightly disagree, $4=$ Slightly agree, $5=$ Moderately agree, 6 = Strongly agree). Higher scores indicated better psychological wellbeing however there are 8 items that are reversed scored so that lower scores are indicative of greater psychological wellbeing. Scores on RPWB have indicated high reliability. Prior studies had internal consistency reliability estimates ranging from 0.86 and 0.93, and test-retest estimates ranged from 0.81-0.88 (e.g. Cheng \& Chan, 2005; Kafka \& Kozma, 2002; Springer \& Hauser, 2006). The reliability estimate obtained from the sample in this study was .81, with a $95 \%$ confidence interval of .77 to .84 . An example of an item from the RPWB is "The demands of everyday life often get me down."

Physical wellbeing. Physical wellbeing was measured using the Medical Outcomes Study-Short Form (MOS-20; Stewart et al., 1988). The MOS-20 was developed to measure multiple types of health behavior, however for this study only the four item-health-perceptions subscale were used. Responses to items are based on a 5point Likert Scale (1= Definitely true, $2=$ Mostly true, $3=$ Not Sure, $4=$ Mostly false, 5 $=$ Definitely false). The use of a single scale on the MOS-20 is consistent with previous research on engagement and wellbeing (e.g. Shuck et al., 2017). Shuck et al., reported 
reliability estimate of .83 . The reliability estimate obtained from the sample in this study was .84 , with a $95 \%$ confidence interval of .81 to .87 . A sample item from the MOS-20 is "I am as healthy as anybody I know."

The reliability estimates for the four scales provides an indication of the average correlation of the items that make up each scale with values ranging from 0 to 1 . Values closer to 1 demonstrate greater reliability. In particular, Cronbach's alpha reliability statistic estimates of .80 or greater is considered to be acceptable for research purposes (Henson, 2001). The scales used in the survey instrument and sample reliability estimates are provided in Table 3 below. Before the survey was administered, approval was obtained from the Human Subjects Committee of the University of Louisville Internal Review Board (see Appendix E). Informed consent was provided to participants to give an overview of the study, along with an explanation of possible risks associated with taking part in the study. Participants received invitation to via email that contained a link to the survey. Clicking on the survey link was considered as acknowledgement of informed consent.

Table 3

Selected Instruments and Reliability Statistics of Survey Items

\begin{tabular}{|c|c|c|c|c|}
\hline $\begin{array}{l}\text { Instrument } \\
\text { section }\end{array}$ & $\begin{array}{c}\text { Items } \\
(n)\end{array}$ & $\begin{array}{l}\text { Variable(s) } \\
\text { measured }\end{array}$ & Source of items & $\begin{array}{l}\text { Reported } \\
\text { Cronbach's } \\
\text { alpha }\end{array}$ \\
\hline $\begin{array}{l}\text { Psychological } \\
\text { Climate } \\
\text { Measure }\end{array}$ & 21 & $\begin{array}{l}\text { Psychological } \\
\text { Climate }\end{array}$ & $\begin{array}{c}\text { Shuck \& Reio, } \\
2014\end{array}$ & .92 \\
\hline $\begin{array}{l}\text { Employee } \\
\text { Engagement } \\
\text { Scale }\end{array}$ & 12 & Engagement & $\begin{array}{c}\text { Shuck et al., } \\
2017\end{array}$ & $\begin{array}{l}.94 \text { (emotional); } \\
.88 \\
\text { (behavioral); } \\
.91 \text { (cognitive) }\end{array}$ \\
\hline $\begin{array}{l}\text { Ryff } \\
\text { Psychological } \\
\text { Well Being }\end{array}$ & 18 & $\begin{array}{l}\text { Psychological } \\
\text { Wellbeing }\end{array}$ & $\begin{array}{c}\text { Kafka \& } \\
\text { Kozma, 2002 }\end{array}$ & .88 \\
\hline
\end{tabular}


Scale

Medical

Outcomes

Study-Short

4

Physical

Wellbeing

Shuck et al.,

2017

.83

Form

\section{Controlling for Error}

In conducting survey research, there are different types of error that need to be minimized. These errors are: nonresponse error, measurement error, sampling and coverage error (Dillman, Smyth, \& Christian, 2014). Nonresponse error is a term used to describe the situation where individuals who did not respond to the survey differ from those that did on the variables measured. To control for nonresponse error, Brandon, Long, Loraas, Mueller-Phillips, and Vansant (2013) suggested that researchers encourage high quality responses and discourage lack of attention from participants. In this study, a short blurb communicating the potential outcomes for participants, as well as reversing Likert response anchors on the engagement scale were used to increase the quality of responses and minimize the lack of attention respectively. Measurement error occurs when characteristics of the survey encourage inaccurate responses or even discourage participants from responding. Examples of these characteristics include poor survey design or data collection mistakes (Dillman et al., 2014). An approach to reduce measurement error that this study employed was to use existing measures that have been psychometrically assessed and validated in prior research. Additionally, Blue allows forced responses to items, thus minimizing the likelihood of missing data for each of scales used in this study. Sampling error happens when only a portion rather than the entire sampling frame is surveyed (Dillman et al., 2014). Using online survey approach 
assumes that members of the sampling frame have access to devices that connect to the Internet to take the survey. Thus, there was a chance that some members of the sampling frame may not have been able to participate in this study. To help minimize sampling error, paper/pencil version of the survey was made available as an option for individuals unable to access the survey online (Dillman et al., 2014).

\section{Data Collection and Analysis}

Data collection took place in early March 2018 and remained open for six weeks. The survey was administered online via email using public listserves consisting of faculty and staff at institutions of higher education in the United States. Data were downloaded from the Blue database management system onto a password-protected computer for the analyses. To begin, data screening procedures were used to ensure the quality of the responses received. These procedures included looking for missing values, presence of outliers, evaluating normality, linearity, and multicolinearity. Normality was evaluated using histograms, P-P plots, as well as skewness and kurtosis. Datasets with skewness value greater than 1 are considered to be highly skewed, while values between 0 and 0.5 reflect a normal distribution (Bulmer, 1979). This study assumed linearity, which is described as when the relationship between the independent and dependent variables is linear (Cohen \& Cohen, 1983). Residual data in the histogram was evaluated to ensure linearity. A normal shaped distribution indicated the data met the assumption of linearity. Multicolinearity was assessed using the correlation coefficients and the Variance Inflation Factor (VIF). Variables that are highly correlated ( $r$ greater than .9 ) with one another indicate the presence of multicolinearity and affect regression parameter estimates (Cohen \& Cohen, 1983; Fields, 2009). VIF provides an estimate of how much 
inflation in variance there is due to highly correlated variables (Green, 1991). An acceptable rule of thumb is that VIF values exceeding 10 indicates the presence of multicolinearity.

Once data screening was complete, descriptive statistics were used to report measures of central tendency including means and standard deviation. Following this, correlations were estimated to answer the first hypothesis and examine the likelihood that psychological climate, engagement, and wellbeing are positively associated. Cresswell (2012) noted correlational tests measure the degree of the association between two variables. Accordingly, Pearson Product-Moment correlations were calculated between psychological climate and wellbeing, psychological climate and engagement, as well as engagement and wellbeing. Coefficient estimates range from -1 to +1 . Coefficient values close to -1 or 1 suggest a strong association between two variables, whereas values close to 0 indicate a weaker association. Values greater than 0 indicate positive association, that is, as the value of one variable increases so does the other. Values less than 0 represent a negative association, where as the value of one variable increases, the value of the other variable decreases. A value of 0 indicates that there is no relationship between the two variables. Cohen's (1988) effect size criteria of $\geq .10=$ small; $\geq .30=$ moderate; and $\geq .50=$ strong was used to interpret the estimates derived from the correlations. Hypotheses 2 stated that there would be a significant difference between faculty and staff in the level of wellbeing. An independent sample $t$ test was used to examine differences between faculty and staff in the level of wellbeing. This test was appropriate because it is used to examine whether there is statistical evidence that mean scores of two independent groups differ on a given variable (Kim, 2015). 
To assess the third hypothesis, moderation analysis was used. Specifically, hierarchical multiple regression was conducted to determine if employee role moderated the relationship between psychological climate and wellbeing. In hierarchical multiple regression, the predictor variables are entered into the regression model in a series of variables blocks, and the final regression model containing all the predictors is compared with the first model to determine significance using the change in $R^{2}$. In this study, two variable blocks were used. In the first variable block, psychological climate and employee role were entered into the regression model as predictors of wellbeing. An interaction term (i.e. the product of scores on psychological climate and employee role) was created and entered into the second variable block. The key decision to determine if moderation occurred was checking the change in $R^{2}$ for significance (i.e. $p<.05$ ), as well as checking the $p$ value of the overall regression model after the second variable block was entered. A significant change in $R^{2}$ indicates that the additional variance in the outcome variable (i.e. wellbeing) can be attributed to the interaction term, and signifies a moderation effect; that within this sample employee role influenced the strength of the relationship between psychological climate and wellbeing.

Moderation analysis was deemed appropriate because according to Hayes and Rockwood (2017), it can be used to address for what categories of people that a moderating effect exists, and the magnitude of this effect. In moderation (see Fig. 1), Hayes and Rockwood noted that the magnitude and direction of the relationship between one variable $(\mathrm{X})$ on another variable $(\mathrm{Y})$ is influenced by the presence of a moderating variable (W). In this study, employee role is the moderating variable that is hypothesized to influence the relationship between psychological climate (X) and wellbeing (Y). 
Moderation can be conducted using hierarchical linear regression where X (psychological climate), W (employee role), and an interaction between X and $\mathrm{W}$ are entered into sequential variable blocks to predict $\mathrm{Y}$ (wellbeing). Psychological climate (X) and employee role (W) were entered into the first variable block, followed by the interaction (XW) in the second variable block. A statistically significant change in $R^{2}$ following the inclusion of XW into the regression model (i.e. $p<.05$ ) would suggest that the relationship between X and Y is moderated by W (Hayes \& Rockwood, 2017; Jose, 2013). The change in $R^{2}$ estimate reflects the practical significance or effect size of the moderation in question. Additionally, a statistically significant $R^{2}$ suggests the following interpretation of the coefficients for the predictors variables: The interaction term (XW) shows that the effect of psychological climate on wellbeing is different for faculty and staff; $\mathrm{X}$ is the effect of psychological climate on wellbeing for faculty (where employee role was dummy coded as 1 = faculty, $0=$ staff); and $\mathrm{W}$ is the difference between faculty and staff on wellbeing when perception of psychological climate is at the mean.

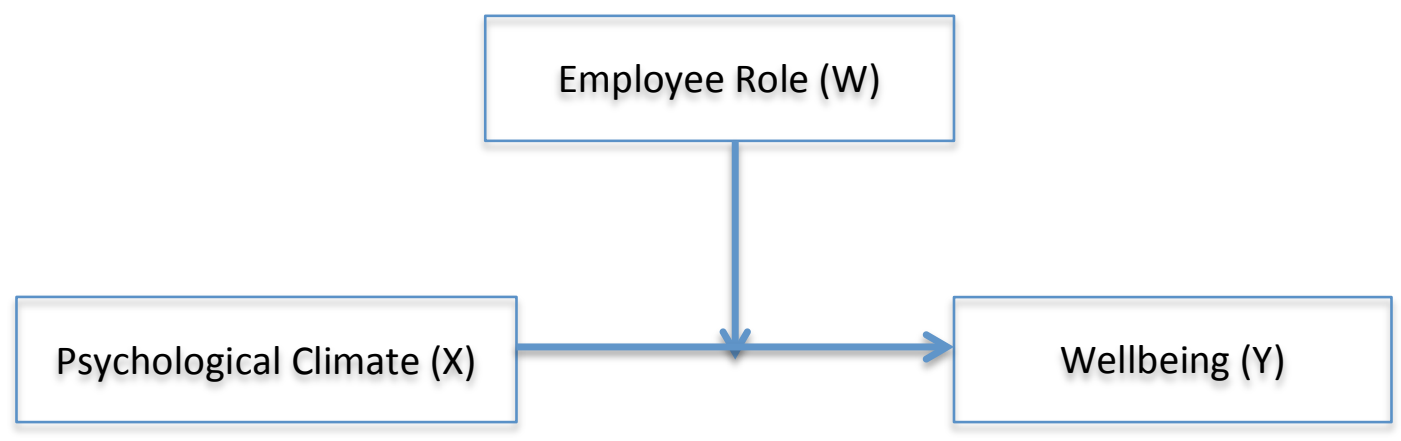

Figure 1. Simple moderation model

The fourth hypothesis was assessed using mediation analysis to examine whether engagement mediated the relationship between psychological climate and wellbeing. Mediation was determined to be the best statistical approach because prior literature has 
suggested that the effects of psychological climate on individual outcomes are indirect and can only be observed using a mediating variable (Brown \& Leigh, 1996). In mediation (see Fig. 2), a variable (X) affects another variable (Y) because it affects a mediating variable $(\mathrm{M})$, which in turn transmits the effects of $\mathrm{X}$ to $\mathrm{Y}$ (Hayes \& Rockwood, 2017). According to Hayes and Rockwood, in order for mediation to work, the mediating variable has to be located between $\mathrm{X}$ and $\mathrm{Y}$. In this study, engagement served as the mediating variable that transmitted the effect of psychological climate to wellbeing. There are different statistical approaches that can be used to examine mediation. The most popular approach used is the test of causal steps that was developed by Baron and Kenny (1986). In this approach, four criteria need to be met using regression to establish mediation: a) the total effect of $\mathrm{X}$ on $\mathrm{Y}$ (path $c$ ) must be significant, $\mathrm{b}$ ) the effect of $\mathrm{X}$ on $\mathrm{M}$ (path $a$ ) must be significant, c) the effect of $\mathrm{M}$ on $\mathrm{Y}$ controlling for $\mathrm{X}$ (path $b$ ) must be significant and d) the direct effect of $\mathrm{X}$ on $\mathrm{Y}$ adjusting for M must be non-significant (path $c^{l}$ ). This approach is waning in popularity due to emerging mediation research that suggested that the product of the outcomes of path $a$ and path $b(a b)$ results in the "quantification of the difference between the effect of $\mathrm{X}$ on Y when M is controlled versus when it is not" (Hayes \& Rockwood, 2017 p. 43). If this outcome, i.e. the indirect effect of $\mathrm{X}$ on $\mathrm{Y}$ or $a b$, is not zero (or an interval estimate determined through bootstrapping not including zero) then mediation is said to have occurred. This contemporary approach to mediation thus eliminates the need for significance testing of the $a$ and $b$ paths as a requirement to determine mediation (Hayes, 2017). Additionally, recent evidence showed that the power in the test of the total effect (i.e. path $c$ ) has less power than the tests of indirect effect (i.e. $a b$ ). Furthermore, this new 
practice is becoming more widely circulated in research various fields (e.g. Cerin \& MacKinnon, 2009; Rucker, Preacher, Tormala, \& Petty, 2011; Zhao, Lynch, \& Chen, 2010). For these reasons, in this study, the contemporary approach to mediation was used. Bootstrapping was used to estimate confidence intervals to test the indirect effect for significance. The bootstrap resampling procedures were set at 5000 along with a bias corrected confidence interval rate of $95 \%$ as recommended by Hayes (2017). According to Hayes (2017), bootstrapping should be used rather than traditional significance tests such as the Sobel test because it provides unbiased confidence interval estimates. More, Hayes noted that the bootstrap method accounts for irregularity in the estimation of path $a b$ thus providing confidence interval estimates that are more likely to be accurate. All the data were analyzed using Statistical Package for Social Sciences (IBM Corp. 2013) and PROCESS (Hayes, 2017). 

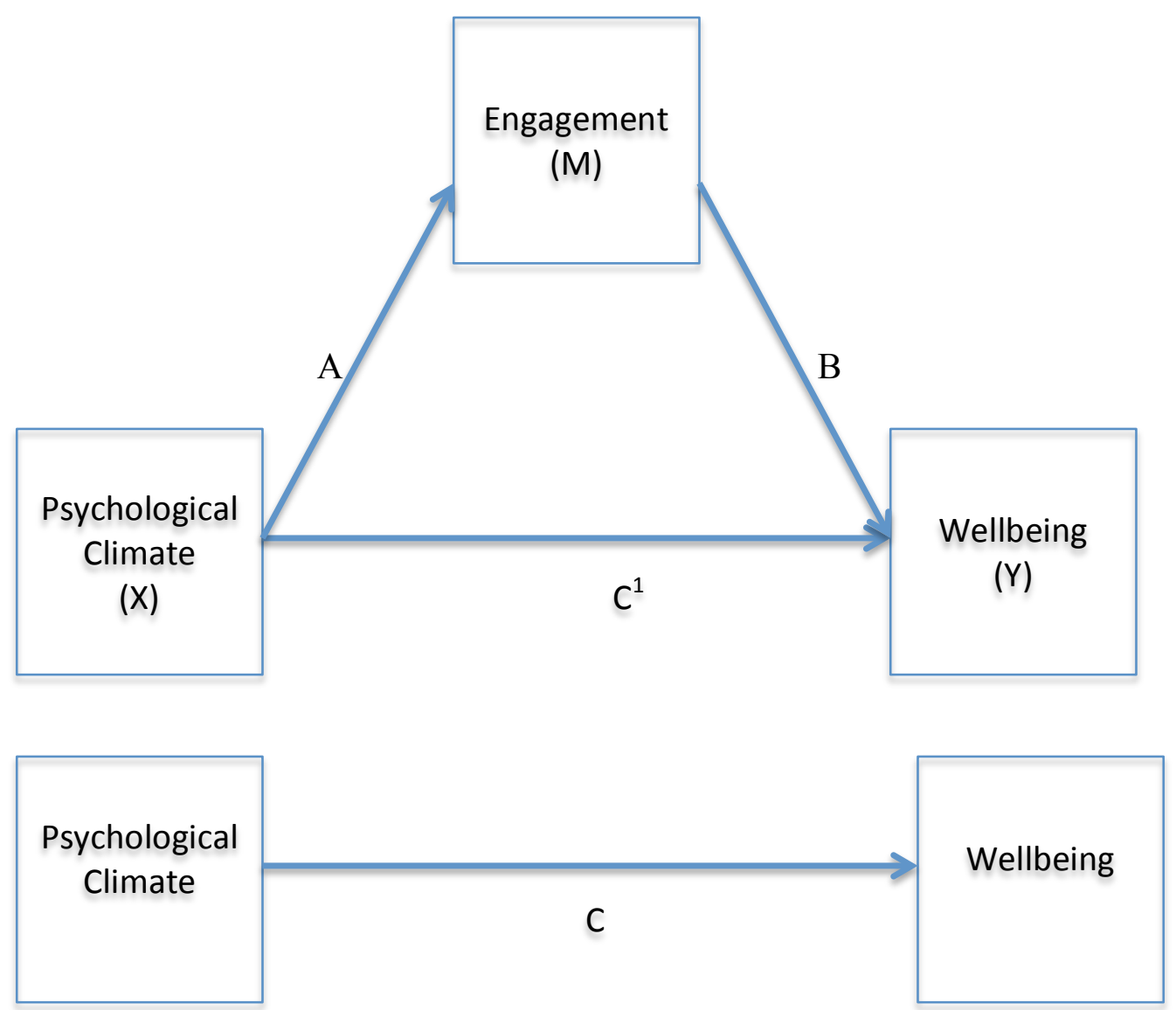

Figure 2. Simple mediation model

Assumptions and Limitations

The purpose of this study was to assess the relationships between psychological climate, engagement, and wellbeing using higher educational as an organizational context. This study was based on the assumption that a) participant responses were not influenced by researcher bias b) participants did not interact with the researcher c) participants were guaranteed anonymity and finally d) responses provided by participants reflected their honest opinions about their perceptions of their workplace, engagement, and wellbeing. As is typical of any research, there were limitations to this study that need to be acknowledged. A key limitation of is the generalizability of the findings to the 
larger population. Generalizable findings to a larger population is possible when the research contains enough descriptive information that reflects the larger population, can be duplicated in differing circumstances, and there is sufficient evidence that the data were reliable and confirmable (Thomas \& Perry, 2004). In view of this, the first limitation of this study is the acknowledgement of the use of self-report data. Self-report data tends to be biased as respondents may over report or under report behaviors to make them appear in a more positive light. For example, respondents may under report poor health related outcomes such as stress, and over report engagement. The presence of this bias is supported by previous research that suggested that in a work environment; individuals are more likely to appraise themselves in a more positive light than appraisals from other sources (Podsakoff \& Organ, 1986). Thus, future research would benefit from the use of data from multiple sources including rating from supervisors and peers, as well as the use of more objective measures if possible.

Related to the issue of self-report data was type of measures used. Measures of engagement tend to produce high scores that are restricted in range. This results in a lack of sufficient variability in participants' responses to make conclusive statements about engagement following data analysis. More research needs to be done to uncover additional ways to quantitatively measure engagement that does not result in restriction of scores. Still on the issue of measurement, there was a limitation concerning the physical wellbeing scale. The MOS-10 (Stewart et al., 1988) sought participants' subjective opinion of their general health in relation to other people that they know. Thus, if a participant knew mostly people who were very ill, they would be likely to rate their health as excellent even if they had health problems of their own. This may have 
somewhat limited the information on physical wellbeing provided in this study, and warrants additional examination.

Another key limitation noted was coverage error. Participants for this study were recruited using publicly available email addresses and listserves. Additional participants were sought by asking participants to recruit other people to take part in the study. This might have resulted in an oversampling of some demographics and might limit the generalizability of the results obtained. Additionally, participation in this study required participants to have access to the Internet. According to Baker et al. (2013), up to $30 \%$ of adults in the United States do not use the Internet regularly. While it might be assumed that employees who work in higher education typically have Internet access, there is a chance that there are some who do not or use it regularly, and therefore did not have the opportunity to participate in the study. Thus, the final sample for this study may not be fully generalizable to the population that is university employees.

The final limitation of this study is concerned with personality related variables. Personality related variables may contribute to person's interpretation of the psychological work climate and the presence or non-presence of engagement. An example of this variable is self-efficacy. Personality related variables were not examined because they fall beyond the scope of this study, but could be a limiting factor to study findings. Despite all these limitations, the results from this study provided original findings that contribute to ongoing research as well as the development of organizational theory related to psychological climate, engagement, and wellbeing. 


\section{CHAPTER IV}

\section{RESULTS}

The purpose of this study was to examine the relationship between psychological climate, engagement, and wellbeing within higher education. Specifically, this study sought to examine whether employee role and engagement moderates and mediates respectively, the relationship between psychological climate and wellbeing. The study was designed to answer the following research questions and hypotheses.

RQ1: What is the relationship between psychological climate, engagement, and wellbeing in higher education?

$\mathrm{H}_{1}$ : There is a positive relationship between psychological climate, engagement, and wellbeing.

$\mathrm{H}_{2}$ : There will be a significant difference between faculty and staff in the level of wellbeing.

RQ2: Does employee role influence the relationship between psychological climate and wellbeing in higher education?

$\mathrm{H}_{3}$ : Employee role will moderate the relationship between psychological climate and psychological wellbeing.

$\mathrm{H}_{4}$ : Employee role will moderate the relationship between psychological climate and physical wellbeing. 
RQ3: Does engagement mediate the relationship between psychological climate and wellbeing in higher education?

$\mathrm{H}_{5}$ : Engagement will mediate the relationship between psychological climate and psychological wellbeing.

$\mathrm{H}_{6}$ : Engagement will mediate the relationship between psychological climate and physical wellbeing.

This chapter provides the results from the study. To begin, the background of the sample demographic and descriptive statistics are discussed. Next, data screening is presented followed by a discussion of the findings from the hypotheses tested.

\section{Background of the Sample}

A total of 259 participants took part in the survey. Because all the items on the survey required mandatory responses, there was no missing data reported. As such, the final sample was composed of $70 \%$ females $(n=182), 30 \%$ males $(n=77), 82 \%$ from four year public institutions $(n=212), 12 \%$ from four year private institutions $(n=32)$, and 6\% from two year public institutions $(n=15)$. More than 50\% reported current length of employment as between $0-5$ years $(n=132)$. The percentage of the final sample employed as faculty was $43 \%(n=111)$ while staff was $57 \%(n=148)$. Racial diversity was represented by 3\% Asian, 14\% Black or African American, 3\% Hispanic or Latino, $77 \%$ White, and $2 \%$ two or more races. Table 4 provides a summary of participant demographics.

Table 4 Respondents Personal and Professional Attributes

$\begin{array}{llcc}\text { Demographic } & \text { Values } & \text { Frequency } & \text { Percent } \\ \text { Gender } & \text { Female } & 182 & 70.3 \\ & \text { Male } & 77 & 29.7\end{array}$




\begin{tabular}{llcc} 
Race & Asian & 7 & 2.7 \\
& Black or African & & \\
& American & 39 & 15.1 \\
& Hispanic or Latino & 8 & 3.1 \\
& White & 199 & 76.8 \\
& Two or More Races & 6 & 2.3 \\
Institution & & 132 & 51.0 \\
& $0-5$ years & 50 & 19.3 \\
& 6-10 years & 24 & 9.3 \\
& $11-15$ years & 27 & 10.4 \\
Role & 16-20 years & 26 & 10.0 \\
& More than 20 years & & \\
& & 148 & 57.1 \\
\hline
\end{tabular}

Note: $N=259$

\section{Data Analyses}

Descriptive statistics including means, correlations, standard deviation and internal consistency reliability for the measures of psychological climate, engagement, psychological wellbeing, and physical wellbeing are reported in Table 5. All four measures used demonstrated good internal reliability ( $\alpha=.81$ to .90$)$, with coefficients above .80 as is considered as the minimum necessary to conduct general research (Henson, 2001). Examination of the mean scores showed that means were above 3.5 on the 5-point Likert scale for psychological climate, engagement, and physical wellbeing. Similarly, mean scores for psychological wellbeing were above 3.8 on the 6-point Likert scale for psychological wellbeing. For engagement however, mean scores ranged from 3.9 to 4.3 suggesting a restriction of range in scores. Restriction of range in scores was also observed for physical wellbeing (3.7 to 4.2$)$. These values suggested that in this sample, faculty and staff considered themselves to be highly engaged, and to have high levels of physical wellbeing. While higher scores on engagement and physical wellbeing are considered good, the restriction of scores can be problematic as it often results in an 
underestimate of correlation values obtained between variables in the study population (Henriksson \& Wolming, 1998). One possible explanation for the restriction of range in engagement and physical wellbeing is that the measures used did not provide enough information to produce more variance in the scores observed. The MOS-20 for example, provided information about participants' health but only in relation to other people that they knew. This could have resulted in an overestimation of the physical health condition of the sample in this study leading to scores restricted to the higher end of the scale.

Correlations of all variables were significant ranging from .15 and .52 , but were considered as weak- moderate using Cohen's (1988) criteria. The weakest correlation ( $r=$ $.15)$ was between physical wellbeing and engagement. It is possible therefore that due to range restriction associated with these variables, this correlation coefficient may be an underestimate of what pertains in the actual population. Overall, the positive correlations suggested that as perception of psychological climate and engagement level increases, so does psychological and physical wellbeing. Conversely, if perceptions of psychological climate and engagement level decreases, so does psychological and physical wellbeing.

Table 5

Descriptive Statistics and Correlations for Psychological Climate, Engagement, and Wellbeing

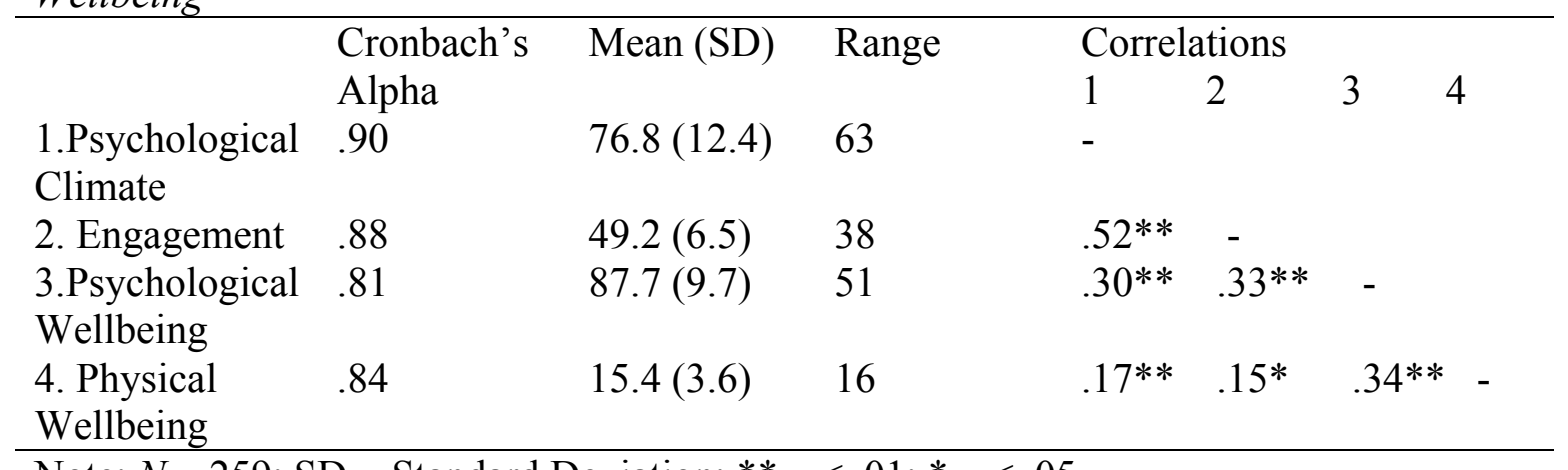

Note: $N=259 ; \mathrm{SD}=$ Standard Deviation; $* * p<.01 ; * p<.05$ 
Multicolinearity was assessed in the sample by correlating the predictor variables (i.e. psychological climate, engagement, and employee role). Psychological climate and engagement were moderately and positively correlated $(r=.52, p<.01)$. A nonsignificant correlation was found between psychological climate and role $(r=.67, p>$ .05). VIF statistics were also calculated to examine for multicollinearity. The highest VIF value that was calculated was 1.361; typically, VIF statistic values approaching 10 indicate multicolinearity (Green, 1991). Based on the correlational values observed (i.e. less than .80) and the VIF statistics, multicolinearity was not deemed an issue in this study. In addition to examining the sample for multicolinearity, the data were also examined to check for outliers and assumptions of normality and linearity. Z-scores were calculated and evaluated to make sure that the data were in acceptable limits for further analyses. Typically, z-scores greater than +/- 3.29 are indicative of outliers (Tabachnick \& Fidell, 2007). Two data points had z-scores on engagement that were greater than $+/-$ 3.29. Hypotheses testing conducted on the data with and without these two data points yielded similar results, and thus they were left in the final data sample.

Table 6

Cases with Data Contributing to Outliers

\begin{tabular}{llllll} 
Variable & Case \# & Z Score & $\begin{array}{l}\text { Actual } \\
\text { Value }\end{array}$ & $\begin{array}{l}\text { Next } \\
\text { Highest }\end{array}$ & Action \\
& & & 22 & -2.7 & Kept \\
Engagement & 142 & -4.2 & 22 & -2.7 & Kept \\
Engagement & 197 & -4.2 & & & \\
\hline
\end{tabular}

Next, the data were examined for approximate normal distribution using histograms and P-P plots. Histograms and P-P plots provide a complementary visual examination of normality and linearity (Field, 2009). Additionally, skewness and kurtosis were examined calculated to confirm normality. A suggested range for normal estimates 
of skewness and kurtosis is within $+/-1.5$ (Tabachnick \& Fidell, 2013). The values for skewness and kurtosis in this sample ranged between -.94 to -.46 and -.08 to 1.5 respectively. The histograms for psychological climate, engagement, and psychological wellbeing suggested that the data were normally distributed. However, the histogram for physical wellbeing suggested that there was some non normal distribution and serves as a limitation of this study.

Table 7

Skewness and Kurtosis of Variables

\begin{tabular}{lcc}
\hline Variable & Skewness & Kurtosis \\
Psychological Climate & -.62 & .03 \\
Engagement & -.70 & 1.5 \\
Psychological Wellbeing & -.46 & -.08 \\
Physical Wellbeing & -.94 & .18 \\
\hline
\end{tabular}

This study used linear models of regression and thus linearity was assumed.

Visual examinations of the P-P plots with psychological wellbeing as the dependent variable suggested that the model structure was linear. However, when physical wellbeing was used as the dependent variable, the P-P plot indicated some non-linearity (See Figure 4). A Durbin-Watsin test was conducted to further evaluate linearity and homoscedasticity. According to Field (2009), values less than 1or greater than 3 would be cause for concern. The value for the dependent variables psychological wellbeing and physical wellbeing was 1.8 and 1.9 respectively, and thus it was concluded that there was no issue for concern. Scatter plots were also used to assess homoscedasticity (see Figure 3). Detailed information on the findings from each analysis is presented next. For each analysis, wellbeing was treated as two constructs, and as such psychological wellbeing and physical wellbeing were analyzed separately. 

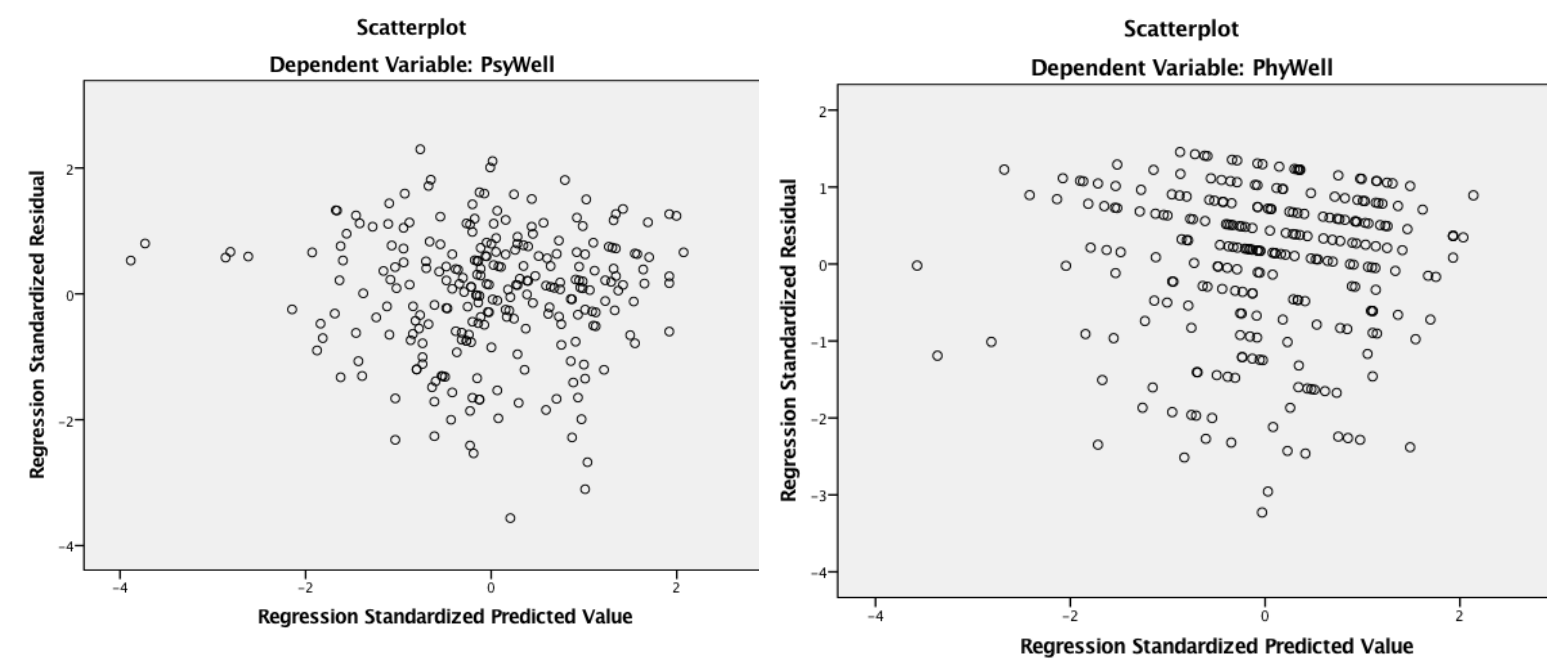

Figure 3. Residual data scatterplots
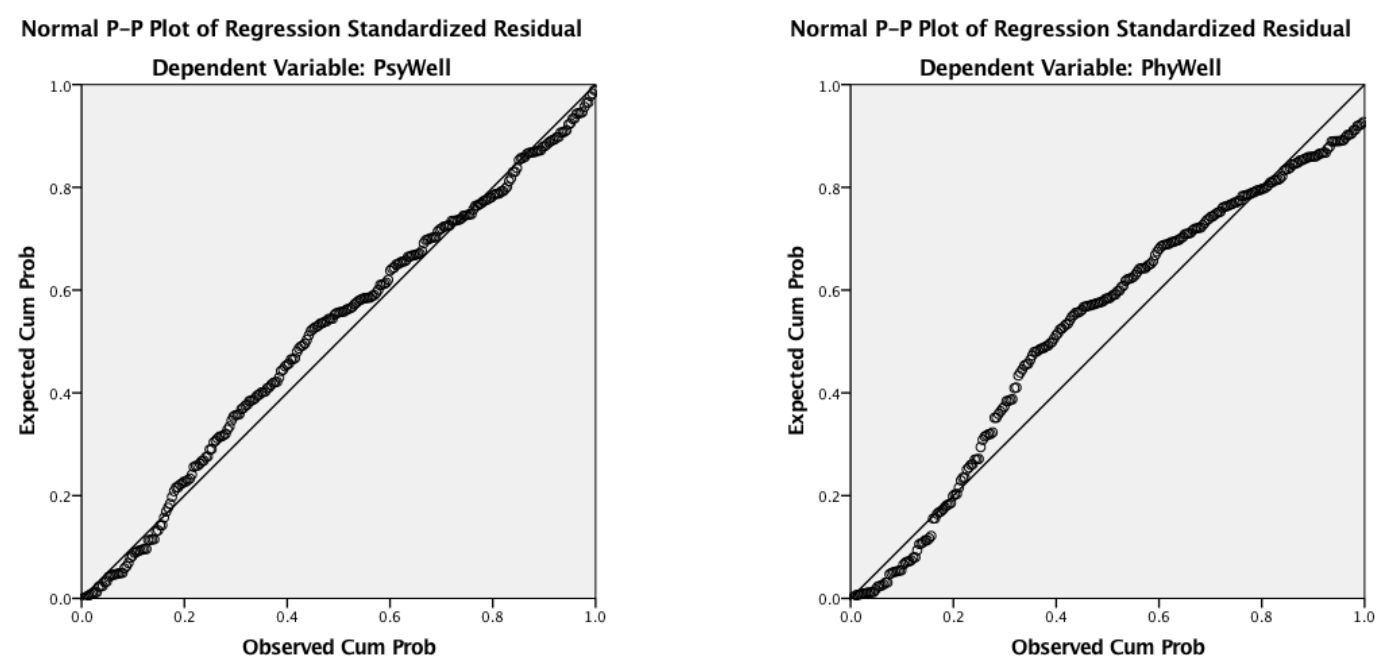

Figure 4. P-P plots

\section{Correlation Analysis}

Pearson Product-Moment correlation coefficients were used to address

Hypothesis 1. Specifically, correlations were computed among the four measures on data for the 259 participants to determine the relationship between psychological climate, engagement, and wellbeing. To determine effect size, Cohen's (1988) criteria was used $(\geq .10=$ small $; \geq .30=$ moderate; and $\geq .50=$ strong $)$. Table 5 reports the Pearson Product-Moment correlation coefficient estimates obtained. As shown, employees' 
perceptions of their psychological climate was positively correlated with their

engagement levels $(r=.52, p<.01)$, their psychological wellbeing $(r=.30, p<.01)$, and their physical wellbeing $(r=.17, p<.01)$. Employee engagement was positively correlated with psychological wellbeing $(r=.33, p<.01)$ and physical wellbeing $(r=.15$, $p<.05)$. While the correlations were positive and significant, the relationships between psychological climate and physical wellbeing, engagement and psychological wellbeing, and engagement and physical wellbeing were weak. In summary, the variables of interest showed significant associations with each other thus providing support for the first hypothesis.

An independent sample $t$-test was used to address the second hypothesis. The independent sample t-test was conducted to compare psychological and physical wellbeing among faculty and staff employees in higher education institutions. Contrary to expectation, there was no significant difference between faculty $(M=89, S D=10.1, N=$ $111)$ and staff $(M=86.8, S D=9.3, N=148)$ in the level of psychological wellbeing $[t(257)=-1.77, p>.05$.$] Similarly, in terms of physical wellbeing [t(257)=-.74, p>$ .05.], there was no significant difference between faculty $(M=15.6, S D=3.5, N=111)$ and staff $(M=15.3, S D=3.6, N=148)$. These results suggest that, in this sample, an employee's role (i.e. faculty or staff) had no influence on their psychological or physical wellbeing.

\section{Moderation Analysis}

A two block hierarchical multiple regression was used to test the hypothesized model outlined in Figure 1. Psychological climate, role, and the interaction between these 
two variables were used as predictors in the regression to test whether employee role moderated the relationship between psychological climate and wellbeing. Moderation was tested using Statistical Package for the Social Sciences (SPSS). Findings from the moderation analysis psychological wellbeing is presented first, followed by findings from the analysis where physical wellbeing was used as the outcome variable. To examine the moderation in hypothesis 3 , only psychological climate and role were entered into the first variable block. An interaction term consisting of the product of psychological climate and role was entered into the second variable block to determine the amount of unique variance in psychological wellbeing explained by the interaction. The hierarchical multiple regression revealed that in the first variable block, psychological climate and role contributed significantly to the regression model $F$ $(2,256)=13.50, p<.01)$ and accounted for $10 \%$ of the variance in psychological wellbeing $\left(R^{2}=.10\right)$. Introducing the interaction term resulted in a non-significant regression model $F(1,255)=1.37, p>.05)$ that produced no additional explanation in the variance in psychological wellbeing $\left(R^{2}=.10\right)$. When all the variables were included in the regression model, only climate was found to significantly predict psychological wellbeing $(\beta=2.25, t=3.0, p<.01)$. In other words, for every one-unit increase in psychological climate, there is a corresponding 2.25 increase in psychological wellbeing when all the other variables are held constant. Crucially, the interaction term was found to be non-significant $(\beta=1.38, t=1.17, p>.05)$ which indicated that there was no interaction effect of psychological climate and employee role on psychological wellbeing (see Table 8). Employee role did not moderate the relationship between psychological climate and psychological wellbeing, and thus hypothesis 3 was not supported. 
Table 8

Summary of Hierarchical Regression Analysis for Variables Predicting Psychological Wellbeing $(N=259)$

\begin{tabular}{|c|c|c|c|c|c|c|c|c|c|c|}
\hline \multirow[t]{2}{*}{ Variable } & \multicolumn{5}{|c|}{ Model 1} & \multicolumn{5}{|c|}{ Model 2} \\
\hline & B & SEB & $\beta$ & $t$ & $p$ & B & SEB & $\beta$ & $t$ & $p$ \\
\hline Psychological Climate & 2.8 & .58 & .29 & 4.9 & .001 & 2.3 & .75 & .23 & 3.0 & .003 \\
\hline Employee Role & 1.8 & 1.2 & .09 & 1.5 & .13 & 1.8 & 1.2 & .09 & 1.5 & .13 \\
\hline $\begin{array}{l}\text { Psychological Climate } \mathrm{x} \\
\text { Employee Role }\end{array}$ & & & & & & 1.4 & 1.2 & .09 & 1.2 & .24 \\
\hline$R^{2}$ & .10 & & & & & .10 & & & & \\
\hline$F$ for change in $R^{2}$ & 13. & & & & & 1.37 & & & & \\
\hline
\end{tabular}

Note: $N=259 ; \mathrm{SD}=$ Standard Deviation; $* * p<.01$

The same procedure was followed to test whether employee role moderated the relationship between psychological climate and physical wellbeing. Psychological climate and role were entered into the first variable block of the regression, and the interaction term was entered into the second variable block. In the first regression model, psychological climate and role contributed significantly to the regression model $F(2,256)$ $=3.84, p<.05)$ and accounted for $3 \%$ of the variance in physical wellbeing $\left(R^{2}=.03\right)$. Introducing the interaction term resulted in a non-significant regression model $F(1,255)$ $=.18, p>.05)$ that produced no additional explanation in the variance in physical wellbeing $\left(R^{2}=.03\right)$. Similar to the previous result, only climate was found to significantly predict physical wellbeing $(\beta=.62, t=2.14, p<.01)$ Thus, for every oneunit increase in psychological climate, there is a corresponding .62 increase in physical wellbeing when all the other variables are held constant. The interaction term was found to be non-significant $(\beta=-.06, t=-.14, p>.05)$, meaning that when combined, psychological climate and employee role did not affect physical wellbeing. This result indicated that employee role did not moderate the relationship between psychological climate and physical wellbeing, and thus hypothesis 4 was not supported. 
Table 9

Summary of Hierarchical Regression Analysis for Variables Predicting Physical Wellbeing $(N=259)$

\begin{tabular}{|c|c|c|c|c|c|c|c|c|c|c|}
\hline \multirow[t]{2}{*}{ Variable } & \multicolumn{5}{|c|}{ Model 1} & \multicolumn{5}{|c|}{ Model 2} \\
\hline & B & SEB & $\beta$ & $t$ & $p$ & $\mathrm{~B}$ & SEB & $\beta$ & $t$ & $p$ \\
\hline Psychological Climate & .60 & .22 & .17 & 2.7 & .008 & .62 & .29 & .17 & 2.1 & .03 \\
\hline Employee Role & .26 & .45 & .04 & .56 & .56 & .26 & .45 & .04 & .58 & .56 \\
\hline $\begin{array}{l}\text { Psychological Climate } \mathrm{x} \\
\text { Employee Role }\end{array}$ & & & & & & -.06 & .45 & -.01 & -.14 & .90 \\
\hline$R^{2}$ & .03 & & & & & .03 & & & & \\
\hline$F$ for change in $R^{2}$ & $3.8 *$ & & & & & .02 & & & & \\
\hline
\end{tabular}

Note: $N=259 ; \mathrm{SD}=$ Standard Deviation; $* * p<.01$

\section{Mediation Analysis}

A series of multiple regressions was used to test the hypothesized model depicted in Figure 2. The key parameter of the model that was focused on was: the indirect effect of psychological climate on wellbeing. Mediation was tested using PROCESS (Hayes, 2017). Findings from the mediation analysis using psychological wellbeing is presented first, followed by findings from the analysis where physical wellbeing was used as the outcome variable.

The mediating effect of engagement on psychological climate and psychological wellbeing was tested by examining the paths exhibited in Figure 2. First, engagement was regressed on psychological climate to establish the coefficient for path $a$. The regression model was significant $\left(F\left([, 257]=92.88, p<.001, R^{2}=.27\right)\right.$, indicating that psychological climate predicted engagement. This resulted in a significant path $(a)$ from psychological climate to engagement $(\beta=.27, t=.96, p<.001)$ that demonstrated that psychological climate was positively associated with the mediator variable of engagement. Next, psychological wellbeing was regressed on psychological climate and engagement to establish the coefficient for path $b$. The regression model was significant 
$\left[F(2,256)=18.97, p<.001, R^{2}=.13\right]$, and suggested that together, psychological climate and engagement explained $13 \%$ of the variance in psychological wellbeing. The resulting path $(b)$ from engagement to psychological wellbeing was significant $(\beta=.36, t$ $=3.5, p<.001)$ as expected. Thus, for every one unit increase in engagement, there is a corresponding increase of .36 in psychological wellbeing when all other variables are held constant. In line with contemporary approaches to mediation (see Hayes \& Rockwood, 2017; Zhao et al., 2010), the indirect effect of psychological climate on psychological wellbeing (path $a b$ ) was computed to establish mediation. This was done by multiplying coefficients for paths $a$ and $b$ and resulted in a coefficient value of .09 (see Table 10). The coefficient of $a b$ represents a quantification of the difference between the effect of psychological climate on psychological wellbeing when engagement is controlled versus when it is not (Hayes \& Rockwood, 2017).

Table 10

Direct and Indirect Effects

\begin{tabular}{|c|c|c|c|c|c|}
\hline Estimated parameters & $\begin{array}{c}\text { Standardized } \\
\text { coefficients }\end{array}$ & $S E$ & $t$ & $p$ & $\begin{array}{c}\text { BC95\%CI } \\
\text { lower/upper }\end{array}$ \\
\hline \multicolumn{6}{|l|}{ Direct effects } \\
\hline $\mathrm{PC} \rightarrow \operatorname{Eng}(a)$ & .27 & .03 & 9.6 & $.001 * *$ & \\
\hline Eng $\rightarrow \mathrm{PW}(b)$ & .36 & .10 & 3.5 & $.001 * *$ & \\
\hline $\mathrm{PC} \rightarrow \mathrm{PW}(\mathrm{c})$ & .23 & .05 & 4.9 & $.001 * *$ & \\
\hline $\mathrm{PC} \rightarrow \mathrm{PW}\left(\mathrm{c}^{1}\right)$ & .13 & .05 & 2.5 & $.01 *$ & \\
\hline \multicolumn{6}{|l|}{ Indirect Effects } \\
\hline $\mathrm{PC} \rightarrow$ Eng $\rightarrow \mathrm{PW}$ & .09 & & & & $.05 / .15$ \\
\hline
\end{tabular}

Note: $\mathrm{PC}=$ psychological climate; Eng = engagement; $\mathrm{PW}=$ psychological wellbeing; $* *$ $p<.01 ; * p<.05$

A 95\% bias corrected bootstrap confidence interval for the indirect effect was constructed by resampling the data 5,000 times to test the significance of path $a b$. The confidence interval was between .05 and .15 , and as it did not include 0 , it served as 
evidence that the indirect effect was statistically significant, and that engagement mediated the relationship between psychological climate and wellbeing.

The same procedure described above was used to test for mediation between psychological climate and physical wellbeing. Engagement was regressed on psychological climate resulting in a significant path $a(\beta=.27, t=9.6, p<.001)$ and model $\left[F(1,257)=92.88, p<.001, R^{2}=.27\right]$. The regression coefficient for path $b(\beta=$ $.05, t=1.2, p>.05$ ) was non significant, however the resulting model was significant $\left[F(2,256)=4.50, p=.01, R^{2}=.03\right]$. The indirect effect or path $a b$ was computed and resulted in a coefficient of .01 (see Table 11). Using the bootstrap procedure, the coefficient of $a b$ was found to be non-significant as it yielded confidence intervals that contained 0 (-.001 to .03$)$. This result showed that engagement did not mediate the relationship between psychological climate and physical wellbeing and therefore hypothesis 6 was not supported.

Table 11

Direct and Indirect Effects

$\begin{array}{lcllll}\text { Estimated parameters } & \begin{array}{c}\text { Standardized } \\ \text { coefficients }\end{array} & S E & t & p & \begin{array}{c}\text { BC95\%CI } \\ \text { lower/upper }\end{array}\end{array}$

Direct effects

$\mathrm{PC} \rightarrow \operatorname{Eng}(a)$

Eng $\rightarrow \mathrm{PhW}(b)$

$\mathrm{PC} \rightarrow \mathrm{PhW}(\mathrm{c})$

$\mathrm{PC} \rightarrow \mathrm{PhW}\left(\mathrm{c}^{1}\right)$

$\begin{array}{llll}.27 & .03 & 9.6 & .001^{* *} \\ .05 & .04 & 1.2 & .20 \\ .05 & .02 & 2.7 & .007^{* *} \\ .03 & .02 & 1.7 & .09\end{array}$

Indirect Effects

$\mathrm{PC} \rightarrow$ Eng $\rightarrow \mathrm{PhW}$

.01

$-.001 / .03$

Note: $\mathrm{PC}=$ psychological climate; $\mathrm{Eng}=$ engagement; $\mathrm{PhW}=$ physical wellbeing; ${ }^{* *} p<$ $.01 ; * p<.05$

\section{Summary}

This study sought to examine the relationship between psychological climate, engagement, and wellbeing in higher education. Specifically, this study examined whether employee role served as a moderator for the relationship between psychological 
climate and wellbeing, and also if engagement would mediate the relationship between the same relationship. The results of this study provided evidence towards the theoretical assumptions that psychological climate, engagement, and wellbeing were related. More, it was shown that engagement mediated the relationship between psychological climate and psychological wellbeing but not for physical wellbeing. Employee role did not moderate the relationship between psychological climate and psychological wellbeing or physical wellbeing. This study also examined whether faculty or staff would significantly differ on wellbeing. The findings indicated no significant relationship between faculty and staff on either psychological wellbeing or physical wellbeing. These results supported hypotheses 1,3, and 5 and did not provide support for hypotheses 2, 4, and 6 . 


\section{CHAPTER V \\ DISCUSSION AND CONCLUSIONS}

The purpose of this study was to examine the relationship between psychological

climate, employee engagement, and wellbeing within higher education. Specifically, this study sought to examine whether engagement mediated the relationship between psychological climate and wellbeing. Additionally, this study sought to investigate whether employee role influenced the direction and strength of the relationship between psychological climate and wellbeing. To expand understanding of how psychological climate, engagement, and wellbeing are connected within the context of higher education, this study added to the growing body of research by contributing evidence toward the following research questions:

RQ1: What is the relationship between psychological climate, engagement, and wellbeing in higher education?

RQ2: Does employee role influence the relationship between psychological climate and wellbeing in higher education?

RQ3: Does engagement mediate the relationship between psychological climate and wellbeing in higher education?

Summary of the Study 
Psychological climate, employee engagement, and wellbeing have received considerable attention among HRD scholars (cf. Dollard \& Bakker, 2010; Shuck \& Reio, 2014). Previous research coalescing around psychological climate, engagement, and wellbeing has reported positive associations whereby an increase in one of these variables corresponds with an increase in the other variables (Shuck et al., 2017; Shuck \& Reio, 2014). More recently, there has been an indication in research and practice that these variables are not only positively associated with each other, but also, that a linear relationship exists between them (i.e., employees' perceptions of psychological climate of their workplace affects their engagement, which in turn affects their wellbeing [Colligans \& Higgins, 2005; Kantor \& Streitfeld, 2015]). This relationship (i.e. psychological climate $\rightarrow$ engagement $\rightarrow$ wellbeing) suggested that engagement might mediate the relationship between psychological climate and wellbeing. The concept of employee engagement mediating the relationship between psychological climate and wellbeing has been tested and upheld in HRD literature within the boundaries of traditional for-profit businesses and companies (Shuck \& Reio, 2014). Missing, however, is evidence of this relationship in other types of organizations such as in institutions of higher education.

Knowledge about how psychological climate, engagement, and wellbeing are linked in institutions of higher education is important because colleges and universities are undergoing rapid shifts to their operations, moving them closer to the way traditional business organizations function (Giroux \& Myrsiades, 2005). Connected, universities are increasingly concerned about the health of their employees, as poor psychological functioning among university employees has been associated with elevated stress levels 
impaired work relationships, and burnout (Tytherleigh et al., 2005; Watts \& Robertson, 2011). As a result, there has been a rise in the number of wellness programs across many institutions of higher education as a means to improve wellbeing among university faculty and staff. In light of the strategic role employee engagement has demonstrated in for-profit organizations, the increasing role of health and wellness university campuses (Ewing et al., 2007; Strand, 2010), as well as the role of climate in driving such outcomes (Shuck \& Reio, 2014), exploring these domains collectively in higher education settings has the potential to provide strategic leverage points for $\mathrm{HRD}$, as well as spur future research opportunities and extend current engagement theory; a significant potential outcome of this research.

\section{Summary Discussion of Results}

Using higher education as a context, this study yielded a number of key findings. First, results from the correlational analyses provided evidence that confirms prior research in the for-profit business and organization setting in relation to the higher education setting: mainly that psychological climate, engagement, and wellbeing are positively associated in institutions of higher education (cf. Shuck \& Reio, 2014; Kataria et al., 2013a). Second, results from the moderation analysis indicated that an employee's role (i.e. faculty or staff) did not influence the direction or strength of the relationship between psychological climate and wellbeing. Third, results from the mediation analysis confirmed the position of engagement as a mediator in the relationship between psychological climate and psychological wellbeing. By examining employees' selfreported experiences of psychological climate, engagement, and wellbeing, this study provided substantive comprehension of the relationship of these variables within higher 
education. The following sections discuss the results from each of the hypotheses tested in greater detail.

\section{Hypothesis 1}

The first hypothesis stated that there would be a positive relationship between psychological climate, engagement, and wellbeing. Using Cohen's (1988) effect size criterion to evaluate the results $(\geq .10=$ small; $\geq .30=$ moderate; and $\geq .50=$ large $)$, it was found that positive relationships existed between psychological climate, engagement, and wellbeing. The coefficients obtained from the Pearson's Product-Moment correlation ranged from .17 to .52 and suggested that these relationships were generally small to moderate correlations. In particular, employees' perception of their psychological climate was positively correlated with their engagement level $(r=.52, p<.01)$, their

psychological wellbeing $(r=.30, p<.01)$, and their physical wellbeing $(r=.17, p<.01)$. Employee engagement was positively correlated with psychological wellbeing $(r=.33, p$ $<.01)$ and physical wellbeing $(r=.15, p<.05)$. These results mirror findings from previous research that found moderate to strong correlations between psychological climate and engagement (Kataria et al., 2013; Kataria et al., 2013b; Shuck \& Reio, 2014). However, the correlation between engagement and wellbeing somewhat contrasted findings in prior research that had shown strong correlations between them greater than .50 (Brunetto et al., 2011; Brunetto et al., 2012; Trinchero et al., 2014). Similarly, the correlations between psychological climate and wellbeing noted in this study differed from past studies where correlation estimates were often moderate to strong (i.e., Eisele \& D’Amato, 2011; Shuck \& Reio, 2014). 
In summary, the results of the correlational analysis supported the first hypothesis. The strongest relationship observed was between psychological climate and engagement, and the weakest relationship was found between psychological climate and wellbeing. The positive associations found between all three variables provided the opportunity to examine mediation and moderation relationships that are discussed later in this section.

\section{Hypothesis 2}

The second hypothesis stated that there would be a significant difference between faculty and staff in their level of wellbeing. Results from the independent t-test conducted revealed no significant difference between faculty and staff in either physical or psychological wellbeing. Thus, within this sample, membership in one group (i.e. faculty or staff) did not imply better or worse levels of wellbeing. This finding contradicted the assumption that higher degrees of autonomy and perceived control over one's work would be linked to better levels of physical and psychological health (Guppy \& Rick, 1996). Additionally, this finding contrasted results from Tytherleigh et al.'s (2005) study that implied that faculty were more likely to show better levels of physical and psychological wellbeing because the perceived autonomy they have of their work acts as a buffer between their workplace climate and wellbeing. Thus, while faculty and staff perform different roles, are assessed differently (Fuller, et al., 2006), and experience different types of stressors (Winefield, et al., 2014) the results did not indicate different outcomes of wellbeing in this study. One possible explanation for this contradiction in findings is that faculty and staff both work toward a core goal of serving students, whether that takes the form of teaching, advising, or administrative duties, and any 
impact on wellbeing may not differ based on role due to this core mission. More, the assumption that faculty may have more control over their work (i.e. where and when to work) may not imply a reduction in the stressors on their jobs that in turn result in a lessened impact their wellbeing.

\section{Hypothesis 3 and 4}

The third and fourth hypotheses tested whether employee role (i.e. faculty or staff) influenced the direction and magnitude of the relationship between psychological climate and wellbeing. Evidence from the hierarchical multiple regression analyses revealed that employee role did not moderate the relationship between psychological climate and psychological wellbeing nor physical wellbeing. In other words, employee role did not change the strength or direction of the relationship between psychological climate and wellbeing. More, when added into the regression model, employee role was not found to be a significant predictor of wellbeing. This finding aligned with the findings from hypothesis 2 in that it diverged from previous research, which, had suggested that the kind of work one does in higher education could influence outcomes on wellbeing (Tytherleigh et al., 2005). Although both hypotheses were not supported, this finding is still important, as it sheds light on an area that had not previously been examined within the extant literature.

\section{Hypothesis 5 and 6}

Hypotheses 5 and 6 were tested to examine if engagement mediated the relationship between psychological climate and wellbeing. Results from the mediation analyses suggested that employee engagement mediated the relationship between psychological climate and psychological wellbeing, but did not mediate the relationship 
between psychological climate and physical wellbeing. Specifically, for hypotheses 5 , findings showed that psychological climate explained $13 \%$ of the variance in psychological wellbeing in model mediated by engagement. The $95 \%$ confidence interval of the indirect effect of psychological climate on psychological wellbeing through engagement's mediation was estimated between $4.58 \%$ and $15.19 \%$. The direct effect of psychological climate on engagement wellbeing resulted in a coefficient of $\beta=$ .27 , and engagement's direct effect on psychological wellbeing was $\beta=.36$. Because the reported coefficient of the path from engagement to psychological wellbeing was positive, it was presumed that employees who scored high on engagement were more likely to report higher scores on psychological wellbeing. Supported by previous research, this study shows that the relationship between psychological climate and psychological wellbeing is in essence caused by engagement (Shuck \& Reio, 2014). Moreover, the findings suggested that psychological climate was an influencing factor in employees' overall engagement, thus aligning with existing research that indicated the meaning and interpretation an employee ascribes to their workplace largely determines whether or not they are engaged (Kataria et al., 2013b; Shuck et al., 2017). This finding, that engagement mediated the relationship between psychological climate and psychological wellbeing in higher education is novel, because it extends the application of engagement mediation models beyond the scope of for profit businesses and organizations and into higher education.

The result from the second mediation analysis performed using physical wellbeing was not found to be significant. Thus, in this study, engagement did not mediate the relationship between psychological climate and physical wellbeing. Further, 
the model suggested that engagement was not a significant predictor of physical wellbeing. When juxtaposed with previous literature on engagement (cf. Hakanen et al., 2006; Peterson et al., 2008; Schaufeli et al., 2008), this finding does appear surprising. Generally, higher engagement has often been linked with better reports of physical health when both objective and subjective measures of physical wellbeing have been used (Hakanen et al., 2006). For instance, higher levels of engagement have been linked with fewer psychosomatic complaints such as headaches (Schaufeli et al., 2008), back pain (Peterson et al., 2008), as well as with healthy cardiac autonomic activity including lower heart rate (Seppala. et al., 2012). It is possible that the outcomes for physical wellbeing reported in this study might have been constrained by the physical wellbeing measure used. This is discussed in more detail in the sections following. Further investigation of the association between psychological climate and physical wellbeing within higher education might therefore be necessary to substantiate this particular finding.

\section{Summary of Findings}

Overall, the study findings confirm the importance of psychological climate, engagement and wellbeing to institutions of higher education. This study indicated that within a higher education setting, psychological climate, employee engagement, and wellbeing were positively associated. More, engagement was found to mediate the relationship between psychological climate and psychological wellbeing but not for physical wellbeing. Employee role was not found to moderate the relationship between psychological climate and wellbeing, and finally, there were no significant differences between faculty and staff on wellbeing. This study expanded the understanding of the relationship between these variables, and thus made an important contribution to 
management and HRD literature by demonstrating their application using higher education as an organizational context.

\section{Implications for Theory, Research and Practice}

In view of the findings from this study, implications for theory, research, and practice are discussed in the next sections. First, implications for theory and research will be provided followed by implications for practice.

\section{Implications for Theory}

The theories of psychological climate and engagement used in this study rest on the fundamental idea that people look for meaning and purpose in the work they do, and as result yearn for positive experiences that affirm their workplaces as meaningful and safe places to work (Brown \& Leigh, 1996; Cartwright \& Homes, 2006; Shuck et al., 2017). Research on engagement, in particular, has shown that several types of benefits can accrue from highly engaged individuals including lower turn over, improved performance, and increased revenue growth (Harter et al., 2010; Shuck, Shuck, \& Reio, 2013). In recent times, researchers have been investigating the link between an employee's work environment, their levels of engagement, and wellbeing. Emergent research around these areas, for example, has shown that better work environments can be linked to higher levels of engagement as well as improved wellbeing in for profit organizations (Shuck \& Reio, 2014). The main theoretical implication of this study was that psychological climate, engagement, and wellbeing theories, as well as those models founded on these variables (e.g. engagement mediation model [Kataria et al., 2013a]) can be productively applied to institutions of higher education. This study took existing theoretical assumptions based on these variables and tested their utility in higher 
education; a unique extension of the research. Doing so revealed several key insights concerning psychological climate, engagement, and wellbeing in higher education. First, it seems clear that psychological climate, engagement, and wellbeing are positively associated. Second, engagement mediated the relationship between psychological climate and psychological wellbeing but not for physical wellbeing. Third, employee role (i.e. being faculty or staff) did not influence the strength of the relationship between psychological climate and wellbeing. Fourth, in spite of the difference in job function, faculty and staff did not differ in wellbeing.

While these findings may seem routine, they were found using the context of higher education and thus extended current knowledge in the HRD literature. Within HRD, specifically, recent studies that examined engagement have concluded that its mediating effects are an essential component for positive changes in the workplace, including better employee wellbeing (Kim, Khan, Wood, \& Tariq, 2016). The emergence of the importance of the mediating effects of engagement aligns with current thinking in HRD that suggests that organizational factors such as work systems and cultures function through mediating mechanisms (e.g. engagement, trust) to improve individual and organizational performance (Son, Lim, Kang, \& Kim, 2014). The interplay of organizational factors and mediating mechanisms resulting in better outcomes for employers and employees is grounded in social exchange theory (Emerson, 1976; Kim et al., 2016), where a series of interdependent interactions between people have the potential translate into high quality relationships (Cropanzano \& Mitchell, 2005). Within the HRD literature, these high quality relationships have been linked to positive outcomes such organizational citizenship behaviors (Kataria et al., 2013a), corporate social 
responsibility (Kim et al., 2016), and better wellbeing (Atkins et al., 2015; Shuck \& Reio, 2014). By demonstrating the mediating effect of engagement on wellbeing, this study offers two important implications for theory. First, findings from this study validate some of the current thinking in HRD on the importance of the mediating effects of engagement on individual outcomes and second, this study makes a unique contribution to HRD by modeling the mediating effects on engagement to institutions of higher education, for the first time within the bounds of the HRD field.

\section{Implications for Research}

Results from the analyses supported the hypothesis that psychological climate, engagement, and wellbeing are positively associated and correspond with findings from previous research. However, the results from the mediation analysis where physical wellbeing was used as the outcome variable was found to be non-significant, and this could partly be attributed to the scale used. The MOS-10 (Stewart et al., 1988) sought participants' subjective opinion of their general health in relation to other people that they know. For example, if a participant knew people who considered themselves to be very ill, they would be likely to rate their health as excellent even if they had health problems of their own. This may have somewhat limited the information on physical wellbeing (through range restriction) or inflated self-perception, and provides an extended opportunity for HRD scholars to conduct further research to validate the findings associated with physical wellbeing. In conducting future research in this area, researchers should consider using more objective measures of physical wellbeing including the use of bio data (e.g. heart rate, blood pressure, weight indices) to assess whether engagement mediates the relationship between psychological climate and physical wellbeing among 
employees in higher education. Using objective measures such as bio data is less likely to produce scores that are range restricted, as was observed in this study, and provide a better assessment of the relationship between psychological climate, engagement, and wellbeing. For example, an experimental research approach could be taken where participants are randomly distributed in two groups to work on a task and complete an engagement survey afterwards. One group could have a leader who has been identified as toxic (e.g. consistently raising their voice at teammates) and the other a supportive leader (e.g. encourages teammates). Bio data obtained from both groups before and after the task can be compared to examine whether engagement is associated with better levels of physical wellbeing. Alternatively, this experiment could be conducted longitudinally to investigate whether higher levels of engagement correspond with better physical wellbeing over time.

Another important implication for research resulting from this study is connected to the sample, which consisted of higher education employees within the United States. Although the nature of higher education is rapidly changing in the United States, neither the current mode of operation, the changes associated with it, nor the rate of these changes are the same in other countries. Thus, future researchers may want to consider examining these variables in countries where higher education operations differ from the United States. For example, would the findings from this study differ in countries such as Qatar and the United Arab Emirates, where foreign universities (e.g. New York University) are being recruited to establish local campuses that provide higher education modeled on their parent institution's practices? Would these internationalized campuses differ from existing local universities and colleges if this study were to be replicated? 
Additionally, future researchers may want to explore how cultural variances such as power distance, individualism versus collectivism, and uncertainty avoidance (Hofstede, 1983) might impact employee's interpretation of their work environment, and subsequently impact their wellbeing. In collectivistic cultures for example, the sense of self is embedded into social groups, meaning that frequent social interaction could positively influence the psychological climate the workplaces as compared to more individualistic cultures (Markus \& Kitayama, 1991; Schaufeli \& Salanova, 2010). The manifestation of climate, engagement, and wellbeing within different cultural contexts could yield new information that might inform HRD theory, research, and practice. Cross-cultural work coalescing around these areas would be particularly welcome by the HRD community, as there is growing interest in examining HRD at a national level to identify how factors such as socio-cultural and political environment affect human capital development (Alagaraja \& Wang, 2012).

\section{Implications for Practice}

Prior research in HRD has shown that employees who have positive perceptions of their workplace climate tend to immerse themselves fully in their work, resulting in positive outcomes on their wellbeing (Shuck \& Reio, 2014). The positive associations between psychological climate, engagement, and wellbeing found in this study confirms past research, and can serve as a roadmap to guide to institutions of higher education on creating and sustaining the benefits associated with a happier and healthier workforce. Any organization that wants happier and healthier workers must first understand the factors that need to be in play to achieve this. Based on the results of this study, institutions of higher education must actively work to ensure that their employees find 
feel valued and useful, as it promotes engagement. This general recommendation is hinged on the finding that engagement mediated the relationship between psychological climate and psychological wellbeing. This finding is prudent considering the increasing importance that colleges and universities are placing on wellness activities and programs in a bid to create a happier and healthier workforce (Cooper \& Barton, 2016; Fullerton, 2011). While the proliferation of wellness programs in higher education is laudable, it cannot, and should not, be used in isolation to create and sustain a healthy workforce. Rather, institutions of higher education should view these programs as a supplement to a sustained positive work environment. Supplementing a good work environment with wellness programs is an astute measure because the most significant health related cost to employers is presenteeism- when people come to work but underperform due to a negative work environment (Berry, Mirabito, \& Baun, 2010). The association found in this study is an indication that how employees interpret their work environments impact their engagement, and subsequently impact their psychological wellbeing. Further, results from this indicated that employees who find their work environments to be negative are less likely to be engaged, and more likely to report lower levels of psychological wellness. Therefore, institutions of higher education that only use wellness programs and activities to improve employee wellbeing might perceive these programs to be redundant if the work environment is toxic. Colleges and universities that do not take the workplace climate into account in employee wellbeing efforts may be limiting the effectiveness of their wellness programs to short boosts in wellbeing that could be wiped way by less than ideal work environments. Furthermore, it is unrealistic to assume that all employees take advantage of these wellness programs, and so those individuals who do not use them may 
not even have access to these short boosts in wellbeing that serve as a temporary reprieve from the effects of working in a negative work environment.

Institutions of higher education must widen the scope of their focus to include the work environment if employee wellbeing is to be sustained. In other words, colleges and universities need to focus on improving the work environment of their employees in addition to creating wellness programs and activities so that increases in wellbeing might be longer lasting. By providing a more positive work environment that fosters engagement, employees are more likely to feel better about their psychological wellbeing. Specific recommendations for improving engagement in higher education for employers are therefore provided next. These recommendations are grouped into individual and organizational interventions. Traditionally, the idea of interventions within the HRD literature is grounded in the medical model, which, treats interventions as something to be applied when there is a problem (Schaufeli \& Salanova, 2010). More recently, interventions have been conceptualized using the positive psychological principle of betterment that takes the view that improving latent constructs such as engagement is a long-term objective that requires continuous and sustained effort (DeHaan \& Ryan, 2014). Thus, the interventions proposed below are grounded in this contemporary approach to implementing interventions.

Organizational interventions. In order for engagement interventions to be effective, institutions of higher education must have a clear strategic focus for what exactly they would like to achieve and the benefits clearly communicated. This includes understanding what engagement is, the outcomes and benefits associated with engagement, and amalgamating this knowledge to craft strategy. Because engagement 
has become such a hot topic in organizational conversations, there is often the chance that an organization may attempt to create an engaged workforce because that is what is in vogue, without necessarily understanding why having an engaged workforce matters and the implications for the bottom line. Understanding the 'why' of engagement is important because it better informs and holds together strategy put in place to create an engaged workforce. For institutions of higher education, the importance of engagement can be strategically linked to employee health. As healthcare costs continue to rise, and institutions of higher education seek ways to combat these costs (Byrne et al., 2011), engagement can be used as vehicle to promote employee wellbeing while simultaneously reducing long term healthcare costs. Understanding the link between engagement and wellbeing, and clearly communicating benefits associated with engagement across the organization will positively impact the effectiveness of interventions implemented from an institutional level.

One area institutions of higher education can apply strategic engagement efforts is in leadership development. Leaders play in important role in the culture of an organization, and changing or influencing organizational culture to recognize and include engagement requires support from leadership (Schein, 2010). Higher educational institutions that have engagement as a strategic focus can aim to permeate sustained engagement into their culture by identifying leader behaviors that foster engagement in the workplace. The idea to synthesize leadership and engagement has been proffered by other researchers (e.g. Carasco-Saul, Kim, \& Kim, 2015; Schaufeli \& Salanova, 2010). Schaufeli and Salanova (2010) for instance have advocated for the use of transformational leadership to improve engagement. Transformational leaders go above 
and beyond the 'employee centered' leadership approach by creating a work environment that fosters a sense of purpose among employees (Bass, 1985). These leaders tend to optimize the emotional climate in the workplace that enhance engagement, which is important considering that engagement has been shown to be 'contagious' in that it crosses over from person to person in an enabling environment (Schaufeli \& Salanova, 2010). Additionally, transformational leadership has been linked with increased health and wellbeing (Nielson et al., 2009) making it even more important given the context of this study. However, this is not to say that transformational leadership is the only leadership style that can be used to create an engaged workforce. Other forms of leadership such as authentic leadership (Walumbwa et al., 2010), relationship and taskoriented leadership (Xu \& Thomas, 2011), charismatic leadership (Babcock-Roberson \& Strickland, 2010) and ethical leadership (Hartog \& Belschak, 2012) have all been positively linked with engagement.

With this information in mind, higher educational institutions can organize engagement-focused leadership training and onboarding for current and future leadership hires. This leadership training could be focused on explaining what engagement means within the institution, why it is important to faculty and staff, and the benefits leaders can get from focusing on engagement (e.g. increased performance, reduced turnover). A unique focus of this training could be identifying roles that leaders should play to help subordinates improve and sustain their engagement. Specifically, leaders should be trained on enhancing subordinates' personal resources such as positive thinking, goal setting, time management and stress management. According to Breevaart, Bakker, Demerouti and Derks (2016) when employees fully develop these personal resources, 
they essentially become self-leaders, because they can effective guide and motivate themselves to behave and act in ways that are desirable to the organization. Leader focused behaviors (whether transformational, charismatic, etc.) and self-leadership are beneficial to organizations because they are associated with higher levels of engagement (Breevaar et al., 2016). Thus, by using leadership training to develop and enhance employee personal resources, institutions of higher education can use leaders and subordinates simultaneously to stimulate engagement in the workplace.

Additionally, institutions of higher education should consider investing in conducting periodic climate audits to assess the level of engagement among employees. The purpose of these audits would be to reveal information that could aid the development of further measures to improve engagement. These audits could include an assessment of the work climate for job stressors such work overload, conflicts, and role problems, as well as unwanted outcomes such as absenteeism, turnover intention, and counterproductive work behaviors. Information from these periodic audits can then be used to inform the development of workshops, training, or even modify existing strategic engagement goals. HRD scholars and practitioners have for many years championed the use of audits to monitor the effectiveness of interventions (Clardy, 2004). The strength of the use of audits in HRD practice lies in the richness of the data obtained from the interventions. As such, an effective climate audit should yield information such as in depth descriptions of engagement interventions in place, sample employee interviews about workplace climate, and training records (Torraco \& Swanson, 1997). This level of detail is imperative when conducting audits because it allows organizational leaders to make correct decisions about specific HRD interventions. It also provides ample data that 
practitioners can use to communicate the overall importance of HRD to organizational leaders (Potnuru, \& Sahoo, 2016).

In sum, colleges and universities can take an institutional level approach to implementing interventions to increase and sustain engagement. For these interventions to effective however, there needs to be a clear strategy involved. This strategy should be informed by three key pieces of information: what is engagement? why does it matter?, and what are the benefits of engagement? Developing and communicating engagement interventions with this foundation is more likely to result in its acceptance throughout an organization and be more effective. This being said, not every organization has engagement as a strategic focus or has engagement as a priority. In these cases, there are individual level interventions that can be taken to initiate a culture of engagement. These individual level interventions represent a bottom up approach to building an engaged workforce that is discussed next.

Individual interventions. In organizations where engagement is not a primary objective, there are specific actions that individuals or leaders of units and teams can take to build an engaged workforce. An example would be practicing kindness (Schaufeli \& Salanova, 2010). Committing acts of kindness has been shown in research to result in numerous outcomes such as increased self confidence, increased likelihood of reciprocating responses, positive feed back (e.g. appreciation, and gratitude), as well as an increase in social interaction (Schaufeli \& Salanova, 2010). These outcomes are the sort of things that create meaning in one's work and should be encouraged within the workforce. The act of practicing kindness is based on the theory of caring, which is described as a genuine and ongoing interest in others that goes beyond feeling and 
concern, and can be demonstrated by acts of compassion that ultimately result of discovery of meaning in one's life (Kroth \& Keeler, 2009). While caring has traditionally been associated with helping professions such as counseling, business organizations are beginning using this concept as a mechanism to gain a competitive advantage by attracting and retaining talent (Kroth \& Keeler, 2009). Within HRD, caring has been touted as a means by which scholars and practitioners can generate strategies to create a positive work environment (Levering, 2009; Meyer \& Herscovitch, 2001).

Grounded in the caring theory, a specific idea that can be adopted by leaders of units and small teams in higher educational institutions is a kindness drive. The kindness drive would require all employees to be intentional about practicing kind acts over a period of time (e.g. 21 days) with the view to assimilating it into the culture of the team or unit. Examples of kind acts that should be encouraged include simple actions such holding doors or elevators open for others, exchanging pleasantries, leaving hand written notes of appreciation, and brewing another pot of coffee after taking the last cup. Another intervention that can be implemented is story telling. There is a lot of research that has shown that sharing good news about positive experiences and accomplishments elicits positive emotions (Gable et al., 2004). As pointed out by Shuck et al. (2017), positive emotion is a core component of engagement and the more positive emotions a person experiences at work, the more likely they are to be engaged. To improve and sustain engagement, leaders of units, teams, and departments should consider weaving good news into compelling stories that can be celebrated by all employees. This could include tenure and promotion, newly published research, work milestones, and retirements. Concerted efforts to repeatedly use story telling to share good news results in a 
compounding of positive events that are more likely to be remembered and associated with the workplace (Schaufeli \& Salanova, 2010).

In sum, there are individual level approaches that can be used to improve engagement in units, teams, and departments within institutions of higher education. Implementing individual level interventions such as practicing kindness and story telling on a consistent basis can create a workplace climate that fosters and sustains engagement. Based on the findings of this study, this in turn will have positive outcomes on employee's psychological wellbeing. If these interventions are used consistently in pockets of groups and teams on college campuses, and the outcomes documented and quantified, a case can be made to senior level administrators and leaders to include engagement as an institutional level strategic objective. Simple metrics such as number of days missed through illness, formal and informal grievance reports, and brief satisfaction surveys administered longitudinally can be used to quantify, track, and report the benefits of sustained engagement practices.

\section{Conclusion}

People want to work in organizations that value them and provide meaningful work that creates sense of purpose in their lives. This aspiration remains the same regardless of the type of organization. This study provided initial evidence that suggested that institutions of higher education in particular are no different from traditional for profit organizations when it comes to the issue of meaningful work. The increasing amount of research in for profit organizations that supports the idea that a healthier workforce is linked to happier employees was reflected among higher educational employees in this study. It is important to note however, that the findings and 
recommendations proffered from this study are based on exploratory evidence that needs to be validated through additional research. In particular, additional studies need to be conducted to examine issues of wellbeing using more objective measures of physical wellbeing. Finally, this study showed that there is opportunity for HRD researchers and practitioners to bring their expertise into institutions of higher education to help improve individual and organizational outcomes. 


\section{REFERENCES}

Abdelhadi, N., \& Drach-Zahavy, A. (2012). Promoting patient care: Work engagement as a mediator between ward service climate and patient-centred care. Journal of Advanced Nursing, 68(6), 1276-1287. https://doi.org/10.1111/j.13652648.2011.05834.x

Alagaraja, M., \& Shuck, B. (2015). Exploring organizational alignment-employee engagement linkages and impact on individual performance: A conceptual model. Human Resource Development Review, 14(1), 17-37. http://dx.doi.org/10.1177/1534484314549455

Alagaraja, M., \& Wang, J. (2012). Development of a national HRD strategy model: Cases of India and China. Human Resource Development Review, 11(4), 407-429.

Albrecht, S. L. (2012). The influence of job, team and organizational level resources on employee well-being, engagement, commitment and extra-role performance: Test of a model. International Journal of Manpower, 33(7), 840-853. https://doi.org/10.1108/01437721211268357

Altbach, P. G. (Ed.). (1999). Private Prometheus: Private higher education and development in the 21st century (Vol. 77). Greenwood Publishing Group.

Aronowitz, S., \& Giroux, H. A. (2000). The corporate university and the politics of education. In The Educational Forum (Vol. 64, No. 4, pp. 332-339). Taylor \& Francis Group. 
Baltes, B. B., Zhdanova, L. S., \& Parker, C. P. (2009). Psychological climate: A comparison of organizational and individual level referents. Human Relations, 62(5), 669-700.

Bakker, A. B. (2009). Building engagement in the workplace. The Peak Performing Organization, 50-72. https://doi.org/10.4324/9780203971611.ch3

Bakker, A.B. (2011). An evidence-based model of work engagement. Current Directions in Psychological Science, 20(4), 265-

269. http://dx.doi.org/10.1177/0963721411414534

Best, J. W., \& Kahn, J. V. (2014). Research in education. NY: Pearson Higher Ed.

Betts, K. (2009). Online human touch (OHT) training \& support: A conceptual framework to increase faculty and adjunct faculty engagement, connectivity, and retention in online education, part 2. Journal of Online Learning and Teaching, 5(1), 29-48.

Berntson, E., \& Marklund, S. (2007). The relationship between perceived employability and subsequent health. Work \& Stress, 21(3), 279292. https://doi.org/10.1080/02678370701659215

Blais, M. A., Lenderking, W. R., Baer, L., de Lorell, A., Peets, K., Leahy, L., \& Burns, C. (1999). Development and initial validation of a brief mental health outcome measure. Journal of Personality Assessment, 73, 359-373. https://doi.org/10.1207/s15327752jpa7303_5

Bleiklie, I., \& Kogan, M. (2007). Organization and governance of universities. Higher Education Policy, 20(4), 477-493. 
Bogdan, R. C., \& Biklen, S. K. (2007). Qualitative research for education (5th ed.). Syracuse, NY: Pearson.

Bornstein, M. H., Jager, J., \& Putnick, D. L. (2013). Sampling in developmental science: Situations, shortcomings, solutions, and standards. Developmental Review, 33(4), $357-370$.

Brandon, D. M., Long, J. H., Loraas, T. M., Mueller-Phillips, J., \& Vansant, B. (2013). Online instrument delivery and participant recruitment services: Emerging opportunities for behavioral accounting research. Behavioral Research in Accounting, 26(1), 1-23.

Brown, S. P., \& Leigh, T. W. (1996). A new look at psychological climate and its relationship to job involvement, effort, and performance. Journal of Applied Psychology, 81(4), 358-368. https://doi.org/10.1037//0021-9010.81.4.358

Brunetto, Y., Shacklock, K., Teo, S., \& Farr-Wharton, R. (2014). The impact of management on the engagement and well-being of high emotional labour employees. The International Journal of Human Resource Management, 25(17), 2345-2363. https://doi.org/10.1080/09585192.2013.877056

Brunetto, Y., Teo, S. T., Shacklock, K., \& Farr-Wharton, R. (2012). Emotional intelligence, job satisfaction, well-being and engagement: explaining organisational commitment and turnover intentions in policing. Human Resource Management Journal, 22(4), 428-441. https://doi.org/10.1111/j.17488583.2012.00198.x

Brunetto, Y., Xerri, M., Shriberg, A., Farr-Wharton, R., Shacklock, K., Newman, S., \& Dienger, J. (2013). The impact of workplace relationships on engagement, well- 
being, commitment and turnover for nurses in Australia and the USA. Journal of Advanced Nursing, 69(12), 2786-2799. https://doi.org/10.1111/jan.12165

Buckingham, M., \& Coffman, C. (1999). First, break all the rules; What the world's greatest managers do differently. New York: Simon and Schuster.

Carini, R. M., Kuh, G. D., \& Klein, S. P. (2006). Student engagement and student learning: Testing the linkages. Research in Higher Education, 47(1), 1-32. https://doi.org/10.1007/s11162-005-8150-9

Cartwright, S., \& Cooper, C. L. (2014). Towards organizational health: Stress, positive organizational behavior, and employee well-being. In Bridging Occupational, Organizational and Public Health (pp. 29-42). Springer Netherlands.

Cartwright, S., \& Holmes, N. (2006). The meaning of work: The challenge of regaining employee engagement and reducing cynicism. Human Resource Management Review, 16, 199-208. https://doi.org/10.1016/j.hrmr.2006.03.012

Chaudhary, R., Rangnekar, S., \& Barua, M. K. (2012). Relationships between occupational self efficacy, human resource development climate, and work engagement. Team Performance Management: An International Journal, 18(7/8), 370-383. https://doi.org/10.1108/13527591211281110

Cohen, J. (1988). Statistical power analysis for the behavioral sciences 2nd edn. Cohen, J. (1992). A power primer. Psychological Bulletin, 112(1), 155.

Colbeck, C. L., \& Wharton-Michael, P. (2006). Individual and organizational influences on faculty members' engagement in public scholarship. New Directions for Teaching and Learning, 2006(105), 17-26. https://doi.org/10.1002/t1.221 
Cole, M. S., Walter, F., Bedeian, A. G., \& O’Boyle, E. H. (2012). Job burnout and employee engagement: A meta-analytic examination of construct proliferation. Journal of Management, 38(5), 1550-1581. https://doi.org/10.1177/0149206311415252

Colligan, T. W., \& Higgins, E. M. (2006). Workplace stress: Etiology and consequences. Journal of Workplace Behavioral Health, 21(2), 89-97. https://doi.org/10.1300/j490v21n02_07

Cooper, K., \& Barton, G. C. (2016). An exploration of physical activity and wellbeing in university employees. Perspectives in Public Health, 136(3), 152-160. https://doi.org/10.1177/1757913915593103

Creswell, J. W. (2005). Educational research: Planning, conducting, and evaluating quantitative and qualitative research (2nd ed.). Upper Saddle River, NJ: Prentice Hall.

Danna, K., \& Griffin, R. W. (1999). Health and well-being in the workplace: A review and synthesis of the literature. Journal of Management, 25(3), 357-384. https://doi.org/10.1177/014920639902500305

DeShields Jr, O. W., Kara, A., \& Kaynak, E. (2005). Determinants of business student satisfaction and retention in higher education: applying Herzberg's two-factor theory. International Journal of Educational Management, 19(2), 128-139.

Dillman, D. A., Smyth, J. D., \& Christian, L. M. (2014). Internet, phone, mail, and mixed-mode surveys: the tailored design method. John Wiley \& Sons.

Dollard, M. F., \& Bakker, A. B. (2010). Psychosocial safety climate as a precursor to conducive work environments, psychological health problems, and employee 
engagement. Journal of Occupational and Organizational Psychology, 83(3), 579-599. https://doi.org/10.1348/096317909x470690

Drew, C. J., Hardman, M. L., \& Hosp, J. L. (2008). Designing and conducting research in education. Thousand Oaks, CA: Sage Publications, Inc.

Ewing, B., Ryan, M., \& Zarco, E. P. (2007). A campus wellness program: Accepting the challenge. Journal-New York State Nurses Association, 38(1),13-20.

Fredrickson, B. L. (2001). The role of positive emotions in positive psychology: The broaden-and-build theory of positive emotions. American Psychologist, 56, 218226. doi:10.1037/0003- 066X.56.3.218

Fredrickson, B. L. (2004). The broaden-and-build theory of positive emotions. Philosophical Transactions of the Royal Society B: Biological Sciences, 359(1449), 1367-1377. https://doi.org/10.4135/9781412956253.n75

Fuller, J. B., Hester, K., Barnett, T., \& Relyea, L. F. C. (2006). Perceived organizational support and perceived external prestige: Predicting organizational attachment for university faculty, staff, and administrators. The Journal of Social Psychology, 146(3), 327-347.

Fullerton, D. S. (2011). A collaborative approach to college and university student health and wellness. New Directions for Higher Education, 2011(153), 61-69.

Geissler, M., \& Grave, B. (2017). The Climate for Entrepreneurship at Higher Education Institutions.

Gillespie, N. A., Walsh, M. H. W. A., Winefield, A. H., Dua, J., \& Stough, C. (2001). Occupational stress in universities: Staff perceptions of the causes, consequences and moderators of stress. Work \& Stress, 15(1), 53-72. 
Giroux, H. (2002). Neoliberalism, corporate culture, and the promise of higher education: The university as a democratic public sphere. Harvard Educational Review, 72(4), 425-464.

Giroux, H. A. (2009). Democracy's nemesis: The rise of the corporate university. Cultural Studies? Critical Methodologies, 9(5), 669-695.

Giroux, H., \& Myrsiades, H. (2001). Beyond the corporate university: Culture and pedagogy in the new millennium. Teaching in Higher Education, 8, 579-597.

Giroux, H. A. (2015). University in chains: Confronting the military-industrial-academic complex. Routledge.

Goh, J., Pfeffer, J., \& Zenios, S. A. (2015). The relationship between workplace stressors and mortality and health costs in the United States. Management Science. doi: $10.1287 / \mathrm{mnsc} .2014 .2115$

Grant, A. M., Christianson, M. K., \& Price, R. H. (2007). Happiness, health, or relationships? Managerial practices and employee well-being tradeoffs. The Academy of Management Perspectives, 21(3), 51-63. https://doi.org/10.5465/amp.2007.26421238

Green, S. B. (1991). How many subjects does it take to do a regression analysis? Multivariate Behavioral Research, 26, 449-510. http://dx.doi.org/10.1207/s15327906mbr2603_7

Green, S. B., \& Salkind, N. J. (2005). Using SPSS for Windows and Macintosh (4th ed.). Upper Saddle River, NJ: Pearson.

Harter, J. K., Schmidt, F. L., Asplund, J. W., Killham, E. A., \& Agrawal, S. (2010). Causal impact of employee work perceptions on the bottom line of 
organizations. Perspectives on Psychological Science, 5(4), 378-389. https://doi.org/10.1177/1745691610374589

Haggerty, G., Blake, M., Naraine, M., Siefert, C., \& Blais, M. A. (2010). Construct validity of the Schwartz Outcome Scale-10: Comparisons to interpersonal distress, adult attachment, alexithymia, the five-factor model, romantic relationship length and ratings of childhood memories. Clinical Psychology \& Psychotherapy, 17(1), 44-50. doi: 10.1002/cpp.643

Harter, J. K., Schmidt, F. L., Asplund, J. W., Killham, E. A., \& Agrawal, S. (2010). Causal impact of employee work perceptions on the bottom line of organizations. Perspectives on Psychological Science, 5(4), 378-389. https://doi.org/10.1177/1745691610374589

Harter, J. K., Schmidt, F. L., \& Hayes, T. L. (2002). Business-unit-level relationship between employee satisfaction, employee engagement, and business outcomes: A meta-analysis. Journal of Applied Psychology, 87, 268-279. https://doi.org/10.1037//0021-9010.87.2.268

Harris, R. J. (1985). A primer of multivariate statistics (2nd ed.). New York: Academic Press.

Henson, R. K. (2001). Understanding internal consistency reliability estimates: A conceptual primer on coefficient alpha. Measurement and Evaluation in Counseling and Development, 34(3), 177-189.

Hinkle, D. E., Wiersma, W., \& Jurs, S. G. (2003). Applied statistics for the behavioral sciences (5th ed). New York: Houghton Mifflin. 
Hofstede, G. (1983). The cultural relativity of organizational practices and theories. Journal of International Business Studies, 14(2), 75-89.

Hu, Y. L., Ching, G. S., \& Chao, P. C. (2012). Taiwan student engagement model: Conceptual framework and overview of psychometric properties. International Journal of Research Studies in Education, 1(1), 69-90. doi:10.5861/ijrse.2012.v1i1.19

Iverson, R. D., Olekalns, M., \& Erwin, P. J. (1998). Affectivity, organizational stressors, and absenteeism: A causal model of burnout and its consequences. Journal of Vocational Behavior, 52(1), 1-23. https://doi.org/10.1006/jvbe.1996.1556

Jones, A. P., \& James, L. R. (1979). Psychological climate: Dimensions and relationships of individual and aggregated work environment perceptions. Organizational Behavior and Human Performance, 23(2), 201-250. https://doi.org/10.1016/0030$\underline{5073(79) 90056-4}$

Kahn, W. (1990). Psychological conditions of personal engagement and disengagement at work. Academy of Management Journal, 33, 692-724. https://doi.org/10.2307/256287

Kahu, E. R. (2013). Framing student engagement in higher education. Studies in Higher Education, 38(5), 758-773. https://doi.org/10.1080/03075079.2011.598505

Kantor, J., \& Streitfeld, D. (2015). Inside Amazon: Wrestling big ideas in a bruising workplace. The New York Times, 15.

Kataria, A., Garg, P., \& Rastogi, R. (2013). Psychological climate and organizational effectiveness: Role of work engagement. IUP Journal of Organizational Behavior, 12(3), 33. https://doi.org/10.20474/jabs-2.4.3 
Kim, W., Khan, G. F., Wood, J., \& Mahmood, M. T. (2016). Employee engagement for sustainable organizations: Keyword analysis using social network analysis and burst detection approach. Sustainability, 8(7), 631.

Kinman, G. (2014). Doing more with less? Work and wellbeing in academics. Somatechnics, 4(2), 219-235.

Klein, K. J., Dansereau, F., \& Hall, R. J. (1994). Levels issues in theory development, data collection, and analysis. Academy of Management Review, 19(2), 195-229. https://doi.org/10.2307/258703

Krause, K. L. (2005). Serious thoughts about dropping out in first year: Trends, patterns and implications for higher education. Studies in Learning, Evaluation, Innovation and Development, 2(3), 55-68.

Law, R., Dollard, M. F., Tuckey, M. R., \& Dormann, C. (2011). Psychosocial safety climate as a lead indicator of workplace bullying and harassment, job resources, psychological health and employee engagement. Accident Analysis \& Prevention, 43(5), 1782-1793. https://doi.org/10.1016/j.aap.2011.04.010

Lewin, K., Lippitt, R., \& White, R. K. (1939). Patterns of aggressive behavior in experimentally created "social climates". The Journal of Social Psychology, 10(2), 269-299. https://doi.org/10.1080/00224545.1939.9713366

Macey, W. H., \& Schneider, B. (2008). The meaning of employee engagement. Industrial and Organizational Psychology, 1(1), 3-30. doi: 10.1111/j.17549434.2007.0002.x

Macklem, K. (2005). The toxic workplace. Maclean's, 118(5), 34. 
Mäkikangas, A., \& Kinnunen, U. (2003). Psychosocial work stressors and well-being: Self-esteem and optimism as moderators in a one-year longitudinal sample. Personality and Individual Differences, 35(3), 537-557. https://doi.org/10.1016/s0191-8869(02)00217-9

Maslach, C., Schaufeli, W. B., \& Leiter, M. P. (2001). Job burnout. Annual Review of Psychology, 52(1), 397-422. https://doi.org/10.1146/annurev.psych.52.1.397

Moore, T. L., \& Ward, K. (2010). Institutionalizing Faculty Engagement through Research, Teaching, and Service at Research Universities. Michigan Journal of Community Service Learning, 17(1), 44-58.

Moradi, A. A. N., Ricciardi, M. R., Archer, T., \& Garcia, D. (2014). Exercise, character strengths, well-being, and learning climate in the prediction of performance over a 6-month period at a call center. Frontiers in Psychology, 5, 1-

11. https://doi.org/10.3389/fpsyg.2014.00497

Nelson, K., Boudrias, J. S., Brunet, L., Morin, D., De Civita, M., Savoie, A., \& Alderson, M. (2014). Authentic leadership and psychological well-being at work of nurses: The mediating role of work climate at the individual level of analysis. Burnout Research, 1(2), 90-101. https://doi.org/10.1016/j.burn.2014.08.001

Nimon, K., Shuck, B., \& Zigarmi, D. (2016). Construct overlap between employee engagement and job satisfaction: a function of semantic equivalence?. Journal of Happiness Studies, 17(3), 1149-1171. https://doi.org/10.1007/s10902-015-9636-6

Nimon, K., Zigarmi, D., Houson, D., Witt, D., \& Diehl, J. (2011). The work cognition inventory: Initial evidence of construct validity. Human Resource Development Quarterly, 22(1), 7-35. https://doi.org/10.1002/hrdq.20065 
Nunnally, J. C., \& Bernstein, I. H. (1978). Psychometric testing. New York: McGraw.

Oertel, S. (2017, January). Structure Determined by Imprinting: Diversity Management in German Universities. In Academy of Management Proceedings (Vol. 2017, No. 1, p. 13979). Academy of Management.

Ohmann, R. (2002, November 25). Citizenship and literacy work: Thoughts without a conclusion. Workplace. Retrieved February 8, 2018, from http://www.louisville.edu/journal/ workplace/issue7/ohmann.html

O’Meara, K., Sandmann, L. R., Saltmarsh, J., \& Giles, D. E. (2011). Studying the professional lives and work of faculty involved in community engagement. Innovative Higher Education, 36(2), 83-96. https://doi.org/10.1007/s10755-010-9159-3

Osam, E. K., Bergman, M., \& Cumberland, D. M. (2017). An integrative literature review on the barriers impacting Adult Learners' return to college. Adult Learning, 28(2), 54-60.

Ouweneel, E., Le Blanc, P. M., \& Schaufeli, W. B. (2012). Don't leave your heart at home: Gain cycles of positive emotions, resources, and engagement at work. Career Development International, 17(6), 537-556. https://doi.org/10.1108/13620431211280123

Parker, C. P., Baltes, B. B., Young, S. A., Huff, J. W., Altmann, R. A., Lacost, H. A., \& Roberts, J. E. (2003). Relationships between psychological climate perceptions and work outcomes: a meta-analytic review. Journal of Organizational Behavior, 24(4), 389-416. ttps://doi.org/10.1002/job.198 
Pedhazur, E. J., \& Schmelkin, L. P. (2013). Measurement, design, and analysis: An integrated approach. Psychology Press: NY.

Pittaway, S. M. (2012). Student and staff engagement: Developing an engagement framework in a Faculty of Education. Australian Journal of Teacher Education, 37(4), 3. https://doi.org/10.14221/ajte.2012v37n4.8

Preacher, K. J., \& Hayes, A. F. (2004). SPSS and SAS procedures for estimating indirect effects in simple mediation models. Behavior Research Methods, Instruments, \& Computers, 36(4), 717-731.

Puig-Ribera, A., McKenna, J., Gilson, N., \& Brown, W. J. (2008). Change in work day step counts, wellbeing and job performance in Catalan university employees: a randomised controlled trial. Promotion \& Education, 15(4), 11-16. https://doi.org/10.1177/1025382308097693

Rao, T. V., \& Abraham, E. (1986). Human resource development climate in Indian organization. Recent Experiences in Human Resources Development, 70-98.

Rich, B. L., Lepine, J. A., \& Crawford, E. R. (2010). Job engagement: Antecedents and effects on job performance. Academy of Management Journal, 53(3), 617-635. https://doi.org/10.5465/amj.2010.51468988

Rose, K., Shuck, B., Twyford, D., \& Bergman, M. (2015). Skunked: An integrative review exploring the consequences of the dysfunctional leader and implications for those employees who work for them. Human Resource Development Review, 14(1), 64-90. https://doi.org/10.1177/1534484314552437 
Rothmann, S. (2008). Job satisfaction, occupational stress, burnout and work engagement as components of work-related wellbeing. SA Journal of Industrial Psychology, 34(3), 11-16. https://doi.org/10.4102/sajip.v34i3.424

Saks, A. M. (2006). Antecedents and consequences of employee engagement. Journal of Managerial Psychology, 21, 600-619. https://doi.org/10.9790/487x-0935257

Salanova, M., Agut, S., \& Peiró, J. M. (2005). Linking organizational resources and work engagement to employee performance and customer loyalty: the mediation of service climate. Journal of Applied Psychology, 90(6), 1217. https://doi.org/10.1037/0021-9010.90.6.1217

Salkever, D. (2000). Activity status, life satisfaction, and perceived productivity for young adults with developmental disabilities. Journal of Rehabilitation, 66(3), 413.

Seijts, G. H., \& Crim, D. (2006). What engages employees the most or, the ten C's of employee engagement. Ivey Business Journal, 70(4), 1-5.

Schaufeli, W. B., Salanova, M., González-Romá, V., \& Bakker, A. B. (2002). The measurement of engagement and burnout: A two sample confirmatory factor analytic approach. Journal of Happiness Studies, 3(1), 71-92.

Schaufeli, W. B., Taris, T. W., \& Van Rhenen, W. (2008). Workaholism, burnout, and work engagement: three of a kind or three different kinds of employee wellbeing?. Applied Psychology, 57(2), 173-203. https://doi.org/10.1111/j.14640597.2007.00285.x 
Schneider, B., White, S. S., \& Paul, M. C. (1998). Linking service climate and customer perceptions of service quality: Tests of a causal model. Journal of Applied Psychology, 83(2), 150. https://doi.org/10.1037//0021-9010.83.2.150

Shimazu, A., \& Schaufeli, W. B. (2009). Is workaholism good or bad for employee wellbeing? The distinctiveness of workaholism and work engagement among Japanese employees. Industrial health, 47(5), 495502. https://doi.org/10.2486/indhealth.47.495

Shuck, B., Adelson, J. L., \& Reio, T. G. (2016). The Employee Engagement Scale: Initial Evidence for Construct Validity and Implications for Theory and Practice. Human Resource Management. 56(6), 953-977. https://doi.org/10.1002/hrm.21811

Shuck, B., Alagaraja, M., Rose, K., Owens, J., Osam, K., \& Bergman, (2017). The health-related upside of employee engagement: Exploratory evidence and implications for theory and practice. Performance Improvement Quarterly. 30(3), 165-178.

Shuck, B., Osam, K., Zigarmi, D., \& Nimon, K. (2017). Definitional and conceptual muddling: Identifying the positionality of employee engagement and defining the construct. Human Resource Development Review. 16(3), 263-293.

Shuck, B., \& Reio Jr, T. G. (2014). Employee engagement and well-being: A moderation model and implications for practice. Journal of Leadership \& Organizational Studies, 21(1), 43-58. https://doi.org/10.1177/1548051813494240

Shuck, B., Reio Jr, T. G., \& Rocco, T. S. (2011). Employee engagement: An examination of antecedent and outcome variables. Human Resource Development International, 14(4), 427-445. https://doi.org/10.1080/13678868.2011.601587 
Shuck, A. L., Shuck, B., \& Reio Jr, T. G. (2013). Emotional labor and performance in the field of child life: Initial model exploration and implications for practice. Children's Health Care, 42(2), 168-190. https://doi.org/10.1080/02739615.2013.766116

Shuck, B., \& Wollard, K. (2010). Employee engagement and HRD: A seminal review of the foundations. Human Resource Development Review, 9(1), 89-110. https://doi.org/10.1177/1534484309353560

Simsek, Z., \& Veiga, J. (2001). A primer on Internet organizational surveys. Organizational Research Methods, 4, 218-235. doi:10.1177/109442810143003

Slaughter, A.-M. (2015). Uber's CEO Plays With Fire. New York Times, A1

Slaughter, A.-M. (2015). A Toxic Work World. New York Times, 20.

Soane, E., Shantz, A., Alfes, K., Truss, C., Rees, C., \& Gatenby, M. (2013). The association of meaningfulness, well-being, and engagement with absenteeism: a moderated mediation model. Human Resource Management, 52(3), 441-456. https://doi.org/10.1002/hrm.21534

Stewart, A. L., Hays, R. D., \& Ware, J. E. (1988). The MOS short-form general health survey: Reliability and validity in a patient population. Medical Care, 26(7), 724735. https://doi.org/10.1097/00005650-198807000-00007

Swanson R. A. (1995). Human resource development: Performance is the key. Human Resource Development Quarterly, 6, 207-213. https://doi.org/10.1002/hrdq.3920060208

Stander, F. W., De Beer, L. T., \& Stander, M. W. (2015). Authentic leadership as a source of optimism, trust in the organisation and work engagement in the public 
health care sector. SA Journal of Human Resource Management, 13(1), 1-12. https://doi.org/10.4102/sajhrm.v13i1.675

Tekula, R., \& Jhamb, J. (2015). Universities as Intermediaries: Impact Investing and Social Entrepreneurship. Metropolitan Universities, 26(1), 35-52.

Thelin, J. R. (2001). Campus and community: A world turned inside out?. The Review of Higher Education, 25(1), 1-14.

Trinchero, E., Borgonovi, E., \& Farr-Wharton, B. (2014). Leader-member exchange, affective commitment, engagement, wellbeing, and intention to leave: public versus private sector Italian nurses. Public Money \& Management, 34(6), 381388. https://doi.org/10.1080/09540962.2014.962361

Truss, K., Soane, E., Delbridge, R., Alfes, K., Shantz, A., \& Petrov, G. (2011). Employee engagement, organisational performance and individual well-being: exploring the evidence, developing the theory. The International Journal of Human Resource Management, 22(1), 232-233. doi:10.1080/09585192.2011.552282

Tytherleigh, M. Y., Webb, C., Cooper, C. L., \& Ricketts, C. (2005). Occupational stress in UK higher education institutions: A comparative study of all staff categories. Higher Education Research \& Development, 24(1), 41-61. https://doi.org/10.1080/0729436052000318569

Van De Voorde, K., Paauwe, J., \& Van Veldhoven, M. (2012). Employee well-being and the HRM-organizational performance relationship: a review of quantitative studies. International Journal of Management Reviews, 14(4), 391-407. https://doi.org/10.1111/j.1468-2370.2011.00322.x 
Wade, A., \& Demb, A. (2009). A conceptual model to explore faculty community engagement. Michigan Journal of Community Service Learning, 15(2), 5-16. https://doi.org/10.5642/cguetd/81

Warr, P. (2002). Psychology at work. Penguin UK.

Watts, J., \& Robertson, N. (2011). Burnout in university teaching staff: A systematic literature review. Educational Research, 53(1), 33-50. https://doi.org/10.1080/00131881.2011.552235

Wilson, C. R. Van Voorhis, \& Morgan, B. L. (2007). Understanding Power and Rules of Thumb for Determining Sample Sizes. Tutorials in Quantitative Methods for Psychology, 3(2), 43-50.

https://doi.org/10.20982/tqmp.03.2.p043

Winefield, H. R., Boyd, C., \& Winefield, A. H. (2014). Work-family conflict and wellbeing in university employees. The Journal of Psychology, 148(6), 683-697. https://doi.org/10.1080/00223980.2013.822343

Wollard, K. K., \& Shuck, B. (2011). Antecedents to employee engagement: A structured review of the literature. Advances in Developing Human Resources, 13(4), 429446. https://doi.org/10.1177/1523422311431220

Wright, T. A., Cropanzano, R., \& Bonett, D. G. (2007). The moderating role of employee positive well being on the relation between job satisfaction and job performance. Journal of Occupational Health Psychology, 12(2), 93. https://doi.org/10.1037/1076-8998.12.2.93 
Zepke, N., \& Leach, L. (2010). Improving student engagement: Ten proposals for action. Active Learning in Higher Education, 11(3), 167-177. https://doi.org/10.1177/1469787410379680

Zhao, X., Lynch Jr, J. G., \& Chen, Q. (2010). Reconsidering Baron and Kenny: Myths and truths about mediation analysis. Journal of Consumer Research, 37(2), 197206. 
Appendix A

Psychological Climate Measure (Brown \& Leigh, 1996)

Supportive Management

S1. My boss is flexible about how I accomplish my job objectives.

S2. My manager is supportive of my ideas and ways of getting things done.

S3. My boss gives me the authority to do my job as I see fit.

S4. I'm careful in taking responsibility because my boss is often critical of new ideas.

S5. I can trust my boss to back me up on decisions I make in the field.

Role Clarity

C11. Management makes it perfectly clear how my job is to be done.

C12. The amount of work responsibility and effort expected in my job is clearly defined.

C13. The norms of performance in my department are well understood and communicated.

Contribution

Co1. I feel very useful in my job.

Co2. Doing my job well really makes a difference.

Co3. I feel like a key member of the organization.

Co4. The work I do is very valuable to the organization. Recognition $(a=.76$ and .70$)$

R1. I rarely feel my work is taken for granted.

R2. My superiors generally appreciate the way I do my job.

R3. The organization recognizes the significance of the contributions I make.

Self-Expression

E1. The feelings I express at work are my true feelings. 
E2. I feel free to be completely myself at work.

E3. There are parts of myself that I am not free to express at work, [reverse scored]

E4. It is okay to express my true feelings in this job.

\section{Challenge}

Ch1. My job is very challenging.

Ch2. It takes all my resources to achieve my work objectives. 


\section{Appendix B}

Employee Engagement Scale (Shuck, Adelson, \& Reio, 2016)

\section{Cognitive Engagement}

CE1. I am really focused when I am working.

CE2. I concentrate on my job when I am at work.

CE3. I give my job responsibility a lot of attention

CE4. At work, I am focused on my job.

\section{Emotional Engagement}

EE1. Working at $<$ my current organization $>$ has a great deal of personal meaning to me.

EE2. I feel a strong sense of belonging to my job.

EE3. I believe in the mission and purpose of $<$ my company $>$.

EE4. I care about the future of $<$ my company $>$.

Behavioral Engagement

BE1. I really push myself to work beyond what is expected of me.

BE2. I am willing to put in extra effort without being asked.

BE3. I often go above what is expected of me to help my team be successful.

BE4. I work harder that expected to help $<$ my company $>$ be successful. 


$$
\begin{gathered}
\text { Appendix C } \\
\text { Wellbeing Scales } \\
\text { Ryff's Psychological Wellbeing Scale }
\end{gathered}
$$

1. I tend to be influenced by people with strong opinions.

2. In general, I feel I am in charge of the situation in which I live.

3. I think it is important to have new experiences that challenge how you think about yourself and the world.

4. Maintaining close relationships has been difficult and frustrating for me.

5. I live life one day at a time and don't really think about the future.

6. When I look at the story of my life, I am pleased with how things have turned out.

7. I have confidence in my opinions, even if they are contrary to the general consensus.

8. The demands of everyday life often get me down.

9. For me, life has been a continuous process of learning, changing and growth.

10. People would describe me as a giving person, willing to share my time with others.

11. Some people wander aimlessly through life, but I am not one of them.

12. I like most aspects of my personality.

13. I judge myself by what I think is important, not by the values of what others think is important.

14. I am quite good at managing the many responsibilities of my daily life.

15. I gave up trying to make a big improvements or changes in my life a long time ago.

16. I have not experienced many warm and trusting relationships with others.

17. I sometimes feel as if I've done all there is to do in life. 
18. In many ways, I feel disappointed about my achievements in life.

Medical Outcomes Study-Short Form (Stewart, Hays, \& Ware, 1988).
a. I am somewhat ill
b. I am as healthy as anybody I know
c. My health is excellent
d. I have been feeling bad lately 
Appendix D

Demographic Information

1. Please state your gender

2. Please indicate your race
a. American Indian/Alaska Native
b. Asian
c. Black or African American
d. Hispanic or Latino or Spanish Origin of a Race
e. Native Hawaiian or Other Pacific Islander
f. White
g. Two or More Races

3. Which of the following best describes your current institution?
a. Four year public institution
b. Four year private institution
c. Two year public institution
d. Two year private institution

4. In what capacity are you employed at your institution?
a. Faculty (please list your rank)
b. Staff (please list your title)

5. How long have you worked at your current institution?
a. 0-5 years
b. 6-10 years 

c. 11-15 years
d. 16-20 years
e. More than 20 years 
Appendix E

IRB Approval

\section{UNIVERSITY OF LOUISVILLE}

\author{
Human \\ Subjects \\ Protection \\ Program \\ Office \\ MedCenter \\ One - Suite \\ 200
}

501 E. Broadway

Louisville, KY 40202-1798

\author{
DATE: \\ TO: \\ FROM: \\ IRB NUMBER: \\ STUDY TITLE: \\ REFERENCE \#: \\ IRB STAFF CONTACT: Jackie Powell, CIP \\ $852-4101$ \\ February 13, 2018 \\ Brad Shuck \\ The University of Louisville Institutional Review Board \\ 17.1324 \\ An Examination of the Linkages between \\ Psychological Climate, Engagement, and \\ Wellbeing for Employees in Higher Education \\ 652825
}

This study was reviewed on $02 / 13 / 2018$ by the Chair of the Institutional Review Board and approved through the Expedited Review Procedure, according to 45 CFR 46.110(b), since this study falls under Category 7: Research on individual or group characteristics or behavior (including, but not limited to, research on perception, cognition, motivation, identity, language, communication, cultural beliefs or practices, and social behavior) or research employing survey, interview, oral history, focus group, program evaluation, human factors evaluation, or quality assurance methodologies

This study was also approved through 45 CFR 46.116 (C), which means that an IRB may waive the requirement for the investigator to obtain a signed informed consent form for some or all subjects if it finds either:

- That the only record linking the subject and the research would be the consent document and the principal risk would be potential harm resulting 
from a breach of confidentiality. Each subject will be asked whether the subject wants documentation linking the subject with the research, and the subject's wishes will govern; or

- $\quad$ That the research presents no more than minimal risk of harm to subjects and involves no procedures for which written consent is normally required outside of the research context.

The following items have been approved:

\begin{tabular}{|l|l|l|l|}
\hline Submission Components & Version & Outcome \\
\hline Form Name & Version 1.0 & Approved as Submitted \\
\hline Submit for Initial Review & Version 2.0 & Approved as Submitted \\
\hline $\begin{array}{l}\text { Review Response } \\
\text { Submission Form }\end{array}$ & Version 1.0 & \multicolumn{2}{l|}{} \\
\hline $\begin{array}{l}\text { Review Response } \\
\text { Submission } \\
\text { Form }\end{array}$ & \multicolumn{3}{l|}{} \\
\hline IRB Study Application & Version 1.2 & Approved as Submitted \\
\hline & \multicolumn{3}{l}{} \\
\hline Study Document & Version \# & Version Date & Outcome \\
\hline Title & Version 1.0 & $01 / 29 / 2018$ & Approved \\
\hline Linkages Email Introduction & Version 1.0 & $01 / 10 / 2018$ & Approved \\
\hline Written Protocol & Version 1.2 & $01 / 10 / 2018$ & Approved \\
\hline Survey & Version 1.0 & $01 / 29 / 2018$ & Approved \\
\hline Linkages Preamble &
\end{tabular}

\section{This study now has final IRB approval from 02/13/2018 through 02/12/2019.}

If you have any questions, please contact the IRB analyst listed above or the Human Subjects Protection Program office at hsppofc@louisville.edu.

We value your feedback. Please let us know how you think we are doing: https://www.surveymonkey.com/r/CCLHXRP

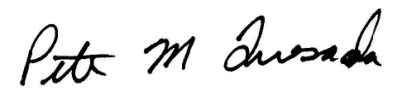

Peter M. Quesada, Ph.D.,

Chair

Social/Behavioral/Educatio 
nal Institutional Review

Board PMQ/jsp 


\section{CURRICULUM VITAE}

\section{Ebo Kobena A. Osam}

College of Education and Human Development| University of Louisville|1905 South $1^{\text {st }}$ Street, Louisville, KY 40292 | kobena.osam@louisville.edu | 270.996.1130|

\section{EDUCATION}

\section{Ph.D. Educational Leadership \& Organizational Development}

2018

University of Louisville, Louisville, KY

Concentration: Human Resource Development

Dissertation Area: Examining the Linkages Between Climate,

Engagement, and Wellbeing

\section{M.A. Industrial-Organizational Psychology}

Western Kentucky University, Bowling Green, KY

Thesis: The Adaptation of a Situational Judgment Test to Measure Leadership Knowledge in the Workplace

Certificate: Leadership Studies

\section{B.A. Psychology}

Minor: Sociology

University of Ghana, Accra Ghana

ACADEMIC EMPLOYMENT

\section{University of Louisville, Louisville, KY}

Educational Leadership and Organizational Development Program

Graduate Assistant

LeadLab

2016

Research Associate

\section{Western Kentucky University, Bowling Green, KY}

Center for Leadership Excellence

2013-2014

Graduate Assistant

School of Leadership Studies

$2012-2013$

Graduate Assistant

PUBLICATIONS

Bergman, M., Osam, E.K., Strickler, B., \& Ash, D. (in press). Engineering the benefits of the new learning economy. Journal of Continuing Higher Education. 
Gittings, G., Bergman, M., \& Osam, K. (in press). The doctoral quest: Managing variables that impact degree completion. Journal of Higher Education Management, 32(2).

Shuck, B., Osam, E.K., Zigarmi, D., \& Nimon, K. (2017). Definitional and conceptual muddling: Defining the construct of employee engagement and identifying positionality. Human Resource Development Review, 16(3), 263-293. doi: $10.1177 / 1534484317720622$

Shuck, B., Alagaraja, M., Rose, K., Osam, E.K., \& Bergman, M. (2017). The healthrelated upside of employee engagement: Exploratory evidence and implications for theory and practice. Performance Improvement Quarterly, 30(3), 165-178. doi:10.1002/piq.21246

Osam, E.K., Bergman, M., \& Cumberland, D. (2017). An integrative literature review on the barriers impacting adult learners' return to college. Adult Learning, 23(2) 54 60. doi:10.1177/1045159516658013

Britt, D. W., Moore, L., Shuck, B., Benson, P. \& Osam, E.K. (2016). Exploring interdepartmental variation in departmental stress using medical claims data. The Open Public Health Journal, 9, 3-10. doi:10.2174/1874944501609010001

Amponsah-Tawiah, K., Dartey-Baah, K., \& Osam, K. (2015). Turning potential collision into cooperation in Ghana's oil industry. Society and Business Review, 10(2), 118 131. doi:10.1108/sbr-12-2014-0059

\section{PRESENTATIONS}

Osam, E.K., Immekus, J., Shuck, B., \& Bowers, A. (2018, March). Factors associated with faculty perceptions of community engaged scholarship in tenure, promotion, and retention decisions and university engagement at the University of Louisville. Paper presented at the 2018 Spring Research Conference, University of Louisville, Louisville, Kentucky.

Osam, E. K., \& Rose, K. (2018, February). An examination of the linkages between climate, engagement, and wellbeing for employees in higher education. Poster presented at the 2018 Academy of Human Resource Development, Richmond, Virginia.

Shuck, B., Osam, E.K., Zigarmi, D., \& Nimon, K. (2017, March). Definitional and conceptual muddling: Defining the construct of employee engagement and identifying positionality. Paper presented at the 2017 Academy of Human Resource Development, San Antonio, Texas.

Nold, K., Osam, E.K., \& Alagaraja, M. (2017, March). A case study on the application of a human performance technology model to a sports manufacturing company. Paper presented at the 2017 Academy of Human Resource Development, San 
Antonio, Texas.

Bergman, M., Osam, E.K., Strickler, B., \& Ash, D. (2017, March). Engineering the benefits of the new learning economy. Paper presented at the 2017 Academy of Human Resource Development, San Antonio, Texas.

Shuck, B., Alagaraja, M., Rose, K., Osam, E.K., \& Bergman, M. (2017, March). The health-related upside of employee engagement: Exploratory evidence and implications for theory and practice. Paper presented at the 2017 Academy of Human Resource Development, San Antonio, Texas.

Rose, K., Bergman, M., Osam, E.K., \& Kacirek, K. (2016, November). Are we good citizens? A conceptual exploration of organizational citizenship behavior for university faculty. Paper presented at the 2016 American Association for Adult and Continuing Education (AAACE), National Conference, Albuquerque, New Mexico.

Bergman, M., \& Osam, E.K. (2016, April). To degree or not to degree: Examining barriers that impact adult learners' return to college. Paper presented at the 2016 Association for Continuing Higher Education South, Charleston, South Carolina.

Osam, E.K. (2013, March). A critical review of leadership research: Linear or spiral evolution? Paper presented at the $43^{\text {rd }}$ Annual WKU Student Research Conference, Bowling Green, KY.

\section{NON-REFEREED AND INVITED PRESENTATIONS}

Immekus, J., Osam, E.K., \& Shuck, B. (2017, August). Blue survey to advance institutional research and initiatives. Presented at the Bluenotes Americas Conference, Louisville, KY.

Immekus, J., \& Osam, E.K. (2016, March). Navigating the Logistical Landscape of Engaged Scholarship. Presented at the Community Engagement Academy at the University of Louisville, Louisville, KY.

\section{MANUSCRIPTS IN PREPARATION/SUBMITTED FOR REVIEW}

Immekus, J., Shuck, B., Osam, E.K., \& Bowers, A. (in progress). Faculty perceptions of community engaged scholarship.

Pitts, H., \& Osam, E.K. (in progress). Confirmatory factor analysis of the child behavior checklist for school-aged children with Williams Syndrome.

\section{MEDIA COVERAGE OF RESEARCH}

Nalevanko, C. (November 28th, 2017). Identifying Employee Engagement: Interview with Shuck and Osam. Business and Management INK Blog. Research featured in article. Retrieved from 
https://managementink.wordpress.com/2017/11/28/identifying-employeeengagement/

\section{TECHNICAL REPORTS}

Immekus, J., Osam, E.K., Bowers, A., \& Shuck, B. (2017, June). Factors Associated with Faculty Perceptions of Community Engaged Scholarship in Tenure, Promotion, and Retention Decisions and University Engagement at the University of Louisville. University of Louisville College of Education and Human Development.

Andris, J., Immekus, J., Osam, E.K., Wells-Smith, T. (2016, July). Global Game Changers Program Evaluation Report. University of Louisville College of Education and Human Development.

Foster, C., Henry, K., \& Seidler, T., Sizemore, P., Kedenburg, G., Moore, D., JohnstonFisher, J., Ruga, K., Osam, K., Kline, S., Mandelke, A., Westlin, J., \& Schroeder, A. N. (2013, May). Employee Stress Report. Western Kentucky University Department of Psychology.

Osam, E.K., Ruga, K. \& Seidler, T. (2013, February). Job Analysis Report. Western Kentucky University Department of Psychology.

Johnston-Fisher, J., Mandelke, A. \& Osam, E.K. (2013, December). Program Evaluation Assessment Report. Western Kentucky University Department of Psychology.

\section{TEACHING EXPERIENCE}

\section{University of Louisville, Louisville, KY}

Supporting Organizational Change

Undergraduate/Online (asynchronous)

Description: A 3 credit hour course focusing on the reasons for and causes of change in organizations, and the professional and personal competencies to support change.

Responsibilities: Designed and co-taught (with instructor of record) a senior level course to 56 students ( 29 students in Fall 15 and 27 students in Fall 16), selected course topics, any other material relevant to the course, and helped evaluated student performance.

\section{Leadership and Management 2018}

Undergraduate/Online (asynchronous)/ 8 week accelerated session

Description: A 3 credit hour course that introduces students to management functions and their application to workplace learning and performance

Responsibilities: As a teaching assistant, I was responsible for facilitating weekly discussion boards for two class sections, holding regular office hours, and grading applied projects.

Adult and Organizational Learning 2017

Spring 2016, 
Graduate/Online (synchronous)

Description: A 3 credit hour course that introduces adult and organizational learning theories and its application in workplace settings.

Responsibilities: As a teaching assistant, I helped design course content and facilitate discussion sessions for 22 students, address comments and concerns, and grade assignments

\section{Diversity in the Workplace}

Fall 2017

Undergraduate/Face-to-Face (8 week accelerated session)

Description: A 3 credit hour course focused on broadening students' understanding of managing diverse workplaces

Responsibilities: As a teaching assistant I was involved with lesson preparation, delivery, and grading.

\section{Doctoral Seminar}

Fall 2017

Graduate/Face-to Face

Description: This course introduces first year $\mathrm{PhD}$ students to locating, reading, and evaluating academic literature, and explores fundamentals of research design.

Responsibilities: I was a teaching assistant for this class and I assisted with facilitating discussion and developing class activities

Problem Analysis in Educational Leadership

Spring 2018

Graduate/Face-to Face

Description: This course guides advanced doctoral students with defining research topic, finding relevant literature, summarizing, and synthesizing past and current state of the topic reported in the literature

Responsibilities: I was a teaching assistant for this class and I assisted with facilitating discussion and developing class activities.

\section{GRANTS}

\section{University of Louisville, Louisville, KY}

Osam (2017). A case study on the application of a human performance technology model to a sports manufacturing company. Department of Educational Leadership and Organizational Development, Mini Grant. $\left(\$ 800{ }^{00}\right)$.

Osam (2016) Engineering the benefits of learning in the new learning economy. Graduate Student Council, Mini Grant. $\left(\$ 3500^{00}\right)$.

Osam (2015). Organizational leadership communication and the development of corporate social responsibility initiatives in oil communities in Ghana. Department of Educational Leadership and Organizational Development, Mini Grant. $\left(\$ 8000^{00}\right)$

\section{AWARDS AND HONORS}

University of Louisville, Louisville, KY

Passed with Honors- PhD. Comprehensive exam 
Tau Sigma high academic achievement award (4.0 GPA)

Dean of Graduate School Honors List

Macy's Logistics and Operations, Portland, TN

Make Magic Award: Teamwork

SERVICE AND ACTIVITIES

Western Kentucky University, Bowling Green, KY

2013

Co-Organizer, World Café: Discussions on race and identity

Co-Organizer, Faculty conversations on adaptive leadership in

2013

higher education

PROFESSIONAL EXPERIENCE AND PROJECTS

Jefferson County Human Resources, Birmingham, AL

2016

HR Workforce Assessor

Macy's Logistics and Operations, Portland, TN

2014-2015

Human Resources Generalist

SCR Sports Inc., Louisville, KY

2015

Organizational Performance Analysis

Hendrickson International, Clarksville, TN,

Job Analysis

Personnel Board of Jefferson County, Birmingham, AL

2012

HR Workforce Assessor

PsyconH.R, Accra, Ghana

HR Advisor

$2010-2011$

PROFESSIONAL AFFILIATIONS

Academy for Human Resource Development (AHRD): Member since 2017

Louisville Society for Human Resource Management (LSHRM): Member since 2016 